\title{
Air-snowpack exchange of bromine, ozone and mercury in the springtime Arctic simulated by the 1-D model PHANTAS - Part 2: Mercury and its speciation
}

\author{
K. Toyota ${ }^{1,2}$, A. P. Dastoor ${ }^{3}$, and A. Ryzhkov ${ }^{3}$ \\ ${ }^{1}$ Department of Earth and Space Science and Engineering, York University, Toronto, Ontario, Canada \\ ${ }^{2}$ Air Quality Modelling and Integration Section, Environment Canada, Toronto, Ontario, Canada \\ ${ }^{3}$ Air Quality Modelling and Integration Section, Environment Canada, Dorval, Quebec, Canada \\ Correspondence to: K. Toyota (kenjiro.toyota@ec.gc.ca)
}

Received: 13 July 2013 - Published in Atmos. Chem. Phys. Discuss.: 26 August 2013

Revised: 24 February 2014 - Accepted: 27 February 2014 - Published: 25 April 2014

\begin{abstract}
Atmospheric mercury depletion events (AMDEs) refer to a recurring depletion of mercury occurring in the springtime Arctic (and Antarctic) boundary layer, in general, concurrently with ozone depletion events (ODEs). To close some of the knowledge gaps in the physical and chemical mechanisms of AMDEs and ODEs, we have developed a one-dimensional model that simulates multiphase chemistry and transport of trace constituents throughout porous snowpack and in the overlying atmospheric boundary layer (ABL). This paper constitutes Part 2 of the study, describing the mercury component of the model and its application to the simulation of AMDEs. Building on model components reported in Part 1 ("In-snow bromine activation and its impact on ozone"), we have developed a chemical mechanism for the redox reactions of mercury in the gas and aqueous phases with temperature dependent reaction rates and equilibrium constants accounted for wherever possible. Thus the model allows us to study the chemical and physical processes taking place during ODEs and AMDEs within a single framework where two-way interactions between the snowpack and the atmosphere are simulated in a detailed, processoriented manner. Model runs are conducted for meteorological and chemical conditions that represent the springtime Arctic ABL characterized by the presence of "haze" (sulfate aerosols) and the saline snowpack on sea ice. The oxidation of gaseous elemental mercury (GEM) is initiated via reaction with $\mathrm{Br}$-atom to form $\mathrm{HgBr}$, followed by competitions between its thermal decomposition and further reactions to give thermally stable $\mathrm{Hg}(\mathrm{II})$ products. To shed light on uncertain
\end{abstract}

kinetics and mechanisms of this multi-step oxidation process, we have tested different combinations of their rate constants based on published laboratory and quantum mechanical studies. For some combinations of the rate constants, the model simulates roughly linear relationships between the gaseous mercury and ozone concentrations as observed during AMDEs/ODEs by including the reaction $\mathrm{HgBr}+\mathrm{BrO}$ and assuming its rate constant to be the same as for the reaction $\mathrm{HgBr}+\mathrm{Br}$, while for other combinations the results are more realistic by neglecting the reaction $\mathrm{HgBr}+\mathrm{BrO}$. Speciation of gaseous oxidized mercury (GOM) changes significantly depending on whether or not $\mathrm{BrO}$ is assumed to react with $\mathrm{HgBr}$ to form $\mathrm{Hg}(\mathrm{OBr}) \mathrm{Br}$. Similarly to ozone (reported in Part 1), GEM is depleted via bromine radical chemistry more vigorously in the snowpack interstitial air than in the ambient air. However, the impact of such in-snow sink of GEM is found to be often masked by the re-emissions of GEM from the snow following the photo-reduction of $\mathrm{Hg}$ (II) deposited from the atmosphere. GOM formed in the ambient air is found to undergo fast "dry deposition" to the snowpack by being trapped on the snow grains in the top $\sim 1 \mathrm{~mm}$ layer. We hypothesize that liquid-like layers on the surface of snow grains are connected to create a network throughout the snowpack, thereby facilitating the vertical diffusion of trace constituents trapped on the snow grains at much greater rates than one would expect inside solid ice crystals. Nonetheless, on the timescale of a week simulated in this study, the signal of atmospheric deposition does not extend notably below the top $1 \mathrm{~cm}$ of the snowpack. We propose 
and show that particulate-bound mercury $(\mathrm{PBM})$ is produced mainly as $\mathrm{HgBr}_{4}^{2-}$ by taking up GOM into bromide-enriched aerosols after ozone is significantly depleted in the air mass. In the Arctic, "haze" aerosols may thus retain PBM in ozonedepleted air masses, allowing the airborne transport of oxidized mercury from the area of its production farther than in the form of GOM. Temperature dependence of thermodynamic constants calculated in this study for Henry's law and aqueous-phase halide complex formation of $\mathrm{Hg}$ (II) species is a critical factor for this proposition, calling for experimental verification. The proposed mechanism may explain observed changes in the GOM-PBM partitioning with seasons, air temperature and the concurrent progress of ozone depletion in the high Arctic. The net deposition of mercury to the surface snow is shown to increase with the thickness of the turbulent $\mathrm{ABL}$ and to correspond well with the column amount of $\mathrm{BrO}$ in the atmosphere.

\section{Introduction}

Dynamic exchange of halogens between ocean, sea ice, snowpack, and atmosphere is the main driver for the frequent occurrence of ozone depletion events (ODEs) and atmospheric mercury depletion events (AMDEs) in the springtime polar boundary layer (Simpson et al., 2007; Steffen et al., 2008). Virtually concurrent occurrence of ODEs and AMDEs indicates a major contribution from common reactants, most likely gaseous bromine radicals $(\mathrm{Br}$ and $\mathrm{BrO})$ associated with the so-called "bromine explosion" (Platt and Lehrer, 1996; Wennberg, 1999; Schroeder et al., 1998). During the AMDEs, gaseous elemental mercury (GEM) is photochemically transformed to oxidized mercury compounds in the gaseous and/or particulate form(s). The oxidized mercury species are then removed from the atmosphere via dry and wet deposition much more efficiently than GEM, entering snowpack that covers most of the land/water surfaces until summer melt (Lu et al., 2001; Lindberg et al., 2002). Subsequently, the oxidized mercury can be methylated via biotic and abiotic processes. Bio-accumulation of mono-methyl mercury through aquatic food chains poses a risk of adverse toxicological impacts on wild life and ultimately imposes health concerns on northern indigenous people for whom fish and marine mammals form a major component of their diet (AMAP, 2011). However, the actual impacts of AMDEs on high mercury levels observed in northern wild life remain uncertain for the following reasons.

First, field measurements of mercury in the snowpack and overlying ambient air, including but not limited to those in the polar region, quite often indicate the photoreduction of deposited oxidized mercury back to GEM and its revolatilization to the air on timescales of days to weeks (Lalonde et al., 2002, 2003; Steffen et al., 2002; Ariya et al., 2004; Kirk et al., 2006; Johnson et al., 2008). This raises a question as to how much of the mercury deposited during the AMDEs may remain in the snowpack until snowmelt when mercury contaminating the snow could enter aquatic food chains. Vertical fluxes of GEM and gaseous oxidized mercury (GOM) determined from in situ measurements at Barrow, Alaska, depicted the net mercury deposition to the snow as a relatively small residual between the net GOM deposition and the net GEM emission during and after AMDEs (Brooks et al., 2006). By assigning a retention timescale of about two weeks in the snowpack against the photo-reduction induced re-emission of deposited mercury, some atmospheric mercury chemical-transport models satisfactorily simulated decrease in the ground-level mixing ratios of GEM during the AMDEs and subsequent increase above the hemispheric background as observed at Arctic coastal sites (Dastoor et al., 2008; Holmes et al., 2010). Holmes et al. (2010) estimated that about $40 \%$ of deposited mercury is preserved in the Arctic snowpack until entering the surface waters via snowmelt. More recently, Dastoor and Durnford (2014), using a multilayer snow mercury model, estimated that only $25 \%$ of the mercury deposited to snow and ice is retained in the Arctic ecosystem. On the other hand, generally higher GEM concentrations over the ice-covered Arctic Ocean than over the nearby ice-free ocean were indicated from yet-scarce field observations in summer (Aspmo et al., 2006; Hirdman et al., 2009; Sommar et al., 2010), implying a significant connection with the atmospheric deposition during the AMDEs. It appears that the evidence obtained so far is insufficient to draw a coherent conclusion to the problem.

Second, owing to many unknowns and substantial uncertainties in the kinetics and mechanisms of mercury oxidation and subsequent scavenging processes in the atmosphere, it is quite difficult to develop process-based models for simulating the impact of AMDEs on mercury budget in the polar regions. As reviewed in Subir et al. (2011), gas-phase kinetics data for the $\operatorname{Hg}(0)$ oxidation from laboratory experiments are subject to large artifacts associated with rate determination techniques and unwanted secondary reactions, leaving error bars often by more than an order of magnitude in the derived rate constants. Additionally, the oxidation of $\mathrm{Hg}(0)$ to $\mathrm{Hg}$ (II) is likely to proceed via multiple reaction steps; therefore, gauging the kinetics for all of the probable reaction steps operating in the natural environment is a formidable task. For example, the reaction $\mathrm{Hg}+\mathrm{Br}$ initially produces $\mathrm{HgBr}$ (Donohoue et al., 2006):

$\mathrm{Hg}+\mathrm{Br} \rightarrow \mathrm{HgBr}$

which either dissociates back to the original reactants or undergoes further reactions with $\mathrm{Br}$-atoms in a simple $\mathrm{Hg}-\mathrm{Br}$ system such as reaction vessels (Goodsite et al., 2004, 2012; Balabanov et al., 2005; Shepler et al., 2007):

$$
\begin{aligned}
& \mathrm{HgBr} \rightarrow \mathrm{Hg}+\mathrm{Br} \\
& \mathrm{HgBr}+\mathrm{Br} \rightarrow \mathrm{HgBr}_{2} .
\end{aligned}
$$


Using a quantum mechanical theory, Goodsite et al. (2004, 2012) estimated rate constants for Reactions (R1)-(R3) and their temperature dependence. They proposed that the estimated increase in the rate constant of Reaction (R2) with temperature may be one of the key factors for the termination of AMDEs towards the summer and that $\mathrm{OH}$-radicals and I-atoms may also react with $\mathrm{HgBr}$ to give thermally stable products, $\mathrm{Hg}(\mathrm{OH}) \mathrm{Br}$ and $\mathrm{HgBrI}$, respectively. Shepler et al. (2007) and Balabanov et al. (2005) used a higher level of quantum mechanical theory to calculate the rate constants for Reactions (R1)-(R3) and predicted two more product channels, namely, Br-abstraction (R4) and Br-exchange (R5):

$\mathrm{HgBr}+\mathrm{Br} \rightarrow \mathrm{Hg}+\mathrm{Br}_{2}$

$\mathrm{HgBr}+\mathrm{Br} \rightarrow \mathrm{BrHg}+\mathrm{Br}$

that compete with the Br-addition channel (R3); see Sect. S1 of the Supplement for more details. Calvert and Lindberg (2004) conjectured yet other reaction steps, where $\mathrm{HgBr}$ first reacts with $\mathrm{BrO}$ to give $\mathrm{Hg}(\mathrm{OBr}) \mathrm{Br}$, which then photolyzes to $\mathrm{Hg}(\mathrm{O}) \mathrm{Br}+\mathrm{Br}$, and eventually produces $\mathrm{Hg}(\mathrm{OH}) \mathrm{Br}$ :

$\mathrm{HgBr}+\mathrm{BrO} \rightarrow \mathrm{Hg}(\mathrm{OBr}) \mathrm{Br}$

$\mathrm{Hg}(\mathrm{OBr}) \mathrm{Br}+\mathrm{h} v \rightarrow \mathrm{Hg}(\mathrm{O}) \mathrm{Br}+\mathrm{Br}$

$\mathrm{Hg}(\mathrm{O}) \mathrm{Br}+\mathrm{HO}_{2} \rightarrow \mathrm{Hg}(\mathrm{OH}) \mathrm{Br}+\mathrm{O}_{2}$.

Rate constants for these reactions were adjusted heuristically in their box model to simulate a conceivably reasonable timescale of AMDEs against that of ODEs (Calvert and Lindberg, 2004). In laboratory experimental systems, some of the reactions are mediated, at least partially, on the chamber wall surface (Ariya et al., 2002; Raofie and Ariya, 2004). But it remains unknown whether or not surface-mediated pathways can enhance the overall oxidation rates of $\mathrm{Hg}(0)$ by $\mathrm{Br}$ and/or $\mathrm{BrO}$ on various environmental surfaces as well (Subir et al., 2011).

Unlike a few mechanistic box and one-dimensional (1-D) models published to date (e.g., Saiz-Lopez et al., 2008; Xie et al., 2008), three-dimensional (3-D) chemical-transport models of mercury have generally assigned the temporal and spatial distributions of $\operatorname{Hg}(0)$ oxidants in the polar boundary layer in a simpler fashion than simulating a full suite of gaseous and heterogeneous reactions involved (e.g., Dastoor et al., 2008; Holmes et al., 2010). Therefore, to some extent, the mechanism of mercury redox reactions and their rate constants are empirically defined to simulate AMDEs realistically in current 3-D models. This practice is justified because of our present lack of a solid understanding of the chemical and physical mechanisms for reactive halogen release into the polar boundary layer (Abbatt et al., 2012) and of the reemission of deposited mercury as noted earlier. A more sophisticated approach is needed in the 3-D models if we are to better assess how AMDEs and resultant mercury deposition might respond to varying environmental factors including climate change. A recent work by Parrella et al. (2012) made a step forward along this line, as their 3-D model simulated the gaseous and heterogeneous chemistry of bromine to estimate the photochemical lifetime of GEM in the global troposphere, even though the model relied on ad hoc parameters in constraining the source term of reactive bromine from sea-salt aerosols and did not consider the sources from polar snow/ice packs.

Once oxidized, mercury retains greater Henry's law and surface adsorption coefficients and is thus more prone to uptake onto aerosols, clouds and various surfaces than in the form of GEM (Subir et al., 2012). In the polar boundary layer, oxidized mercury exists as either GOM or particulatebound mercury (PBM) (Brooks et al., 2006, 2008; Cobbett et al., 2007; Steen et al., 2011). Their accurate partitioning needs be known because the rates of dry and wet deposition can be vastly different between GOM and PBM (Brooks et al., 2006; Skov et al., 2006; Amos et al., 2012). As anticipated from thermodynamic grounds, temperature and the amount of host aerosols do appear to influence the partitioning between GOM and PBM in the polar boundary layer, but other factors (such as aerosol composition) remain to be characterized to derive a more precise partitioning of GOM-PBM (Cobbett et al., 2007; Brooks et al., 2008; Amos et al., 2012).

In order to gain better understanding of the problems noted above, we have incorporated a multiphase chemical mechanism for mercury in a 1-D model of air-snowpack chemistry and transport, PHANTAS (a model of PHotochemistry ANd Transport in Air and Snowpack) (see Part 1 of the study, viz., Toyota et al., 2014, for basic formulations of the model). Within the current limitation of our process-level understanding of the physics and chemistry of the natural snowpack, PHANTAS has minimized the number of ad hoc parameters for simulating the release of reactive bromine species from the salty snowpack and resultant ozone loss, as compared to earlier models. This paper constitutes Part 2 of the study, in which we investigate potential key steps leading to the net oxidation of GEM in the atmospheric boundary layer (ABL) and the snowpack interstitial air (SIA) during AMDEs, and the fate of oxidized mercury in the ABL, in the SIA and on the surface of snow grains within the snowpack. Our mechanism of multiphase mercury chemistry accounts for temperature dependence of the reaction rate and equilibrium constants wherever possible. Previous mechanistic box and 1-D models of the same kind neglected either an explicit treatment of condensed-phase chemistry (Saiz-Lopez et al., 2008) or temperature dependence in the gas- and aqueous-phase reactions of mercury (Xie et al., 2008). Discussion in this paper, in many respects, builds on the simulation of reactive bromine release and ozone depletion in the springtime Arctic as reported in Part 1. In particular, a potential link is indicated for the first time between the GOM-PBM partitioning during AMDEs and the partitioning of inorganic bromine changing concurrently with the depletion of ozone. 


\section{Model description}

\subsection{General framework}

PHANTAS is a 1-D model that represents the multiphase chemistry and transport of trace constituents from the bottom of the saline snowpack and to beyond the turbulent ABL. The model is designed primarily for the representation of gas-phase and aqueous-phase halogen chemistry linked to ODEs and AMDEs in polar regions. In Part 1 of the study (Toyota et al., 2014), we described multiphase chemical processes other than those specific to mercury as well as parameterizations for the vertical transfer of gaseous, particulate and snow-trapped species between different domains of the air-snowpack system. Here, we briefly repeat the description of model components reported already in Part 1 and supplement this with the description of molecular diffusivity for gaseous mercury species. A detailed description of the mercury chemical mechanism then follows in the next section. It should be noted that the same set of chemical mechanism including mercury is employed for model runs in Part 1 and here in Part 2 except for sensitivity runs to study the role of specific reactions in mercury chemistry (see Sect. S1 of the Supplement in Part 1 for a full list of reactions).

The chemical mechanism of PHANTAS has been adapted from that originally developed by Toyota et al. (2004) for a box model of multiphase halogen chemistry involving deliquesced sea-salt aerosols in the marine boundary layer, called SEAMAC (size-SEgregated Aerosol model for Marine Air Chemistry); see Sect. 2.2 in Part 1. A common set of reactions is employed to describe a system of gases and aerosols in the atmosphere and a system of gases and liquid-like entities in the snowpack. We assume that the surface of snow grains is coated by a liquid-like layer (LLL), into which all the in-snow solutes are excluded from solid ice (Sect. 2.5 in Part 1). To what extent this assumption makes sense is a matter of debate (e.g., Mulvaney et al., 1988; Rosenthal et al., 2007; Barret et al., 2011; Thomas et al., 2011) but is beyond the scope of this study. Also, even if snow-trapped impurities are largely excluded from the solid ice matrix, they might find their places to stay in veins and pockets at grain boundaries and within grains (e.g., Domine et al., 2013). Hence our approach would likely give upper limits for the LLL volume and the amount of dissolved constituents involved actively in the multiphase photochemical reactions within the snowpack. We employ a simple thermodynamic parameterization by Cho et al. (2002) to predict the volume fraction $\left(f_{\mathrm{q}}\right)$ of the LLL in the total volume of snow grains from the bulk concentrations of major ionic components contained in the snow; at initial bulk concentrations assumed for $\mathrm{Na}^{+}\left(72 \mu \mathrm{molL}{ }^{-1}\right), \mathrm{Cl}^{-}\left(70 \mu \mathrm{molL}{ }^{-1}\right), \mathrm{NO}_{3}^{-}\left(2 \mu \mathrm{molL}^{-1}\right)$, and $\mathrm{Br}^{-}\left(0.108 \mu \mathrm{molL} \mathrm{L}^{-1}\right)$, we obtain $f_{\mathrm{q}}=1.11 \times 10^{-5}$ (Table 3 in Part 1). By assigning the bulk density of snowpack at $0.31 \mathrm{~g} \mathrm{~cm}^{-3}$ and the diameter of each grain at $0.3 \mathrm{~mm}$, specific surface area (SSA) is adjusted at $217 \mathrm{~cm}^{2} \mathrm{~g}^{-1}$ of snow, consistent with measurements for springtime Arctic snowpack (Domine et al., 2002). Expressed in a different physical unit, the ratio of surface area to air volume in the SIA is $101 \mathrm{~cm}^{2} \mathrm{~cm}^{-3}$. Under these conditions, the thickness of the LLL is estimated to be $0.556 \mathrm{~nm}$. The volume fraction of SIA in the snowpack is dictated by porosity at 0.663 (as introduced in the beginning of Sect. 2 in Part 1). Atmospheric aerosols in the present version of PHANTAS are composed only of "sulfate aerosols", namely, the mixture of $\mathrm{NH}_{4} \mathrm{HSO}_{4}-\mathrm{H}_{2} \mathrm{SO}_{4}-\mathrm{H}_{2} \mathrm{O}$ as a major aerosol substrate and a predominant component of Arctic haze (Sect. 2.8 in Part 1). Thus, the model does not account for halogen release from airborne sea-salt particles associated with blowing snow events (e.g., Yang et al., 2008). This also means that model runs in the present study do not necessarily address issues related to ODEs and AMDEs in the Antarctic (or Southern Ocean) ABL where the persistent "haze" is absent. Currently, PHANTAS does not retain a capability carried by SEAMAC of simulating size-resolved aerosol chemistry (Toyota et al., 2001).

In the present configuration, the model consists of 55 layers in the vertical, among which 22 layers represent the porous snowpack of $35 \mathrm{~cm}$ in depth as typically observed on sea ice in the springtime Arctic (Warren et al., 1999) and 33 layers represent the ABL as well as some extra layers in the free troposphere. Spacing between the layers is not uniform and is made very small around the atmospheresnowpack interface (e.g., $\Delta z=10^{-4} \mathrm{~m}$ at the top of the snowpack and $\Delta z=10^{-2} \mathrm{~m}$ at the bottom of the atmosphere) to resolve sharp changes in tracer diffusivity and in chemical reaction pathways across this region. The layer spacing in the entire snowpack (22 layers) and in the atmosphere below $10 \mathrm{~m}$ above the snow surface (12 layers) remains the same between model runs, while it changes between the model runs above the $10 \mathrm{~m}$ height in the atmosphere (21 layers) according to the diagnosed height of the turbulent $\mathrm{ABL}\left(Z_{\mathrm{ABL}}\right)$ at noon when $Z_{\mathrm{ABL}}$ is at maximum.

The profile of vertical diffusivity for tracers in the ABL and its diurnal variations are diagnosed by solving a set of micro-meteorological equations with constraints from several pre-defined input parameters including wind speed at a reference height ( $2 \mathrm{~m}$ in this study), diurnally varying sensible heat fluxes at the air-snowpack interface (typical of March in Beaufort Sea, Persson et al., 2002), static stability (or the Brunt-Väisälä frequency, $N=0.031 \mathrm{~s}^{-1}$ ) in the free troposphere (Steeneveld et al., 2007), and the Coriolis parameter (at $71^{\circ} \mathrm{N}$ ); see Sect. 2.7 in Part 1. Tracer diffusivity above $Z_{\mathrm{ABL}}$ is assumed to be controlled by molecular diffusion for gases and by Brownian diffusion for aerosols. Molecular diffusivity $\left(D_{\mathrm{g}}\right)$ for GEM is calculated based on an empirical formula by Massman (1999) and is re-used for other gaseous mercury species $(\mathrm{XHg})$ with molar-mass-based scaling (i.e., $D_{\mathrm{g}, \mathrm{XHg}}=D_{\mathrm{g}, \mathrm{GEM}} \times$ $\left.\sqrt{M_{\mathrm{GEM}} / M_{\mathrm{XHg}}}\right)$. For non-mercury species, $D_{\mathrm{g}}$ is calculated by using an empirical formula and associated parameters 
from Fuller et al. $(1966,1969)$. In the SIA, molecular diffusion is assumed to control the vertical transfer of gaseous tracers while being scaled down by $50 \%$ to account for the effect of tortuosity (Albert and Shultz, 2002). The effect of wind pumping in the SIA is represented in the form of effective diffusivity, which is superimposed on molecular diffusivity when the surface air flow is diagnosed to be aerodynamically rough and is thus likely to develop persistent pressure perturbations along the mean streamline of wind over the snow micro-topography (e.g., Cunningham and Waddington, 1993); see Sect. 2.4 in Part 1.

There has only been scarce discussion of mechanisms leading (or not) to the vertical mass transfer of the icetrapped trace constituents within the natural snowpack (e.g., Domine et al., 2004, 2008). Also, we note the lack of consensus on the actual mechanisms facilitating the mass transport even in the experimentally prepared ice samples (Huthwelker et al., 2006). Thus, formulating the vertical transfer rates of trace constituents trapped in/on ice in natural snowpack is a subject of great uncertainty. As noted above, there is a fundamental uncertainty in the location of impurities once trapped by snow grains. However, if all the impurities are located in the LLL uniformly coating the surface of snow grains in contact with SIA, it may be reasonable to assume that the sintering of snow grains connects the LLL throughout the snowpack. This forms a basis of our hypothesis for the LLL network where dissolved constituents are subject to vertical diffusion across the snowpack layers (Sect. 2.6 in Part 1). Ions and molecules in the surface disordered region of ice (viz., the LLL) are certainly more mobile than those trapped inside the ice matrix, if not diffused exactly at the same rates as in bulk supercooled water (e.g., Carignano et al., 2007; Gladich et al., 2011). Hence our model assumes that the vertical transfer rates of dissolved constituents can be approximated by the temperature-dependent self-diffusion coefficient $\left(D_{\mathrm{aq}}\right)$ of bulk supercooled water, adopted here from Smith and Kay (1999), while being scaled down by a factor of 10 to account for the "proximity effect" imposed by the underlying wall of solid ice (Dash et al., 1995; Carignano et al., 2007) and further by a factor of 2 to account for the tortuosity of the hypothetical LLL network (Sect. 2.6 in Part 1). We note, however, that such a vertical mass transfer would hardly occur beyond the spatial scale of a single grain, if the liquid-like portion of snow forms veins at the grooves of grain boundaries (e.g., Domine et al., 2013) rather than a uniform coating on the grains as assumed here. Therefore, a sensitivity of model results to the assumption of LLL network is explored by turning $D_{\text {aq }}$ to zero in one of the model runs.

The transfer rates of gaseous tracers across the interface between the atmosphere and the SIA are controlled largely by vertical diffusivity on the atmosphere side, because very small $\Delta z$ is adopted on the snowpack side (Sect. 2.7 in Part 1). For species like $\mathrm{Br}_{2}$ sourced mainly in the snowpack, net transfer occurs generally from the SIA to the atmosphere. On the contrary, species like $\mathrm{HBr}$ undergo net trans- fer from the atmosphere to the SIA most of the time. To calculate the vertical fluxes of species contained in aerosols at the bottom of the atmosphere, we assign the dry deposition velocity of sub- $\mu \mathrm{m}$ sulfate aerosols at $\sim 0.02 \mathrm{~cm} \mathrm{~s}^{-1}$ based on the Petroff and Zhang (2010) parameterization (Sect. 2.8 in Part 1). This results in a one-way transfer of aerosols from the atmosphere to the snowpack, unlike the transfer of gaseous tracers assumed to occur in both ways between the atmosphere and the SIA. We then allocate all the deposited amount of aerosol constituents to the top layer of the snowpack, while being subject to vertical diffusion through the hypothetical network of LLL afterwards. In reality, aerosols entering the SIA might travel farther than assumed here, but existing theoretical treatments seem to overpredict this insnow travel distance of aerosols (Harder et al., 1996). According to Petroff and Zhang (2010), the trapping of aerosol particles by snow grains appears to be controlled by poorly characterized phoretic effects.

Actinic fluxes in the atmosphere are calculated with a twostream algorithm by Kylling et al. (1995), for a clear sky on 30 March at $71^{\circ} \mathrm{N}$ with a total column ozone of 400 Dobson units over the snow surface with a wavelength-independent snow albedo of 0.9 (Warren and Wiscombe, 1980). The actinic flux also penetrates the snowpack while being attenuated with depth; in this work, the e-folding depth for the attenuation is assumed to be $7.5 \mathrm{~cm}$ (King and Simpson, 2001; Peterson et al., 2002; Qiu et al., 2002; Simpson et al., 2002); see Sect. 2.3 in Part 1.

\subsection{Mercury chemical mechanism}

Mercury chemical mechanism is developed by combining and adapting the mechanisms from other recent models of photochemical interactions between mercury and bromine in the polar boundary layer and in the global troposphere (Calvert and Lindberg, 2004; Hedgecock et al., 2005; Xie et al., 2008; Holmes et al., 2010). Figure 1 illustrates an overview of the mercury mechanism developed here, while Table 1 lists all the mercury reactions and their rate or equilibrium coefficients used for our baseline scenario.

We assume that the gas-phase oxidation of GEM is initiated only via reaction with $\mathrm{Br}$-atom to give $\mathrm{HgBr}$ (Reaction R1), followed either by its thermal decomposition to $\mathrm{Hg}$ $+\mathrm{Br}$ (Reaction $\mathrm{R} 2$ ) or by further reactions to give relatively stable $\mathrm{Hg}(\mathrm{II})$ products such as $\mathrm{HgBr}_{2}$ and $\mathrm{Hg}(\mathrm{OBr}) \mathrm{Br}$ (e.g., Reactions R3 and R6) while partially returning to elemental $\mathrm{Hg}$ (Reaction R4). Given the uncertainties in viability and/or rate constants for each of these reaction steps (see Introduction and Sect. S1 of the Supplement), we conduct sensitivity studies where we select different sets of rate constants for R1, R2, R3 and R6 (Table 2) and in some cases switch off R6 (Table 3). Excellent agreement between experimental data by Donohoue et al. (2006) and a theoretical calculation by Goodsite et al. (2012) gives some confidence in adopting the rate constant for R1 from Donohoue et al. (scenarios 1, 
Table 1. List of reactions and multiphase mass transfers for mercury species and the rate and equilibrium constants used in our baseline scenario (scenario 1A).

\begin{tabular}{|c|c|c|c|c|c|}
\hline \multicolumn{6}{|c|}{ Gas-phase reactions } \\
\hline Reaction & \multicolumn{2}{|l|}{ Rate constant } & \multicolumn{2}{|l|}{ Unit } & Reference \\
\hline $\mathrm{Hg}+\mathrm{Br}+\mathrm{M} \rightarrow \mathrm{HgBr}+\mathrm{M}$ & \multicolumn{2}{|c|}{$k=1.44 \times 10^{-32}(T / 300)^{-1.86}[\mathrm{M}]$} & \multicolumn{2}{|c|}{$\left[\mathrm{cm}^{3}\right.$ molecule $\left.^{-1} \mathrm{~s}^{-1}\right]$} & 1 \\
\hline $\mathrm{HgBr}+\mathrm{M} \rightarrow \mathrm{Hg}+\mathrm{Br}+\mathrm{M}$ & \multicolumn{2}{|c|}{$k=2.94 \times 10^{-9} \exp (-7670 / T)$} & \multicolumn{2}{|c|}{$\left[\mathrm{cm}^{3}\right.$ molecule $\left.{ }^{-1} \mathrm{~s}^{-1}\right]$} & 2 \\
\hline $\mathrm{HgBr}+\mathrm{Br} \rightarrow \mathrm{HgBr}_{2}$ & \multicolumn{2}{|c|}{$k=2.98 \times 10^{-11}$} & \multicolumn{2}{|c|}{$\left[\mathrm{cm}^{3}\right.$ molecule $\left.{ }^{-1} \mathrm{~s}^{-1}\right]$} & 3 \\
\hline $\mathrm{HgBr}+\mathrm{Br} \rightarrow \mathrm{Hg}+\mathrm{Br}_{2}$ & \multicolumn{2}{|c|}{$k=3.89 \times 10^{-11}$} & \multicolumn{2}{|c|}{$\left[\mathrm{cm}^{3}\right.$ molecule $\left.{ }^{-1} \mathrm{~s}^{-1}\right]$} & 3 \\
\hline $\mathrm{HgBr}+\mathrm{BrO} \rightarrow \mathrm{Hg}(\mathrm{OBr}) \mathrm{Br}$ & \multicolumn{2}{|c|}{$k=2.98 \times 10^{-11}$} & \multicolumn{2}{|c|}{$\left[\mathrm{cm}^{3}\right.$ molecule $\left.{ }^{-1} \mathrm{~s}^{-1}\right]$} & $\left(=k_{\mathrm{HgBr}}+\mathrm{Br}\right)$ \\
\hline $\mathrm{Hg}(\mathrm{OBr}) \mathrm{Br}+\mathrm{h} \nu \rightarrow \mathrm{Hg}(\mathrm{O}) \mathrm{Br}+\mathrm{Br}$ & \multicolumn{2}{|c|}{$J_{\mathrm{HOBr}}$} & \multicolumn{2}{|c|}{$\left[\mathrm{s}^{-1}\right]$} & 4 \\
\hline $\mathrm{Hg}(\mathrm{O}) \mathrm{Br}+\mathrm{HO}_{2} \rightarrow \mathrm{Hg}(\mathrm{OH}) \mathrm{Br}+\mathrm{O}_{2}$ & \multicolumn{2}{|c|}{$k=2.2 \times 10^{-11}$} & \multicolumn{2}{|c|}{$\left[\mathrm{cm}^{3}\right.$ molecule $\left.{ }^{-1} \mathrm{~s}^{-1}\right]$} & 4 \\
\hline \multicolumn{6}{|c|}{ Henry's law equilibria: equilibrium constants given by $K_{\mathrm{H}}=K_{\mathrm{H}}^{\ominus} \exp \left[-\Delta H_{\text {solv }}^{\ominus} / R \times\left(1 / T-1 / T^{\ominus}\right)\right]$} \\
\hline Reaction & $K_{\mathrm{H}}^{\ominus}$ & Unit & $-\Delta H_{\mathrm{solv}}^{\ominus} / R$ & Unit & Reference \\
\hline $\mathrm{Hg}($ gas $) \rightleftarrows \mathrm{Hg}(\mathrm{aq})$ & $1.28 \times 10^{-1}$ & {$\left[\mathrm{M} \mathrm{atm}^{-1}\right]$} & 2482 & {$[\mathrm{~K}]$} & 5 \\
\hline $\mathrm{Hg}(\mathrm{OH})_{2}(\mathrm{gas}) \rightleftarrows \mathrm{Hg}(\mathrm{OH})_{2}(\mathrm{aq})$ & $1.28 \times 10^{4}$ & {$\left[\mathrm{M} \mathrm{atm}^{-1}\right]$} & 3901 & {$[\mathrm{~K}]$} & 6 \\
\hline $\mathrm{HgCl}_{2}($ gas $) \rightleftarrows \mathrm{HgCl}_{2}(\mathrm{aq})$ & $1.00 \times 10^{6}$ & {$\left[\mathrm{M} \mathrm{atm}^{-1}\right]$} & 8060 & {$[\mathrm{~K}]$} & 7 \\
\hline $\mathrm{HgBr}_{2}($ gas $) \rightleftarrows \mathrm{HgBr}_{2}(\mathrm{aq})$ & $1.17 \times 10^{5}$ & {$\left[\mathrm{M} \mathrm{atm}^{-1}\right]$} & 8912 & {$[\mathrm{~K}]$} & 8 \\
\hline $\mathrm{Hg}(\mathrm{OH}) \mathrm{Cl}($ gas $) \rightleftarrows \mathrm{Hg}(\mathrm{OH}) \mathrm{Cl}(\mathrm{aq})$ & $1.00 \times 10^{6}$ & {$\left[\mathrm{M} \mathrm{atm}^{-1}\right]$} & 8060 & {$[\mathrm{~K}]$} & $\left(=K_{\mathrm{H}, \mathrm{HgCl}_{2}}\right)$ \\
\hline $\mathrm{HgClBr}(\mathrm{gas}) \rightleftarrows \mathrm{HgClBr}(\mathrm{aq})$ & $1.00 \times 10^{6}$ & {$\left[\mathrm{M} \mathrm{atm}^{-1}\right]$} & 8060 & {$[\mathrm{~K}]$} & $\left(=K_{\mathrm{H}, \mathrm{HgCl}_{2}}\right)$ \\
\hline $\mathrm{Hg}(\mathrm{OH}) \mathrm{Br}(\mathrm{gas}) \rightleftarrows \mathrm{Hg}(\mathrm{OH}) \mathrm{Br}(\mathrm{aq})$ & $1.17 \times 10^{5}$ & {$\left[\mathrm{M} \mathrm{atm}^{-1}\right]$} & 8912 & {$[\mathrm{~K}]$} & $\left(=K_{\mathrm{H}, \mathrm{HgBr}_{2}}\right)$ \\
\hline $\mathrm{Hg}(\mathrm{OBr}) \mathrm{Br}(\mathrm{gas}) \rightleftarrows \mathrm{Hg}(\mathrm{OBr}) \mathrm{Br}(\mathrm{aq})$ & $1.17 \times 10^{5}$ & {$\left[\mathrm{M} \mathrm{atm}^{-1}\right]$} & 8912 & {$[\mathrm{~K}]$} & $\left(=K_{\mathrm{H}, \mathrm{HgBr}_{2}}\right)$ \\
\hline \multicolumn{6}{|c|}{ Aqueous-phase equilibria: equilibrium constants given by $K_{\mathrm{eq}}=K_{\mathrm{eq}}^{\ominus} \exp \left[-\Delta H_{\mathrm{rxn}}^{\ominus} / R \times\left(1 / T-1 / T^{\ominus}\right)\right]$} \\
\hline Reaction & $K_{\text {eq }}^{\ominus}$ & Unit & $-\Delta H_{\mathrm{rxn}}^{\ominus} / R$ & Unit & Reference \\
\hline $\mathrm{Hg}^{2+}+\mathrm{OH}^{-} \rightleftarrows \mathrm{HgOH}^{+}$ & $2.62 \times 10^{10}$ & {$\left[\mathrm{M}^{-1}\right]$} & 2966 & {$[\mathrm{~K}]$} & 8,9 \\
\hline $\mathrm{HgOH}^{+}+\mathrm{OH}^{-} \rightleftarrows \mathrm{Hg}(\mathrm{OH})_{2}$ & $2.70 \times 10^{11}$ & {$\left[\mathrm{M}^{-1}\right]$} & 5449 & {$[\mathrm{~K}]$} & 8,9 \\
\hline $\mathrm{Hg}^{2+}+\mathrm{Cl}^{-} \rightleftarrows \mathrm{HgCl}^{+}$ & $5.50 \times 10^{6}$ & {$\left[\mathrm{M}^{-1}\right]$} & 2730 & {$[\mathrm{~K}]$} & 8,9 \\
\hline $\mathrm{HgCl}^{+}+\mathrm{Cl}^{-} \rightleftarrows \mathrm{HgCl}_{2}$ & $2.55 \times 10^{6}$ & {$\left[\mathrm{M}^{-1}\right]$} & 3637 & {$[\mathrm{~K}]$} & 8,9 \\
\hline $\mathrm{HgCl}_{2}+\mathrm{Cl}^{-} \rightleftarrows \mathrm{HgCl}_{3}^{-}$ & $6.86 \times 10^{0}$ & {$\left[\mathrm{M}^{-1}\right]$} & 630 & {$[\mathrm{~K}]$} & 8,9 \\
\hline $\mathrm{HgCl}_{3}^{-}+\mathrm{Cl}^{-} \rightleftarrows \mathrm{HgCl}_{4}^{2-}$ & $1.31 \times 10^{1}$ & {$\left[\mathrm{M}^{-1}\right]$} & -223 & {$[\mathrm{~K}]$} & 8,9 \\
\hline $\mathrm{Hg}^{2+}+\mathrm{Br}^{-} \rightleftarrows \mathrm{HgBr}^{+}$ & $1.07 \times 10^{9}$ & {$\left[\mathrm{M}^{-1}\right]$} & 5196 & {$[\mathrm{~K}]$} & 8,9 \\
\hline $\mathrm{HgBr}^{+}+\mathrm{Br}^{-} \rightleftarrows \mathrm{HgBr}_{2}$ & $2.50 \times 10^{8}$ & {$\left[\mathrm{M}^{-1}\right]$} & 5454 & {$[\mathrm{~K}]$} & 8,9 \\
\hline $\mathrm{HgBr}_{2}+\mathrm{Br}^{-} \rightleftarrows \mathrm{HgBr}_{3}^{-}$ & $1.45 \times 10^{2}$ & {$\left[\mathrm{M}^{-1}\right]$} & 1329 & {$[\mathrm{~K}]$} & 8,9 \\
\hline $\mathrm{HgBr}_{3}^{-}+\mathrm{Br}^{-} \rightleftarrows \mathrm{HgBr}_{4}^{2-}$ & $2.27 \times 10^{1}$ & {$\left[\mathrm{M}^{-1}\right]$} & 1942 & {$[\mathrm{~K}]$} & 8,9 \\
\hline $\mathrm{HgOH}^{+}+\mathrm{Cl}^{-} \rightleftarrows \mathrm{Hg}(\mathrm{OH}) \mathrm{Cl}$ & $6.70 \times 10^{6}$ & {$\left[\mathrm{M}^{-1}\right]$} & 4455 & {$[\mathrm{~K}]$} & 8,9 \\
\hline $\mathrm{HgOH}^{+}+\mathrm{Br}^{-} \rightleftarrows \mathrm{Hg}(\mathrm{OH}) \mathrm{Br}$ & $1.25 \times 10^{9}$ & {$\left[\mathrm{M}^{-1}\right]$} & 4455 & {$[\mathrm{~K}]$} & 8,9, see Note ${ }^{a}$ \\
\hline $\mathrm{HgCl}^{+}+\mathrm{OH}^{-} \rightleftarrows \mathrm{Hg}(\mathrm{OH}) \mathrm{Cl}$ & $3.19 \times 10^{10}$ & {$\left[\mathrm{M}^{-1}\right]$} & 4691 & {$[\mathrm{~K}]$} & 8,9 \\
\hline $\mathrm{HgBr}^{+}+\mathrm{OH}^{-} \rightleftarrows \mathrm{Hg}(\mathrm{OH}) \mathrm{Br}$ & $3.06 \times 10^{10}$ & {$\left[\mathrm{M}^{-1}\right]$} & 4691 & {$[\mathrm{~K}]$} & 8,9, see Note ${ }^{a}$ \\
\hline $\mathrm{HgCl}_{2}+\mathrm{Br}^{-} \rightleftarrows \mathrm{HgClBr}+\mathrm{Cl}^{-}$ & $3.37 \times 10^{2}$ & non-dimensional & 2200 & {$[\mathrm{~K}]$} & $8,9,10$ \\
\hline $\mathrm{HgClBr}+\mathrm{Br}^{-} \rightleftarrows \mathrm{HgBr}_{2}+\mathrm{Cl}^{-}$ & $5.67 \times 10^{1}$ & non-dimensional & 2083 & {$[\mathrm{~K}]$} & $8,9,10$ \\
\hline $\mathrm{HgCl}_{3}^{-}+\mathrm{Br}^{-} \rightleftarrows \mathrm{HgCl}_{2} \mathrm{Br}^{-}+\mathrm{Cl}^{-}$ & $3.05 \times 10^{2}$ & non-dimensional & 1755 & {$[\mathrm{~K}]$} & $8,9,10$ \\
\hline $\mathrm{HgCl}_{2} \mathrm{Br}^{-}+\mathrm{Br}^{-} \rightleftarrows \mathrm{HgClBr}_{2}^{-}+\mathrm{Cl}^{-}$ & $7.38 \times 10^{1}$ & non-dimensional & 1661 & {$[\mathrm{~K}]$} & $8,9,10$ \\
\hline $\mathrm{HgClBr}_{2}^{-}+\mathrm{Br}^{-} \rightleftarrows \mathrm{HgBr}_{3}^{-}+\mathrm{Cl}^{-}$ & $1.80 \times 10^{1}$ & non-dimensional & 1566 & {$[\mathrm{~K}]$} & $8,9,10$ \\
\hline $\mathrm{HgCl}_{4}^{2-}+\mathrm{Br}^{-} \rightleftarrows \mathrm{HgCl}_{3} \mathrm{Br}^{2-}+\mathrm{Cl}^{-}$ & $1.87 \times 10^{2}$ & non-dimensional & 1929 & {$[\mathrm{~K}]$} & $8,9,10$ \\
\hline $\mathrm{HgCl}_{3} \mathrm{Br}^{2-}+\mathrm{Br}^{-} \rightleftarrows \mathrm{HgCl}_{2} \mathrm{Br}_{2}^{2-}+\mathrm{Cl}^{-}$ & $5.07 \times 10^{1}$ & non-dimensional & 1834 & {$[\mathrm{~K}]$} & $8,9,10$ \\
\hline $\mathrm{HgCl}_{2} \mathrm{Br}_{2}^{2-}+\mathrm{Br}^{-} \rightleftarrows \mathrm{HgClBr}_{3}^{2-}+\mathrm{Cl}^{-}$ & $1.64 \times 10^{1}$ & non-dimensional & 1740 & {$[\mathrm{~K}]$} & $8,9,10$ \\
\hline $\mathrm{HgClBr}_{3}^{2-}+\mathrm{Br}^{-} \rightleftarrows \mathrm{HgBr}_{4}^{2-}+\mathrm{Cl}^{-}$ & $4.50 \times 10^{0}$ & non-dimensional & 1645 & {$[\mathrm{~K}]$} & $8,9,10$ \\
\hline
\end{tabular}


Table 1. Continued.

\begin{tabular}{|c|c|c|c|}
\hline \multicolumn{4}{|c|}{ Aqueous-phase reactions } \\
\hline Reaction & Rate constant & Unit & Reference \\
\hline $\mathrm{Hg}+\mathrm{O}_{3} \rightarrow \mathrm{HgO}+\mathrm{O}_{2}$ & $k=4.7 \times 10^{7}$ & {$\left[\mathrm{M}^{-1} \mathrm{~s}^{-1}\right]$} & 11 \\
\hline $\mathrm{HgO}+\mathrm{H}^{+} \rightarrow \mathrm{Hg}^{2+}+\mathrm{OH}^{-}$ & $k=1.0 \times 10^{10}$ & {$\left[\mathrm{M}^{-1} \mathrm{~s}^{-1}\right]$} & 12 \\
\hline $\mathrm{Hg}+\mathrm{OH} \rightarrow \mathrm{Hg}^{+}+\mathrm{OH}^{-}$ & $k=2.4 \times 10^{9}$ & {$\left[\mathrm{M}^{-1} \mathrm{~s}^{-1}\right]$} & 13 \\
\hline $\mathrm{Hg}^{+}+\mathrm{O}_{2} \rightarrow \mathrm{Hg}^{2+}+\mathrm{O}_{2}^{-}$ & $k=1.0 \times 10^{9}$ & {$\left[\mathrm{M}^{-1} \mathrm{~s}^{-1}\right]$} & 14 \\
\hline $\mathrm{Hg}^{+}+\mathrm{OH} \rightarrow \mathrm{Hg}^{2+}+\mathrm{OH}^{-}$ & $k=1.0 \times 10^{10}$ & {$\left[\mathrm{M}^{-1} \mathrm{~s}^{-1}\right]$} & 14 \\
\hline $\mathrm{Hg}+\mathrm{HOCl} \rightarrow \mathrm{Hg}^{2+}+\mathrm{Cl}^{-}+\mathrm{OH}^{-}$ & $k=2.09 \times 10^{6}$ & {$\left[\mathrm{M}^{-1} \mathrm{~s}^{-1}\right]$} & 15 \\
\hline $\mathrm{Hg}+\mathrm{ClO}^{-} \rightarrow \mathrm{Hg}^{2+}+\mathrm{Cl}^{-}+2 \mathrm{OH}^{-}$ & $k=1.99 \times 10^{6}$ & {$\left[\mathrm{M}^{-1} \mathrm{~s}^{-1}\right]$} & 15 \\
\hline $\mathrm{Hg}+\mathrm{HOBr} \rightarrow \mathrm{Hg}^{2+}+\mathrm{Br}^{-}+\mathrm{OH}^{-}$ & $k=2.79 \times 10^{-1}$ & {$\left[\mathrm{M}^{-1} \mathrm{~s}^{-1}\right]$} & 16 \\
\hline $\mathrm{Hg}+\mathrm{BrO}^{-} \rightarrow \mathrm{Hg}^{2+}+\mathrm{Br}^{-}+2 \mathrm{OH}^{-}$ & $k=2.73 \times 10^{-1}$ & {$\left[\mathrm{M}^{-1} \mathrm{~s}^{-1}\right]$} & 16 \\
\hline $\mathrm{Hg}+\mathrm{Br}_{2} \rightarrow \mathrm{Hg}^{2+}+2 \mathrm{Br}^{-}$ & $k=1.96 \times 10^{-1}$ & {$\left[\mathrm{M}^{-1} \mathrm{~s}^{-1}\right]$} & 16 \\
\hline $\mathrm{Hg}^{2+}+\mathrm{O}_{2}^{-} \rightarrow \mathrm{Hg}^{+}+\mathrm{O}_{2}$ & $k=5.0 \times 10^{3}$ & {$\left[\mathrm{M}^{-1} \mathrm{~s}^{-1}\right]$} & 17 \\
\hline $\mathrm{Hg}^{2+}+\mathrm{HO}_{2} \rightarrow \mathrm{Hg}^{+}+\mathrm{O}_{2}+\mathrm{H}+$ & $k=5.0 \times 10^{3}$ & {$\left[\mathrm{M}^{-1} \mathrm{~s}^{-1}\right]$} & $\left(=k_{\mathrm{Hg}^{2+}+\mathrm{O}_{2}^{-}}\right)$ \\
\hline $\mathrm{Hg}^{+}+\mathrm{O}_{2}^{-} \rightarrow \mathrm{Hg}+\mathrm{O}_{2}$ & $k=1.0 \times 10^{10}$ & {$\left[\mathrm{M}^{-1} \mathrm{~s}^{-1}\right]$} & see Note ${ }^{b}$ \\
\hline $\mathrm{Hg}^{+}+\mathrm{HO}_{2} \rightarrow \mathrm{Hg}+\mathrm{O}_{2}+\mathrm{H}+$ & $k=1.0 \times 10^{10}$ & {$\left[\mathrm{M}^{-1} \mathrm{~s}^{-1}\right]$} & see Note ${ }^{b}$ \\
\hline $\mathrm{Hg}(\mathrm{OBr}) \mathrm{Br}+\mathrm{h} v \rightarrow \mathrm{Hg}(\mathrm{O}) \mathrm{Br}+\mathrm{Br}$ & $J_{\mathrm{HOBr}}$ & {$\left[\mathrm{s}^{-1}\right]$} & see Note ${ }^{c}$ \\
\hline $\mathrm{Hg}(\mathrm{O}) \mathrm{Br}+\mathrm{HO}_{2} \rightarrow \mathrm{Hg}(\mathrm{OH}) \mathrm{Br}+\mathrm{O}_{2}$ & $k=1.0 \times 10^{10}$ & {$\left[\mathrm{M}^{-1} \mathrm{~s}^{-1}\right]$} & see Note ${ }^{c}$ \\
\hline $\mathrm{Hg}(\mathrm{O}) \mathrm{Br}+\mathrm{O}_{2}^{-} \rightarrow \mathrm{Hg}(\mathrm{OH}) \mathrm{Br}+\mathrm{O}_{2}+\mathrm{OH}^{-}$ & $k=1.0 \times 10^{10}$ & {$\left[\mathrm{M}^{-1} \mathrm{~s}^{-1}\right]$} & see Note ${ }^{c}$ \\
\hline $\mathrm{Hg}^{2+}+\mathrm{h} v \stackrel{2 \mathrm{e}^{-}}{\rightarrow} \mathrm{Hg}$ & $\alpha_{\mathrm{PRHg}} \times J_{\mathrm{O}_{3} \rightarrow \mathrm{O}\left({ }^{1} \mathrm{D}\right)}$ & {$\left[\mathrm{s}^{-1}\right]$} & see Note ${ }^{\mathrm{d}}$ \\
\hline $\mathrm{HgOH}^{+}+\mathrm{h} v \stackrel{2 \mathrm{e}^{-}}{\rightarrow} \mathrm{Hg}+\mathrm{OH}^{-}$ & $\alpha_{\mathrm{PRHg}} \times J_{\mathrm{O}_{3} \rightarrow \mathrm{O}\left({ }^{1} \mathrm{D}\right)}$ & {$\left[\mathrm{s}^{-1}\right]$} & see Note ${ }^{d}$ \\
\hline $\mathrm{Hg}(\mathrm{OH})_{2}+\mathrm{h} v \stackrel{2 \mathrm{e}^{-}}{\rightarrow} \mathrm{Hg}+2 \mathrm{OH}^{-}$ & $\alpha \mathrm{PRHg} \times J_{\mathrm{O}_{3} \rightarrow \mathrm{O}\left({ }^{1} \mathrm{D}\right)}$ & {$\left[\mathrm{s}^{-1}\right]$} & see Note ${ }^{d}$ \\
\hline $\mathrm{HgCl}^{+}+\mathrm{h} v \stackrel{2 \mathrm{e}^{-}}{\rightarrow} \mathrm{Hg}+\mathrm{Cl}^{-}$ & $\alpha_{\mathrm{PRHg}} \times J_{\mathrm{O}_{3} \rightarrow \mathrm{O}\left({ }^{1} \mathrm{D}\right)}$ & {$\left[\mathrm{s}^{-1}\right]$} & see Note ${ }^{\mathrm{d}}$ \\
\hline $\mathrm{HgCl}_{2}+\mathrm{h} v \stackrel{2 \mathrm{e}^{-}}{\rightarrow} \mathrm{Hg}+2 \mathrm{Cl}^{-}$ & $\alpha_{\mathrm{PRHg}} \times J_{\mathrm{O}_{3} \rightarrow \mathrm{O}\left({ }^{1} \mathrm{D}\right)}$ & {$\left[\mathrm{s}^{-1}\right]$} & see Note ${ }^{d}$ \\
\hline $\mathrm{HgCl}_{3}^{-}+\mathrm{h} v \stackrel{2 \mathrm{e}^{-}}{\rightarrow} \mathrm{Hg}+3 \mathrm{Cl}^{-}$ & $\alpha_{\mathrm{PRHg}} \times J_{\mathrm{O}_{3} \rightarrow \mathrm{O}\left({ }^{1} \mathrm{D}\right)}$ & {$\left[\mathrm{s}^{-1}\right]$} & see Note ${ }^{\mathrm{d}}$ \\
\hline $\mathrm{HgCl}_{4}^{2-}+\mathrm{h} v \stackrel{2 \mathrm{e}^{-}}{\rightarrow} \mathrm{Hg}+4 \mathrm{Cl}^{-}$ & $\alpha_{\mathrm{PRHg}} \times J_{\mathrm{O}_{3} \rightarrow \mathrm{O}\left({ }^{1} \mathrm{D}\right)}$ & {$\left[\mathrm{s}^{-1}\right]$} & see Note ${ }^{d}$ \\
\hline $\mathrm{HgBr}^{+}+\mathrm{h} v \stackrel{2 \mathrm{e}^{-}}{\rightarrow} \mathrm{Hg}+\mathrm{Br}^{-}$ & $\alpha_{\mathrm{PRHg}} \times J_{\mathrm{O}_{3} \rightarrow \mathrm{O}\left({ }^{1} \mathrm{D}\right)}$ & {$\left[\mathrm{s}^{-1}\right]$} & see Note ${ }^{\mathrm{d}}$ \\
\hline $\mathrm{HgBr}_{2}+\mathrm{h} v \stackrel{2 \mathrm{e}^{-}}{\rightarrow} \mathrm{Hg}+2 \mathrm{Br}^{-}$ & $\alpha_{\mathrm{PRHg}} \times J_{\mathrm{O}_{3} \rightarrow \mathrm{O}\left({ }^{1} \mathrm{D}\right)}$ & {$\left[\mathrm{s}^{-1}\right]$} & see Note ${ }^{d}$ \\
\hline $\mathrm{HgBr}_{3}^{-}+\mathrm{h} v \stackrel{2 \mathrm{e}^{-}}{\rightarrow} \mathrm{Hg}+3 \mathrm{Br}^{-}$ & $\alpha_{\mathrm{PRHg}} \times J_{\mathrm{O}_{3} \rightarrow \mathrm{O}\left({ }^{1} \mathrm{D}\right)}$ & {$\left[\mathrm{s}^{-1}\right]$} & see Note ${ }^{d}$ \\
\hline $\mathrm{HgBr}_{4}^{2-}+\mathrm{h} v \stackrel{2 \mathrm{e}^{-}}{\rightarrow} \mathrm{Hg}+4 \mathrm{Br}^{-}$ & $\alpha_{\mathrm{PRHg}} \times J_{\mathrm{O}_{3} \rightarrow \mathrm{O}\left({ }^{1} \mathrm{D}\right)}$ & {$\left[\mathrm{s}^{-1}\right]$} & see Note ${ }^{\mathrm{d}}$ \\
\hline $\mathrm{Hg}(\mathrm{OH}) \mathrm{Cl}+\mathrm{h} v \stackrel{2 \mathrm{e}^{-}}{\rightarrow} \mathrm{Hg}+\mathrm{OH}^{-}+\mathrm{Cl}^{-}$ & $\alpha_{\mathrm{PRHg}} \times J_{\mathrm{O}_{3} \rightarrow \mathrm{O}\left({ }^{1} \mathrm{D}\right)}$ & {$\left[\mathrm{s}^{-1}\right]$} & see Note ${ }^{d}$ \\
\hline $\mathrm{Hg}(\mathrm{OH}) \mathrm{Br}+\mathrm{h} v \stackrel{2 \mathrm{e}^{-}}{\rightarrow} \mathrm{Hg}+\mathrm{OH}^{-}+\mathrm{Br}^{-}$ & $\alpha_{\mathrm{PRHg}} \times J_{\mathrm{O}_{3} \rightarrow \mathrm{O}\left({ }^{1} \mathrm{D}\right)}$ & {$\left[\mathrm{s}^{-1}\right]$} & see Note ${ }^{d}$ \\
\hline $\mathrm{HgClBr}+\mathrm{h} v \stackrel{2 \mathrm{e}^{-}}{\rightarrow} \mathrm{Hg}+\mathrm{Cl}^{-}+\mathrm{Br}^{-}$ & $\alpha \mathrm{PRHg} \times J_{\mathrm{O}_{3} \rightarrow \mathrm{O}\left({ }^{1} \mathrm{D}\right)}$ & {$\left[\mathrm{s}^{-1}\right]$} & see Note ${ }^{d}$ \\
\hline $\mathrm{HgCl}_{2} \mathrm{Br}^{-}+\mathrm{h} \nu \stackrel{2 \mathrm{e}^{-}}{\rightarrow} \mathrm{Hg}+2 \mathrm{Cl}^{-}+\mathrm{Br}^{-}$ & $\alpha_{\mathrm{PRHg}} \times J_{\mathrm{O}_{3} \rightarrow \mathrm{O}\left({ }^{1} \mathrm{D}\right)}$ & {$\left[\mathrm{s}^{-1}\right]$} & see Note ${ }^{\mathrm{d}}$ \\
\hline $\mathrm{HgClBr}_{2}^{-}+\mathrm{h} v \stackrel{2 \mathrm{e}^{-}}{\rightarrow} \mathrm{Hg}+\mathrm{Cl}^{-}+2 \mathrm{Br}^{-}$ & $\alpha_{\mathrm{PRHg}} \times J_{\mathrm{O}_{3} \rightarrow \mathrm{O}\left({ }^{1} \mathrm{D}\right)}$ & {$\left[\mathrm{s}^{-1}\right]$} & see Note ${ }^{\mathrm{d}}$ \\
\hline $\mathrm{HgCl}_{3} \mathrm{Br}^{2-}+\mathrm{h} v \stackrel{2 \mathrm{e}^{-}}{\rightarrow} \mathrm{Hg}+3 \mathrm{Cl}^{-}+\mathrm{Br}^{-}$ & $\alpha_{\mathrm{PRHg}} \times J_{\mathrm{O}_{3} \rightarrow \mathrm{O}\left({ }^{1} \mathrm{D}\right)}$ & {$\left[\mathrm{s}^{-1}\right]$} & see Note ${ }^{\mathrm{d}}$ \\
\hline $\mathrm{HgCl}_{2} \mathrm{Br}_{2}^{2-}+\mathrm{h} v \stackrel{2 \mathrm{e}^{-}}{\rightarrow} \mathrm{Hg}+2 \mathrm{Cl}^{-}+2 \mathrm{Br}^{-}$ & $\alpha_{\mathrm{PRHg}} \times J_{\mathrm{O}_{3} \rightarrow \mathrm{O}\left({ }^{1} \mathrm{D}\right)}$ & {$\left[s^{-1}\right]$} & see Note ${ }^{\mathrm{d}}$ \\
\hline $\mathrm{HgClBr}_{3}^{2-}+\mathrm{h} v \stackrel{2 \mathrm{e}^{-}}{\rightarrow} \mathrm{Hg}+\mathrm{Cl}^{-}+3 \mathrm{Br}^{-}$ & $\alpha_{\mathrm{PRHg}} \times J_{\mathrm{O}_{3} \rightarrow \mathrm{O}\left({ }^{1} \mathrm{D}\right)}$ & {$\left[\mathrm{s}^{-1}\right]$} & see Note ${ }^{d}$ \\
\hline
\end{tabular}

References: 1. Donohoue et al. (2006); 2. Shepler et al. (2007); 3. Balabanov et al. (2005); 4. Calvert and Lindberg (2004); 5. Sanemasa (1975); 6. Iverfeldt and Lindqvist (1980); 7. Sommar et al. (2000); 8. Hepler and Olofsson (1975); 9. Wagman et al. (1982); 10. Marcus and Eliezer (1962); 11. Munthe and McElroy (1992); 12. Pleijel and Munthe (1995); 13. Gårdfeldt et al. (2001); 14. Nazhat and Asmus (1973); 15. Lin and Pehkonen (1998); 16. Wang and Pehkonen (2004); 17. Gårdfeldt and Jonsson (2003).

${ }^{\text {a }}$ Temperature dependence is taken from $K_{\text {eq }}$ for $\mathrm{Hg}(\mathrm{OH}) \mathrm{Cl} ;{ }^{\mathrm{b}}$ Assumed to be very fast; ${ }^{\mathrm{c}}$ Analogically expanded from gas-phase reactions; ${ }^{\mathrm{d}} \alpha_{\mathrm{PRHg}}=0.354$ for the scenario of "slow" photo-reduction in the snowpack (see Sect. 2.2). 


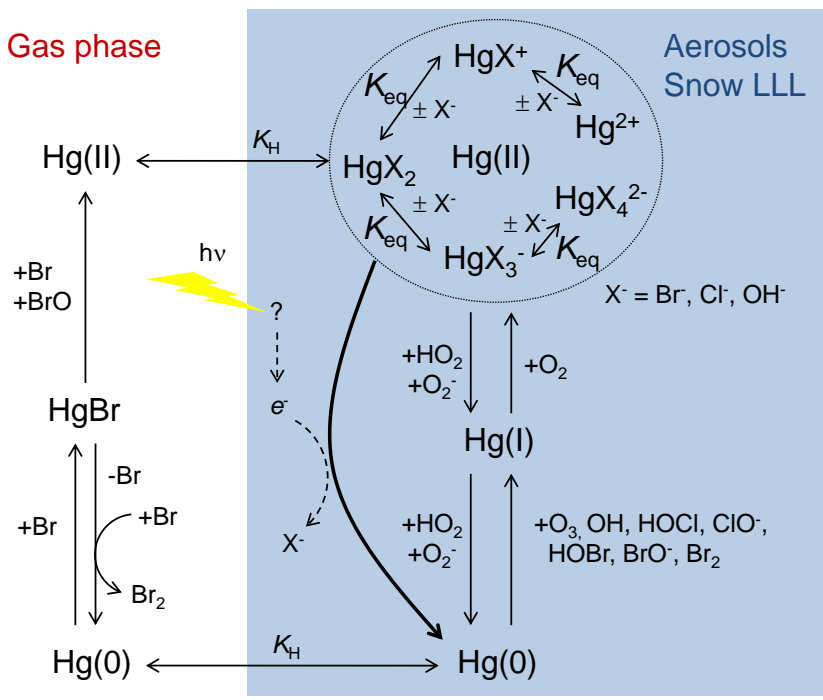

Fig. 1. Outline of mercury chemical mechanism in PHANTAS.

3, and 4). Nonetheless, since Shepler et al. (2007) employed a higher level of theory for the calculation of rate constants than Goodsite et al. (2012), we also test the greater rate constant for R1 adopted from Shepler et al. (scenario 2). In scenario 4, the thermal decomposition of $\mathrm{HgBr}$ (Reaction R2) and the stabilization of $\mathrm{HgBr}$ via Br-addition (Reaction R3) are assumed to follow the rate constants determined via calculations in Goodsite et al. $(2004,2012)$. In scenarios 1 to 3, we adopt the rate constants for these reactions from Shepler et al. (2007) and Balabanov et al. (2005), respectively, both of which employed the higher level of theory than Goodsite et al. $(2004,2012)$. All the scenarios adopt the rate constant for the $\mathrm{Br}$-abstraction channel of the reaction $\mathrm{HgBr}+\mathrm{Br}(\mathrm{Re}-$ action R4) from Balabanov et al. (2005). Our base case is scenario 1A (see Tables 2-3), which is used for model runs discussed in this paper unless otherwise noted.

For the simulation of mercury chemistry in the polar and/or global troposphere, models often employ reactions between GEM and other oxidants such as $\mathrm{BrO}, \mathrm{O}_{3}$ and $\mathrm{OH}$ deemed to occur in the gas phase (e.g., Dastoor and Larocque, 2004; Selin et al., 2007; Dastoor et al., 2008). In the present study, we neglect these reactions. The concurrent occurrence of ODEs and AMDEs implies minimal contributions from $\mathrm{O}_{3}$ and $\mathrm{OH}$ to the oxidation of GEM in the springtime polar boundary layer. The rate constant for the "gasphase" oxidation of $\mathrm{Hg}(0)$ by $\mathrm{BrO}$ was measured experimentally, but it was subject to the uncertainty of two orders of magnitude (Raofie and Ariya, 2003). In addition, a majority of the reactions appeared to have been mediated via unknown heterogeneous processes on the surface of the reaction vessel (Raofie and Ariya, 2004). Discrepancies in the reported rate constants for the reactions between GEM and its presumed oxidants in the atmosphere imply critical roles played by heterogeneous surface reactions and/or third-body effects in the experimental systems and, by extension, in the natural environment (Subir et al., 2011, and references therein). This issue is also relevant to the oxidation of GEM by $\mathrm{Br}$-atoms (Ariya et al., 2002). However, better understanding of mechanistic details is required before we can represent them adequately in the models (Pal and Ariya, 2004; Raofie and Ariya, 2004; Calvert and Lindberg, 2005; Snider et al., 2008; Subir et al., 2011, 2012). Fortunately, all of these uncertainties do not seem to disprove the major role of bromine chemistry as a cause of AMDEs in the polar boundary layer (Calvert and Lindberg, 2004; Dastoor et al., 2008; Seigneur and Lohman, 2008; Xie et al., 2008; Stephens et al., 2012).

Temperature dependence in the partitioning behavior of $\mathrm{Hg}$ (II) between gas and aqueous phases has been ignored or under-represented in earlier mercury models (e.g., Xie et al., 2008). Here we address the effects of changing aerosol bromide contents in the gas-aerosol $\mathrm{Hg}$ (II) partitioning, in addition to their temperature dependence, in the springtime Arctic context. For this purpose, we calculate the temperature dependence of Henry's law coefficients $\left(K_{\mathrm{H}}\right)$ for $\mathrm{Hg}(\mathrm{II})$ species and of stability constants $\left(K_{\text {eq }}\right)$ for $\mathrm{Hg}$ (II)-halide coordination complexes that form in the aqueous phase (such as $\mathrm{HgCl}_{4}^{2-}$ and $\mathrm{HgBr}_{4}^{2-}$ ) by using the van't Hoff equation while taking thermodynamic parameters from the literature if available. For $\mathrm{Hg}(0), \mathrm{Hg}(\mathrm{OH})_{2}$ and $\mathrm{HgCl}_{2}, K_{\mathrm{H}}$ and its temperature dependence have been determined experimentally (e.g., Sanemasa, 1975; Iverfeldt and Lindqvist, 1980; Lindqvist and Rodhe, 1985; Sommar et al., 2000; Andersson et al., 2008), and therefore the experimental data are favored for use in our model over the thermodynamic estimation. We also postulate the formation of mixed-halide complexes such as $\mathrm{HgCl}_{3} \mathrm{Br}^{2-}$ (see Appendix A).

Experimental evidence suggests that the net rate of photoreduction from $\mathrm{Hg}(\mathrm{II})$ to $\mathrm{Hg}(0)$ in water and in the LLL on ice is controlled by the abundance and functional characteristics of dissolved organic matter (DOM) mediating the photoreduction and by impeding effects from co-existent halide anions and dissolved oxygen (e.g., Allard and Arsenie, 1991; Xiao et al., 1995; Si and Ariya, 2008, 2011; Lalonde et al., 2003; Bartels-Rausch et al., 2011). In this study, we do not aim at addressing this problem by breaking down the whole process into a series of reaction elements. Rather, we adopt a simple parameterization in which a prescribed first-order rate constant is employed in the same fashion as Holmes et al. (2010). Here, the rate of gross photo-reduction from in-snow $\mathrm{Hg}(\mathrm{II})$ (regardless of its chemical forms) to $\mathrm{Hg}(0)$ is assumed to be either $5 \%$ per day ("slow" photo-reduction scenario, Johnson et al., 2008) or $30 \%$ per day ("fast" photo-reduction scenario, Kirk et al., 2006) on daily mean at the top of the snowpack. However, as the Johnson et al. (2008) study was among the most comprehensive ones conducted in the field under springtime Arctic settings, we use the "slow" photoreduction scenario as a base case unless otherwise stated (see also Table 3). Snow chamber studies from various regions and conditions indicate a major role of UV-B radiation (i.e., 
Table 2. List of rate constants for the gas-phase reactions of mercury used in a sensitivity study. See also Table 3 for scenario sub-category.

\begin{tabular}{|c|c|c|c|}
\hline Reaction & Rate constant & Unit & Reference \\
\hline \multicolumn{4}{|l|}{ Scenario 1 (baseline scenario) } \\
\hline $\begin{array}{l}\mathrm{Hg}+\mathrm{Br}+\mathrm{M} \rightarrow \mathrm{HgBr}+\mathrm{M} \\
\mathrm{HgBr}+\mathrm{M} \rightarrow \mathrm{Hg}+\mathrm{Br}+\mathrm{M} \\
\mathrm{HgBr}+\mathrm{Br} \rightarrow \mathrm{HgBr}_{2} \\
\mathrm{HgBr}+\mathrm{BrO} \rightarrow \mathrm{Hg}(\mathrm{OBr}) \mathrm{Br}\end{array}$ & $\begin{array}{l}k=1.44 \times 10^{-32}(T / 300)^{-1.86}[\mathrm{M}] \\
k=2.94 \times 10^{-9} \exp (-7670 / T) \\
k=2.98 \times 10^{-11} \\
k=2.98 \times 10^{-11}\end{array}$ & $\begin{array}{l}{\left[\mathrm{cm}^{3} \text { molecule }{ }^{-1} \mathrm{~s}^{-1}\right]} \\
{\left[\mathrm{cm}^{3} \text { molecule }{ }^{-1} \mathrm{~s}^{-1}\right]} \\
{\left[\mathrm{cm}^{3} \text { molecule } \mathrm{s}^{-1}\right]} \\
{\left[\mathrm{cm}^{3} \text { molecule } \mathrm{s}^{-1}\right]}\end{array}$ & $\begin{array}{l}\text { Donohoue et al. (2006) } \\
\text { Shepler et al. (2007) } \\
\text { Balabanov et al. }(2005) \\
\left(=k_{\mathrm{HgBr}}+\mathrm{Br}\right)\end{array}$ \\
\hline \multicolumn{4}{|l|}{ Scenario 2} \\
\hline $\begin{array}{l}\mathrm{Hg}+\mathrm{Br}+\mathrm{M} \rightarrow \mathrm{HgBr}+\mathrm{M} \\
\mathrm{HgBr}+\mathrm{M} \rightarrow \mathrm{Hg}+\mathrm{Br}+\mathrm{M} \\
\mathrm{HgBr}+\mathrm{Br} \rightarrow \mathrm{HgBr}_{2} \\
\mathrm{HgBr}+\mathrm{BrO} \rightarrow \mathrm{Hg}(\mathrm{OBr}) \mathrm{Br}\end{array}$ & $\begin{array}{l}k=2.79 \times 10^{-32} \exp (112 / T)[\mathrm{M}] \\
k=2.94 \times 10^{-9} \exp (-7670 / T) \\
k=2.98 \times 10^{-11} \\
k=2.98 \times 10^{-11}\end{array}$ & $\begin{array}{l}{\left[\mathrm{cm}^{3} \text { molecule }{ }^{-1} \mathrm{~s}^{-1}\right]} \\
{\left[\mathrm{cm}^{3} \text { molecule }\right.} \\
{\left[\mathrm{cm}^{3} \mathrm{molecule}^{-1} \mathrm{~s}^{-1}\right]} \\
{\left[\mathrm{cm}^{3} \text { molecule }\right.}\end{array}$ & $\begin{array}{l}\text { Shepler et al. (2007) } \\
\text { Shepler et al. (2007) } \\
\text { Balabanov et al. }(2005) \\
\left(=k_{\mathrm{HgBr}}+\mathrm{Br}\right)\end{array}$ \\
\hline \multicolumn{4}{|l|}{ Scenario 3} \\
\hline $\begin{array}{l}\mathrm{Hg}+\mathrm{Br}+\mathrm{M} \rightarrow \mathrm{HgBr}+\mathrm{M} \\
\mathrm{HgBr}+\mathrm{M} \rightarrow \mathrm{Hg}+\mathrm{Br}+\mathrm{M} \\
\mathrm{HgBr}+\mathrm{Br} \rightarrow \mathrm{HgBr}_{2} \\
\mathrm{HgBr}+\mathrm{BrO} \rightarrow \mathrm{Hg}(\mathrm{OBr}) \mathrm{Br}\end{array}$ & $\begin{array}{l}k=1.44 \times 10^{-32}(T / 300)^{-1.86}[\mathrm{M}] \\
k=2.94 \times 10^{-9} \exp (-7670 / T) \\
k=6.95 \times 10^{-11} \\
k=6.95 \times 10^{-11}\end{array}$ & $\begin{array}{l}{\left[\mathrm{cm}^{3} \text { molecule }{ }^{-1} \mathrm{~s}^{-1}\right]} \\
{\left[\mathrm{cm}^{3} \text { molecule }{ }^{-1} \mathrm{~s}^{-1}\right]} \\
{\left[\mathrm{cm}^{3} \text { molecule } \mathrm{s}^{-1}\right]} \\
{\left[\mathrm{cm}^{3} \text { molecule } \mathrm{s}^{-1}\right]}\end{array}$ & $\begin{array}{l}\text { Donohoue et al. (2006) } \\
\text { Shepler et al. (2007) } \\
\text { see Note }^{\mathrm{a}} \\
\left(=k_{\mathrm{HgBr}}+\mathrm{Br}\right)\end{array}$ \\
\hline \multicolumn{4}{|l|}{ Scenario 4} \\
\hline $\begin{array}{l}\mathrm{Hg}+\mathrm{Br}+\mathrm{M} \rightarrow \mathrm{HgBr}+\mathrm{M} \\
\mathrm{HgBr}(+\mathrm{M}) \rightarrow \mathrm{Hg}+\mathrm{Br}(+\mathrm{M}) \\
\mathrm{HgBr}+\mathrm{Br} \rightarrow \mathrm{HgBr}_{2} \\
\mathrm{HgBr}+\mathrm{BrO} \rightarrow \mathrm{Hg}(\mathrm{OBr}) \mathrm{Br}\end{array}$ & $\begin{aligned} k & =1.44 \times 10^{-32}(T / 300)^{-1.86}[\mathrm{M}] \\
k & =4.0 \times 10^{9} \exp (-7292 / T) \\
k & =2.5 \times 10^{-10}(T / 300)^{-0.57} \\
k & =2.5 \times 10^{-10}(T / 300)^{-0.57}\end{aligned}$ & $\begin{array}{l}{\left[\mathrm{cm}^{3} \text { molecule }{ }^{-1} \mathrm{~s}^{-1}\right]} \\
{\left[\mathrm{s}^{-1}\right]} \\
{\left[\mathrm{cm}^{3} \text { molecule }^{-1} \mathrm{~s}^{-1}\right]} \\
{\left[\mathrm{cm}^{3} \text { molecule }^{-1} \mathrm{~s}^{-1}\right]}\end{array}$ & $\begin{array}{l}\text { Donohoue et al. (2006) } \\
\text { Goodsite et al. (2012) } \\
\text { Goodsite et al. (2004) } \\
\left(=k_{\mathrm{HgBr}}+\mathrm{Br}\right)\end{array}$ \\
\hline
\end{tabular}

a The sum of the rate constants for Br-addition (R3) and Br-exchange (R5) channels as calculated by Balabanov et al. (2005).

Table 3. Scenario sub-category for the sensitivity study of the mercury chemical mechanism.

\begin{tabular}{|c|c|c|c|}
\hline Item & A & B & $\mathrm{C}$ \\
\hline $\begin{array}{l}\text { Gas-phase reaction } \mathrm{HgBr}+\mathrm{BrO} \\
\text { In-snow photo-reduction rates for } \\
\text { dissolved } \mathrm{Hg}(\mathrm{II}) \text { (see Note* })\end{array}$ & $\begin{array}{c}\text { on } \\
\text { slow }\end{array}$ & $\begin{array}{l}\text { on } \\
\text { fast }\end{array}$ & $\begin{array}{l}\text { off } \\
\text { slow }\end{array}$ \\
\hline
\end{tabular}

* Rate constants for the photo-reduction are assigned empirically to give the daily mean values of $5 \%$ and $30 \%$ per day at the top of the snowpack in the "slow" and "fast" cases, respectively, while both changing diurnally and decreasing with depth in the snowpack (see Sect. 2.2).

$\lambda \lesssim 320 \mathrm{~nm}$ ) (Lalonde et al., 2003; Dommergue et al., 2007; Faïn et al., 2007; Johnson et al., 2008; Durnford and Dastoor, 2011). Hence we scale the $\mathrm{Hg}$ (II) photo-reduction rate from its daily mean at the top of the snowpack by the calculated photolysis rate of $\mathrm{O}_{3}$ to $\mathrm{O}\left({ }^{1} \mathrm{D}\right)$ changing diurnally and decreasing with depth in the snowpack. Our chemical mechanism also includes the photo-reduction of $\mathrm{Hg}$ (II) to $\mathrm{Hg}$ (I) by $\mathrm{HO}_{2}$ and $\mathrm{O}_{2}^{-}$in the aqueous phase (Pehkonen and Lin, 1998), but fast re-oxidation of $\mathrm{Hg}(\mathrm{I})$ by dissolved $\mathrm{O}_{2}$ renders this pathway ineffective as a route to the $\operatorname{Hg}(0)$ formation (Nazhat and Asmus, 1973; Gårdfeldt and Jonsson, 2003). Aqueous-phase reduction of $\mathrm{Hg}$ (II) involving $\mathrm{SO}_{3}^{2-}$ and/or $\mathrm{HSO}_{3}^{-}$(e.g., Van Loon et al., 2000, 2001) is neglected in this study. We note, however, that this reduction mechanism might play a role under some circumstances in the Arctic where the anthropogenic emissions of $\mathrm{SO}_{2}$ are declining and yet abundant in recent decades (e.g., Quinn et al., 2007).

\subsection{Meteorology and chemistry scenarios}

Except model runs for sensitivity studies, the same model runs are re-used here from Part 1 of the study on insnow bromine activation and ozone deletion in the springtime Arctic ABL. Therefore, a detailed description of initial and boundary conditions assumed for model meteorology and chemistry is available in Part 1 (see Sect. 2.10 and Tables 2-5).

In each model run, to calculate vertical diffusivity profiles in the ABL, we assume a constant reference-height $(2 \mathrm{~m})$ wind speed $\left(U_{2}=2 \mathrm{~m} \mathrm{~s}^{-1}, 4.5 \mathrm{~m} \mathrm{~s}^{-1}, 8.5 \mathrm{~m} \mathrm{~s}^{-1}\right.$ or $\left.12 \mathrm{~m} \mathrm{~s}^{-1}\right)$ and repeat the same diurnal variations in the surface sensible heat flux $\left(-9 \sim-1 \mathrm{~W} \mathrm{~m}^{-2}\right.$, Persson et al., 2002) over eight model days. The top height of the turbulent ABL $\left(Z_{\mathrm{ABL}}\right)$ and the values of turbulent diffusivity throughout the ABL both increase with increasing $U_{2}$ and also exhibit diurnal variations with maxima at noon and minima at midnight (see Fig. 3a-c in Part 1). For example, $Z_{\mathrm{ABL}}$ changes over a day between 7-44 m, 119-128 m, 264-268 $\mathrm{m}$ and 426-429 m 
at $U_{2}=2 \mathrm{~m} \mathrm{~s}^{-1}, 4.5 \mathrm{~m} \mathrm{~s}^{-1}, 8.5 \mathrm{~m} \mathrm{~s}^{-1}$ and $12 \mathrm{~m} \mathrm{~s}^{-1}$, respectively (see Fig. 2a in Part 1). The sum of aerodynamic resistance and quasi-laminar layer resistance for $\mathrm{HgBr}_{2}$ to the snow surface at the height of $1 \mathrm{~m}$ in the ambient air decreases from the diurnal range of $419-2070 \mathrm{~s} \mathrm{~m}^{-1}$ at $U_{2}=2 \mathrm{~m} \mathrm{~s}^{-1}$ to $\sim 58 \mathrm{~s} \mathrm{~m}^{-1}$ at $U_{2}=12 \mathrm{~m} \mathrm{~s}^{-1}$ (see Fig. $2 \mathrm{~b}$ in Part 1), dictating changes in apparent dry deposition velocities for $\mathrm{HgBr}_{2}$ and other GOM species as discussed later.

PHANTAS is not fully capable of simulating temperature dependence of potential significance in reactive halogen release from the salty snowpack and from other forms of condensate in the atmosphere. This is because the model does not handle the precipitation of specific salts from the LLL (and hence changes in its composition) with decreasing temperatures across the eutectic points of salts being precipitated (e.g., Koop et al., 2000; Sander et al., 2006; Morin et al., 2008), although it does calculate increase in the total solute concentration via freezing out of water in the LLL in an approximate fashion (Cho et al., 2002). This has led to our choice that kinetic rate and thermodynamic equilibrium constants are calculated for temperature at $253 \mathrm{~K}$ in the whole model domain for all but sensitivity runs. At this temperature, chloride and bromide contained in the snowpack are expected to be dissolved totally in the LLL rather than precipitated as solid salts (Koop et al., 2000). Although the role of temperature in halogen activation from environmental snow surfaces is an unsettled issue, field observations do suggest the frequent occurrence of ODEs and AMDEs at $253 \mathrm{~K}$ (Tarasick and Bottenheim, 2002; Cole and Steffen, 2010; Pöhler et al., 2010). To examine the potential role of temperature in the gas-aerosol partitioning of $\mathrm{Hg}(\mathrm{II})$, we have also performed a sensitivity study in which some of the thermodynamic constants for $\mathrm{Hg}$ (II) species are re-calculated by assuming temperatures higher than $253 \mathrm{~K}$ (see Sect. 3.3).

We have selected the initial concentrations of trace gases and aerosol composition to represent an air mass in the springtime Arctic lower troposphere under a non-ODE/nonAMDE condition (see Table 4 in Part 1). However, for the simplicity of model setup and results interpretation, inorganic bromine is assumed not to exist in the atmosphere in the initial state of each model run. It thus ignores the measurable background of inorganic bromine perhaps persistently present in the free troposphere (e.g., Fitzenberger et al., 2000; Evans et al., 2003). The simulated buildup of reactive bromine in the $\mathrm{ABL}$ and in the SIA originates from a photochemical conversion of bromide contained in moderately saline and acidic snowpack, with a negligible source also given by a photolysis of $\mathrm{CHBr}_{3}$. Aerosols are initially composed of the mixture of $\mathrm{NH}_{4} \mathrm{HSO}_{4}-\mathrm{H}_{2} \mathrm{SO}_{4}-\mathrm{H}_{2} \mathrm{O}$ only, but they can serve as substrate to retain a significant amount of bromide and $\mathrm{Hg}$ (II) species once ozone is depleted in the air (see Sect. 3.1).

Following a box model study on AMDEs by Xie et al. (2008), we start our model runs with the initial mixing ratio of GEM at $0.168 \mathrm{pmol} \mathrm{mol}^{-1}$ both in the ambient air and in the SIA. This mixing ratio is very close to the median $\left(\sim 0.17 \mathrm{pmol} \mathrm{mol}^{-1}\right)$ of GEM mixing ratios observed below $4 \mathrm{~km}$ (except in the near-surface air with frequent AMDEs) in the North American Arctic to the north of $50^{\circ} \mathrm{N}$ during the Arctic Research of the Composition of the Troposphere from Aircraft and Satellites (ARCTAS) campaign in April 2008 (Mao et al., 2010). We note, however, that GEM mixing ratios $(\sim 1.7 \mathrm{ng}$ per standard cubic meter or $\sim 0.20 \mathrm{pmol} \mathrm{mol}^{-1}$ ) notably higher than our initial value were measured at altitudes between 1 and $7 \mathrm{~km}$ over the Beaufort Sea and the Arctic Ocean in April 1998 (Banic et al., 2003). Again, for the sake of simplicity, other forms of mercury (i.e., condensed-phase elemental mercury, gaseous and condensed-phase oxidized mercury) than GEM are assumed not to exist in the entire model domain at the beginning of each run.

\section{Results and discussion}

\subsection{Connections between the chemistry of bromine, ozone and mercury in the ABL}

Our model simulates a strong activation of bromine chemistry that occurs inside the porous snowpack under sunlight. It results in very high mixing ratios of inorganic gaseous bromine in the SIA from the first day of each model run, including that of $\mathrm{BrO}$ radical exceeding $100 \mathrm{pmol} \mathrm{mol}^{-1}$ during the day (see Fig. 4 in Part 1), and the evasion of gaseous bromine (mainly as $\mathrm{Br}_{2}$ ) from the SIA to the ambient air. For model runs at $U_{2}=2.0 \mathrm{~m} \mathrm{~s}^{-1}, 4.5 \mathrm{~m} \mathrm{~s}^{-1}$ and $8.5 \mathrm{~m} \mathrm{~s}^{-1}$ discussed here, it takes 2 to 5 days for the abundance of reactive gaseous bromine in the ABL to reach its maximum in each run (Fig. 2a-c, top row). The maxima of atmospheric $\mathrm{BrO}$ mixing ratios simulated in these runs (ca. $40-50 \mathrm{pmol} \mathrm{mol}^{-1}$ ) are in the same range as measured previously in the springtime Arctic boundary layer (Tuckermann et al., 1997; Pöhler et al., 2010; Liao et al., 2011). In our model, a principal factor that controls the buildup rate of atmospheric bromine is the thickness of the turbulent ABL; the lower the surface wind speed, the shallower the ABL, and the faster the buildup of bromine in the ABL (see Sect. 3.1 in Part 1).

Ozone is then destroyed vigorously in the ambient air (and more so in the SIA) via catalytic reaction cycles involving $\mathrm{Br}$ atoms and $\mathrm{BrO}$ radicals (Fig. 2a-c, bottom row). Since ozone itself participates in the activation of bromine chemistry via the "bromine explosion" (Platt and Lehrer, 1996; Wennberg, 1999), gaseous inorganic bromine stops building up in the air once ozone is depleted below about $5-10 \mathrm{nmol} \mathrm{mol}^{-1}$ depending on model runs. At this point, a major fate of $\mathrm{Br}-$ atoms in the air changes from the reaction with ozone to reactions with aldehydes emitted from the snowpack, first producing $\mathrm{HBr}$ and then taken up by sulfate aerosols to maintain high levels of particulate bromide (Fig. 2a-c, top row). The particulate bromide is believed to comprise a major part 

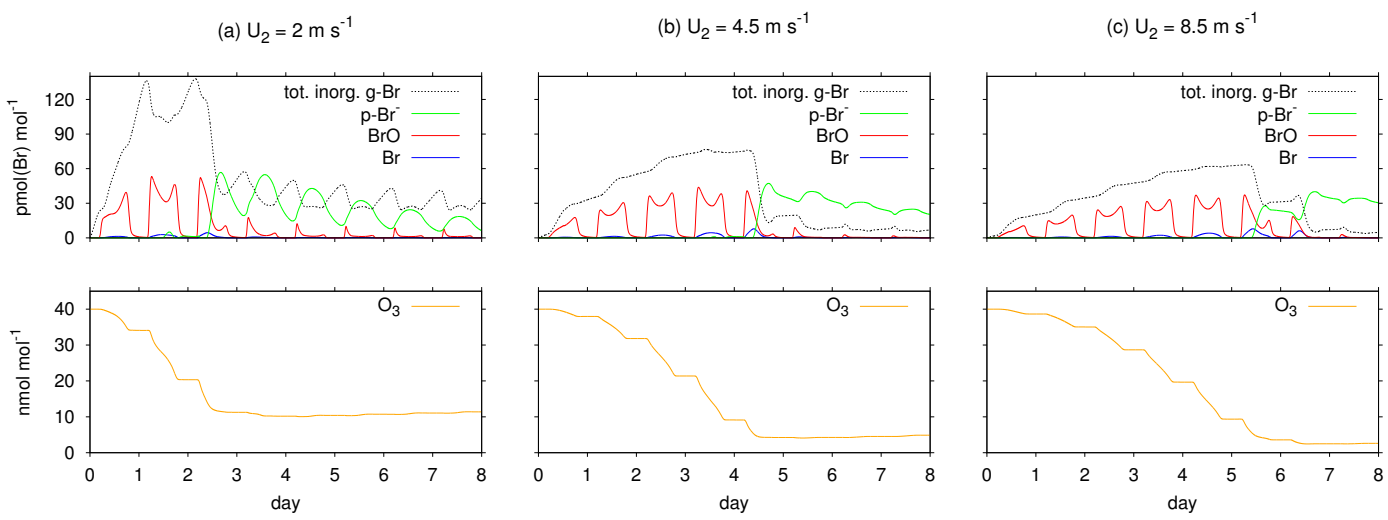

Fig. 2. Temporal evolution for the mixing ratios of inorganic bromine species (top row) and ozone (bottom row) at the height of $1.5 \mathrm{~m}$ in the ambient air from model runs employing scenario $1 \mathrm{~A}$ at $U_{2}=2.0 \mathrm{~m} \mathrm{~s}^{-1}$ (a), $4.5 \mathrm{~m} \mathrm{~s}^{-1}$ (b), and $8.5 \mathrm{~m} \mathrm{~s}^{-1}$ (c). Total inorganic gaseous bromine in dotted black lines, particulate (or aerosol) bromide in green lines, BrO radical in red lines, Br-atom in blue lines and ozone in orange lines.

of "filterable bromine", whose concentrations have been observed to ramp up during ODEs (Barrie et al., 1988; Oltmans et al., 1989; Sander et al., 1997).

Figure $3 \mathrm{a}-\mathrm{c}$ show temporal evolution for the mixing ratios of GEM, GOM and PBM in the entire model domain simulated at $U_{2}=2.0 \mathrm{~m} \mathrm{~s}^{-1}, 4.5 \mathrm{~m} \mathrm{~s}^{-1}$ and $8.5 \mathrm{~m} \mathrm{~s}^{-1}$, respectively. As a result of bromine radical chemistry in the gas phase, the abundance of GEM is simulated to drop in the $\mathrm{ABL}$ from the initial mixing ratio of $0.168 \mathrm{pmol} \mathrm{mol}^{-1}$ to the temporal minima of ca. 0.004-0.02 $\mathrm{pmol} \mathrm{mol}^{-1}$ depending on model runs. The decrease in atmospheric GEM levels continues until a major shift in the partitioning of inorganic bromine occurs from gaseous species including $\mathrm{Br}$ and $\mathrm{BrO}$ to particulate bromide in the sulfate aerosols. As discussed above, this shift occurs at the same time as ozone is depleted to low levels, providing one explanation for excellent correlations between ozone and gaseous mercury mixing ratios observed in the course of ODEs/AMDEs from both hemispheres during polar spring (e.g., Schroeder et al., 1998; Ebinghaus et al., 2002). We note, however, that, in scenarios where net mercury oxidation takes place at greater rates than in our baseline scenario of mercury chemistry, the depletion of GEM itself can be a more critical factor for limiting the oxidation of GEM in the air (Sect. 3.4).

As long as particulate bromide levels are suppressed via multiphase recycling that drives the "bromine explosion", mercury oxidized from GEM accumulates in the gas phase as GOM in the ABL. The composition of GOM simulated in our model is a mixture of several major species (Fig. 4a). A dominant entry pathway from GEM to GOM is a formation of $\mathrm{Hg}(\mathrm{OBr}) \mathrm{Br}$ via Reaction (R1) followed by Reaction (R6) (see Sect. 3.4). Here, the rate constant for the latter reaction (viz., $\mathrm{HgBr}+\mathrm{BrO}$ ) is simply assumed to be the same as that for Reaction (R3) (viz., $\mathrm{HgBr}+\mathrm{Br}$ ), as was done in a box model study by Calvert and Lindberg (2004). According to bond energy calculations, this approximation is quite reason- able (Dibble et al., 2012). However, the rate constant for Reaction (R3) itself has never been measured experimentally but derived only by theoretical calculations (Goodsite et al., 2004; Balabanov et al., 2005). We return to this issue in a sensitivity study discussed later. Also, the fate of $\mathrm{Hg}(\mathrm{OBr}) \mathrm{Br}$ to give $\mathrm{Hg}(\mathrm{OH}) \mathrm{Br}$ in the gas phase is hypothetical, where we have adopted the same mechanism as Calvert and Lindberg (2004). On the basis of their empirical adjustment of kinetic parameters, the lifetime of $\mathrm{Hg}(\mathrm{OBr}) \mathrm{Br}$ against photolytic decomposition via Reaction (R7) is assumed to be identical to that of $\mathrm{HOBr}$ against its photolysis. The product, $\mathrm{Hg}(\mathrm{O}) \mathrm{Br}$, is then assumed to react with $\mathrm{HO}_{2}$ via Reaction (R8) to give $\mathrm{Hg}(\mathrm{OH}) \mathrm{Br}$, a principal reservoir of GOM in the present model runs. Subsequently, ion-exchange reactions involving chloride and bromide (despite their trace concentrations most of the time) in sulfate aerosols convert a portion of $\mathrm{Hg}(\mathrm{OH}) \mathrm{Br}$ heterogeneously to $\mathrm{HgBr}_{2}, \mathrm{HgClBr}$, $\mathrm{HgCl}_{2}$ and $\mathrm{Hg}(\mathrm{OH}) \mathrm{Cl}$. The ion-exchange reactions were also incorporated in some of the earlier box models of multiphase mercury chemistry in the marine boundary layer (Hedgecock et al., 2005) and in the polar boundary layer (Xie et al., 2008). However, with no account of reactions to form mixed-ligand $\mathrm{Hg}$ (II) (e.g., $\mathrm{HgClBr}$ ), the ion-exchange reactions appear to have played a minimal role in these models with regard to the GOM speciation. Also, Xie et al. (2008) neglected the photolysis of $\mathrm{Hg}(\mathrm{OBr}) \mathrm{Br}$ and thus predicted this species to be the most abundant in the oxidized mercury pool. The formation of $\mathrm{Hg}(\mathrm{OBr}) \mathrm{Br}$ was not considered in the Hedgecock et al. (2005) model.

Once particulate bromide starts building up in sulfate aerosols after ozone is depleted to sufficiently low levels, GOM is taken up by the aerosols to form PBM (Fig. 3a-c, bottom row). Here, $\mathrm{HgBr}_{4}^{2-}$ makes up a dominant fraction of PBM (Fig. 4a). It arises from the ion-exchange reactions, which, as noted above, affect the speciation of GOM as well. This time, however, high concentrations of bromide 
(a) $\mathrm{U}_{2}=2 \mathrm{~m} \mathrm{~s}^{-1}$
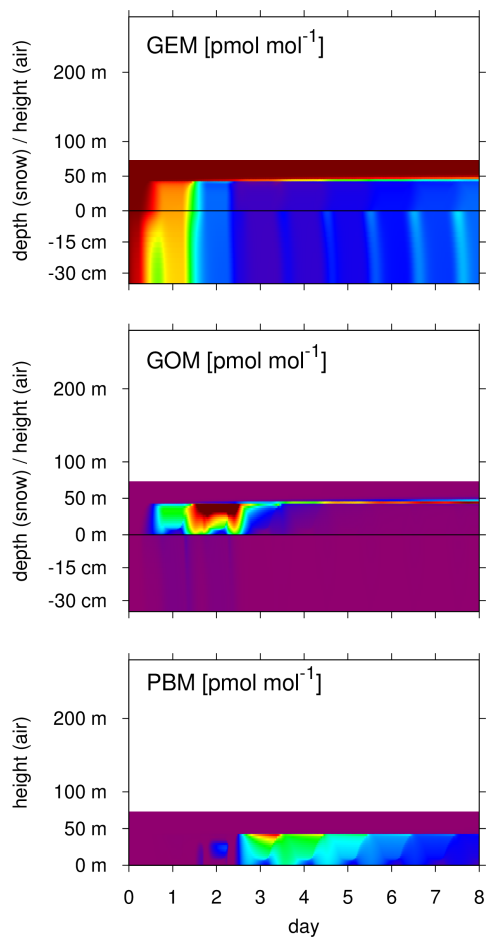

(b) $\mathrm{U}_{2}=4.5 \mathrm{~m} \mathrm{~s}^{-1}$
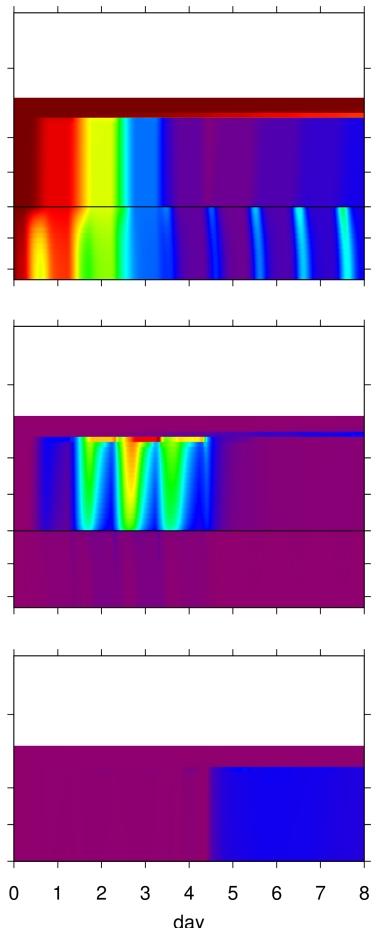

(c) $\mathrm{U}_{2}=8.5 \mathrm{~m} \mathrm{~s}^{-1}$
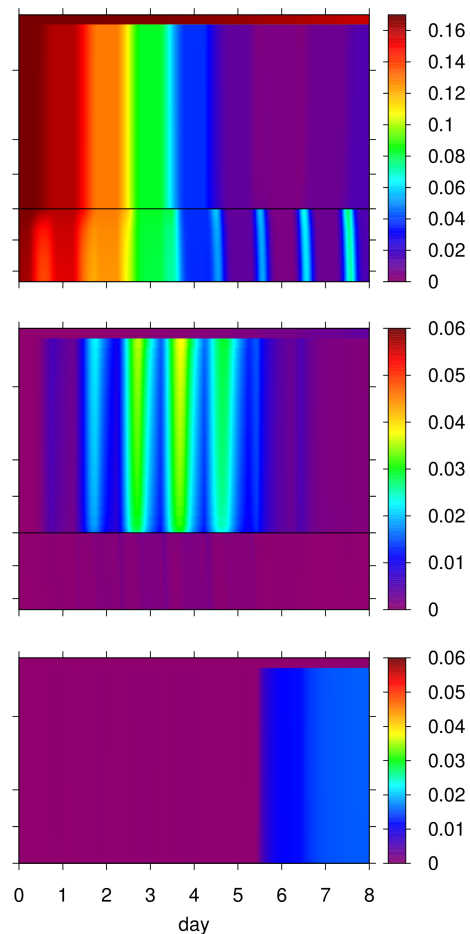

Fig. 3. Time-height cross sections for the mixing ratios of GEM (top row), GOM (middle row), and PBM (bottom row) from model runs employing scenario $1 \mathrm{~A}$ at $U_{2}=2.0 \mathrm{~m} \mathrm{~s}^{-1}$ (a), $4.5 \mathrm{~m} \mathrm{~s}^{-1}$ (b), and $8.5 \mathrm{~m} \mathrm{~s}^{-1}$ (c).

thermodynamically favor the formation of a complex fully coordinated by bromide (i.e., $\mathrm{HgBr}_{4}^{2-}$ ) to accumulate in the aerosols. To our knowledge, this is the first study in which the role of aerosol composition, especially that of bromide, is indicated as a major factor controlling the GOM-PBM partitioning in the atmosphere. In Sect. 3.3, we discuss this issue in more detail.

\subsection{In-snow oxidation and reduction of mercury}

Since daytime mixing ratios of bromine radicals are predicted to be generally higher in the SIA than in the ambient air (see Fig. 4 in Part 1), the GEM mixing ratios drop more rapidly in the SIA (while in the dark recovering to the same levels as in the ambient air) during the first couple of days in all the model runs. Unlike in the ambient air, the oxidation of GEM does not result in the buildup of GOM in the SIA. Instead, GOM is rapidly taken up by the LLL on the grain surface of the snowpack. As the levels of $\mathrm{Hg}$ (II) deposited to the snowpack increase with time, the production of $\mathrm{Hg}(0)$ via photo-reduction of $\mathrm{Hg}$ (II) in the LLL starts to dominate the oxidative loss of $\operatorname{Hg}(0)$ in the SIA. This is reflected in rapid increase in the GEM mixing ratios in the SIA, reaching daily maxima around noon near the top of the snowpack. The in-snow recovery of GEM levels migrates downwards from the top layers via gas diffusion in the SIA, as the ma- jority of in-snow $\mathrm{Hg}$ (II) originally enters the snowpack via "dry deposition" (or gas diffusion) from the atmosphere and is located within the top $1 \mathrm{~cm}$ of the snowpack (see Sect. 3.6). Increasing rates of $\mathrm{Hg}$ (II) photo-reduction towards the top of the snowpack also contribute to the stronger in-snow source of GEM in the top layers.

Unique behavior of GEM concentrations in the SIA, sometimes higher and at other times lower than in the overlying ambient air and generally driven by sunlight, has been observed in the field (e.g., Ferrari et al., 2004, 2005; Fain et al., 2006). Our model results are qualitatively consistent with such observations. However, at the "slow" photo-reduction rates assumed here (i.e., $5 \%$ per day at the top of the snowpack), the recovery of GEM in the ABL remains marginal over the 8 day time span of our model runs. On the other hand, a strong recovery of GEM often exceeding the background concentrations has been observed to occur in the near-surface ambient air at polar coastal sites, sometimes as rapidly as in less than a day between AMDEs (Steffen et al., 2002; Brooks et al., 2008; Johnson et al., 2008). Even if we assume a faster photo-reduction rate for in-snow $\mathrm{Hg}$ (II) (i.e., $30 \%$ per day at the top of the snowpack) on the basis of a field study at the coast of Hudson Bay (Kirk et al., 2006), our model does not predict such an intense and rapid GEM recovery in the ambient air (Figs. S3-4 in the Supplement). 


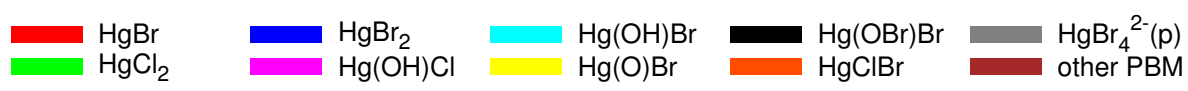

Scenario $1 \mathrm{~A}\left(\mathrm{U}_{2}=4.5 \mathrm{~m} \mathrm{~s}^{-1}, \mathrm{~N}=0.031 \mathrm{~s}^{-1}\right)$
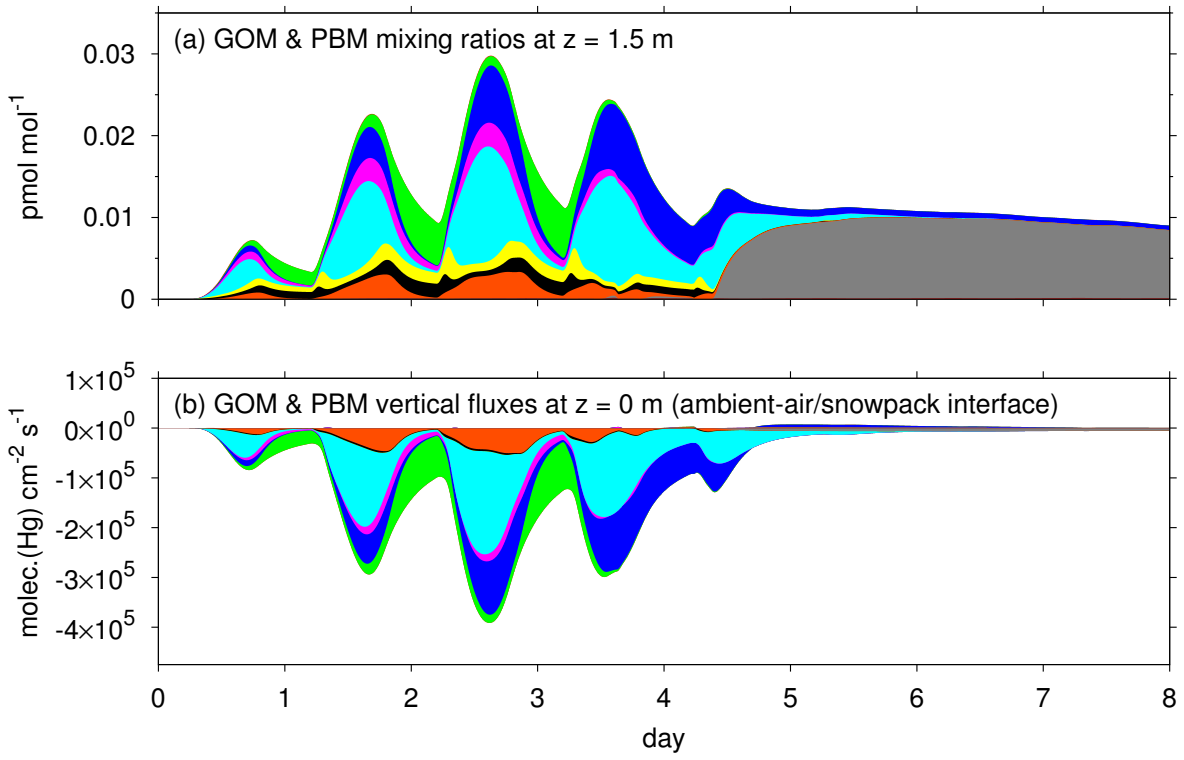

Fig. 4. Speciation and vertical fluxes of GOM and PBM as simulated with scenario $1 \mathrm{~A}$ at $U_{2}=4.5 \mathrm{~m} \mathrm{~s}^{-1}$ : (a) mixing ratios of GOM and PBM species at $z=1.5 \mathrm{~m}$ in ambient air above the snowpack and (b) vertical fluxes of GOM and PBM species at $z=0 \mathrm{~m}$, i.e., between ambient air and snowpack. Because of very low mixing ratios simulated, gaseous $\mathrm{Hg}(\mathrm{OH})_{2}$ is neglected in these plots.

This discrepancy could have been reconciled, at least partially, by designing model runs with day-to-day changes in vertical diffusivity profiles in the ABL rather than employing the same diurnal variations in vertical diffusivity over 8 days. Hence our present results do not necessarily suggest a deficiency in the chemical and physical schemes of our snowpack model in regard to the photo-reduction of $\mathrm{Hg}(\mathrm{II})$. Also, we note a fundamental limitation of the 1-D model approach in representing spatial inhomogeneity. For example, Hirdman et al. (2009) found changes in air mass to play a major role in the variability of atmospheric GEM concentrations in spring and summer at the Zeppelin mountain station on the western coast of Spitsbergen, whilst Steffen et al. (2013) indicated that in-snow $\mathrm{Hg}$ (II) is reducible to $\mathrm{Hg}(0)$ more easily over land than over sea ice from GEM measurements in the ambient air near Barrow, Alaska. Additionally, open leads and polynya between the frozen surface of seawater can also be an important source of GEM to the atmosphere (Aspmo et al., 2006; Outridge et al., 2008; Durnford et al., 2012; Fisher et al., 2012). If we are to reproduce the rate and magnitude of GEM recovery as observed in the polar boundary layer, we would need to account for these processes by using a 3-D modeling framework; this will be the subject of a further study.

\subsection{Gas-aerosol partitioning of oxidized mercury: a case in the Arctic boundary layer}

Amos et al. (2012) incorporated a parameterization of gasaerosol $\mathrm{Hg}$ (II) partitioning in their 3-D model of mercury chemistry and transport in the global troposphere. The empirical approach by Amos et al. (2012) related the coefficient of GOM-PBM partitioning to temperature and the total mass of aerosols in such a way that the fraction of PBM will increase with decreasing temperature and increasing aerosol mass. However, their scheme did not account for aerosol composition. They found a reasonable success of the parameterization in reproducing seasonal variations in the gas-aerosol partitioning of $\mathrm{Hg}(\mathrm{II})$ observed at North American continental sites, but little was evaluated in the polar boundary layer. On the other hand, multi-year measurements of speciated mercury, namely, GEM, reactive gaseous mercury (RGM) and PBM, at Alert, Canada, identified robust seasonal variations in the RGM-PBM partitioning at this site (Cobbett et al., 2007; Steffen et al., 2014). The identity of RGM is supposedly the same as that of GOM, while being defined operationally by a sampling protocol of the instrument with its collection efficiency occasionally subject to notable artifacts (Lyman et al., 2010). Until this instrumental issue is better characterized, we have no other choice but to resort to an assumption that the measured concentrations of RGM represent the actual concentrations of GOM. Steffen et al. (2014) 
showed seasonal transitions in the RGM / PBM ratios at Alert to be strongly related to temperature and the mass concentrations of haze aerosols. Our model results here suggest that bromide content in the haze aerosols, rather than the concentration of the haze aerosols themselves, is actually a key player for the determination of ratios between RGM (or GOM) and PBM during the AMDEs (Figs. 4a and 2b, top row).

A shift in the GOM-PBM partitioning has a significant consequence for the rate of deposition of oxidized mercury from the atmosphere. As shown in Fig. 4b, the net vertical flux of oxidized mercury from the atmosphere to the snowpack decreases by more than a magnitude after PBM takes over GOM in the partitioning of oxidized mercury. Dry deposition velocities for PBM contained in the sub- $\mu \mathrm{m}$ sulfate aerosols are calculated to be $\sim 0.02 \mathrm{~cm} \mathrm{~s}^{-1}$ in our model runs (Sect. 2.1). The apparent dry deposition velocities (defined by a ratio of the vertical flux of a trace constituent against its concentration at the same height) for a majority of GOM species (e.g., $\mathrm{HgBr}_{2}, \mathrm{Hg}(\mathrm{OH}) \mathrm{Br}, \mathrm{HgCl}_{2}$ ) are close to the inverse of aerodynamic resistance and are thus greater than the dry deposition velocities for PBM by an order of magnitude or more (Fig. 5a-i). In other words, GOM will likely undergo localized and intense dry deposition soon after its formation in the atmosphere, whereas the impact of the PBM dry deposition will be quite modest locally and extending over greater spatial scales. From the field measurements of vertical fluxes of RGM over the Arctic snow cover, Skov et al. (2006) concluded that the dry deposition velocities of RGM were limited in general by aerodynamic resistance to the snow surface, in agreement with our simulation. Also, Steffen et al. (2014) found that the highest deposition of atmospheric mercury at Alert occurred when a major shift in the partitioning of ambient concentrations of oxidized mercury took place from PBM to RGM in May. Our model simulation is consistent with their finding at least qualitatively in that the deposition of GOM is a major source of mercury entering the surface snow. In this study, wet deposition is ignored for all the chemical species, but changes in the GOM-PBM partitioning can also make a difference in the wet deposition rate of oxidized mercury (e.g., Douglas et al., 2008; Amos et al., 2012). Considering relatively long lifetime against dry deposition, PBM contained in the sub- $\mu \mathrm{m}$ aerosols will be lost from the atmosphere primarily via wet deposition happening episodically. Unfortunately, our knowledge is still incomplete for simulating precipitation processes and their impacts on wet deposition of aerosols and gases in the polar region (Inoue et al., 2006; Korhonen et al., 2008; Shindell et al., 2008).

From 6 years of observations (1980-1986) at Alert, Barrie and Barrie (1990) showed the concentrations of "filterable bromine" to peak sharply from late March to early April. Although it has not been investigated, this seasonality may have shifted forward in recent decades (cf. Cole and Steffen, 2010). If indeed particulate bromide plays a major role in the GOM-PBM partitioning as simulated in our model, seasonal trends in particulate bromide concentrations may provide one explanation for the observed increase in RGM/PBM ratio at Alert in May (Steffen et al., 2014). In addition, thermodynamic constants adopted in our chemical scheme are consonant with observed trends in the RGM/PBM ratio against temperature. Figure 6 a shows the dependence of simulated GOM-PBM partitioning on the temperature assumed for the calculations of Henry's law for GOM species and aqueous-phase stability constants for $\mathrm{Hg}$ (II)-ligands in the atmospheric aerosols as well as in the LLL of the snow. If a temperature of $268 \mathrm{~K}$ is assumed (instead of $253 \mathrm{~K}$ ) in calculating the $\mathrm{Hg}$ (II) partitioning between gas and aqueous phases, the simulated buildup of PBM after the maturity of AMDEs plateaus once the concentrations of PBM and GOM become comparable. If we assume the temperature of $298 \mathrm{~K}$, the simulated levels of PBM become negligibly small and thus GOM becomes a dominant component of $\mathrm{Hg}$ (II) regardless of bromide content in the aerosols. In spring at Alert, median air temperatures are $248 \mathrm{~K}$ and $267 \mathrm{~K}$, respectively, when PBM dominates RGM and vice versa (Steffen et al., 2014). We note that, even at the temperature of $253 \mathrm{~K}$, GOM dominates the simulated partitioning of oxidized mercury in our model while the concentrations of particulate bromide are maintained at low levels via active multiphase recycling before the depletion of ozone. Therefore, in order to provide a satisfactory explanation for seasonality in the GOM-PBM partitioning at Alert on the basis of our proposed mechanism, it is also required to assume a non-locality of AMDEs, in that the oxidation of GEM via bromine radical chemistry has terminated by the time air masses arrive at Alert, until mid-April when PBM has been observed to dominate the partitioning almost all the time (Cobbett et al., 2007; Steffen et al., 2014). A study by Bottenheim and Chan (2006) appears to support the prevalence of distant origins of reactive halogens causing ODEs and AMDEs observed at Alert. By analyzing the cluster of 10 day backward trajectories of air masses arriving at Alert over 9 years, these authors suggested that a majority of ODEs at Alert could have been initiated several days ago over sea ice upwind across the central Arctic Ocean.

The model simulations indicate that the apparent dry deposition velocities of GOM species over the snow surface also depend on temperature, owing to the temperature dependence of $K_{\mathrm{H}}(\mathrm{Hg}(\mathrm{II}))$ and $K_{\mathrm{eq}}(\mathrm{Hg}(\mathrm{II}))$ that control the partitioning of oxidized mercury between the SIA and the LLL in the snowpack in our model (Fig. 6b). Obviously, the apparent dry deposition velocity of GOM is more than halved by raising temperature from $253 \mathrm{~K}$ to $298 \mathrm{~K}$. However, it does not appear that the apparent dry deposition velocities of GOM species change significantly at temperatures between 253 and 268 K (see also Fig. S5 in the Supplement). Since these model runs ignored changes in the LLL thickness on the snow grains with temperature, we conducted three more sensitivity runs by calculating all the chemical and physical parameters in the model at $268 \mathrm{~K}$ (in which case the snowpack LLL volume increased approximately 5-fold, case 1) 

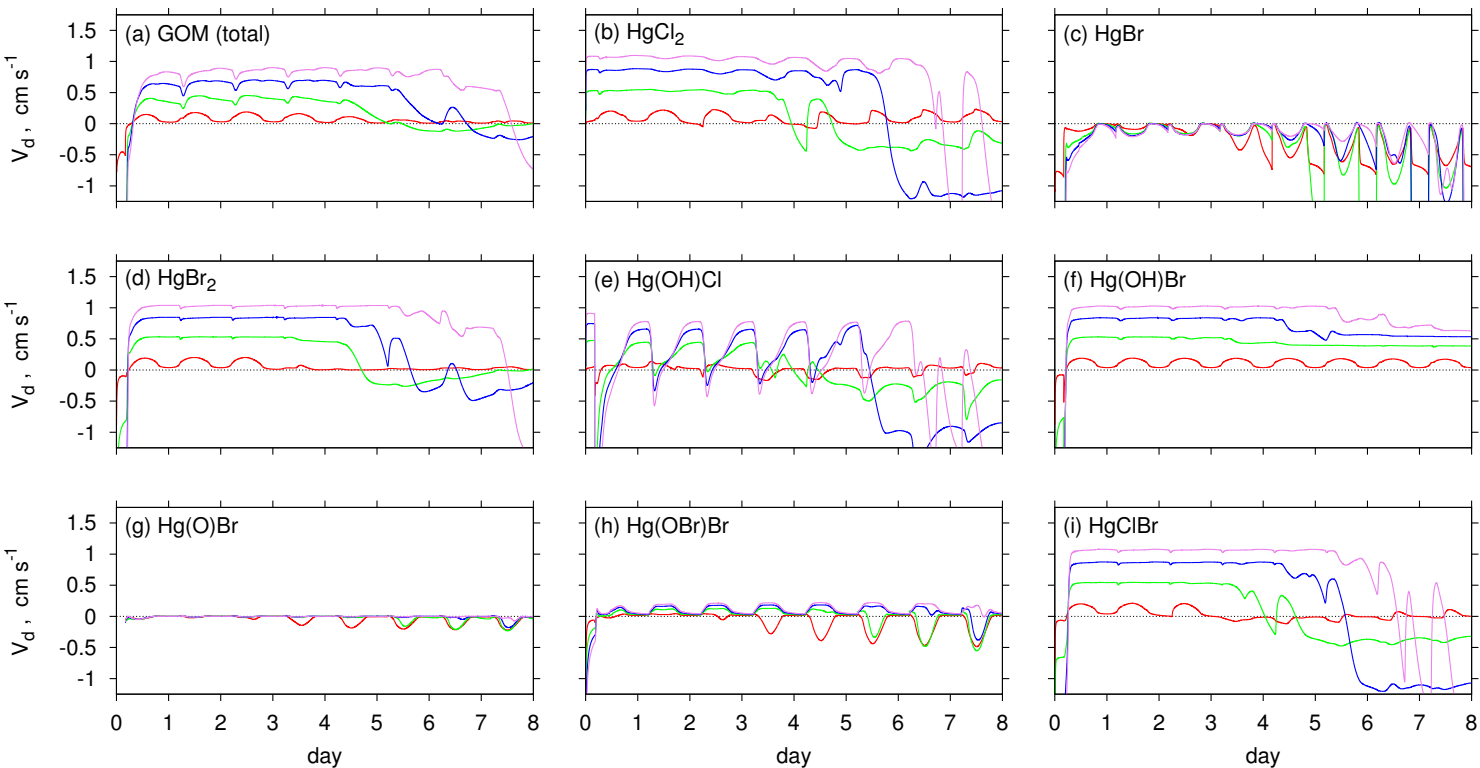

$$
\mathrm{U}_{2}=2 \mathrm{~m} \mathrm{~s}^{-1} \longrightarrow \quad \mathrm{U}_{2}=4.5 \mathrm{~m} \mathrm{~s}^{-1}
$$

$$
\mathrm{U}_{2}=8.5 \mathrm{~m} \mathrm{~s}^{-1}-\mathrm{U}_{2}=12 \mathrm{~m} \mathrm{~s}^{-1}
$$

Fig. 5. Apparent dry deposition velocities of GOM and its each component species (except $\mathrm{Hg}(\mathrm{OH})_{2}$, which constitutes a minimal partitioning in GOM simulated here) at $1.5 \mathrm{~m}$ above the snow surface from model runs employing scenario $1 \mathrm{~A}$ at $U_{2}=2.0 \mathrm{~m} \mathrm{~s}^{-1}$ (red lines), $4.5 \mathrm{~m} \mathrm{~s} \mathrm{~s}^{-1}$ (green lines), $8.5 \mathrm{~m} \mathrm{~s}^{-1}$ (blue lines), and $12.0 \mathrm{~m} \mathrm{~s}^{-1}$ (violet lines): (a) the sum of all GOM species, $(\mathbf{b}) \mathrm{HgCl}_{2},(\mathbf{c}) \mathrm{HgBr}_{1}(\mathbf{d}) \mathrm{HgBr}$, (e) $\mathrm{Hg}(\mathrm{OH}) \mathrm{Cl}$, (f) $\mathrm{Hg}(\mathrm{OH}) \mathrm{Br},(\mathbf{g}) \mathrm{Hg}(\mathrm{O}) \mathrm{Br}$, (h) $\mathrm{Hg}(\mathrm{OBr}) \mathrm{Br}$, and (i) $\mathrm{HgClBr}$.
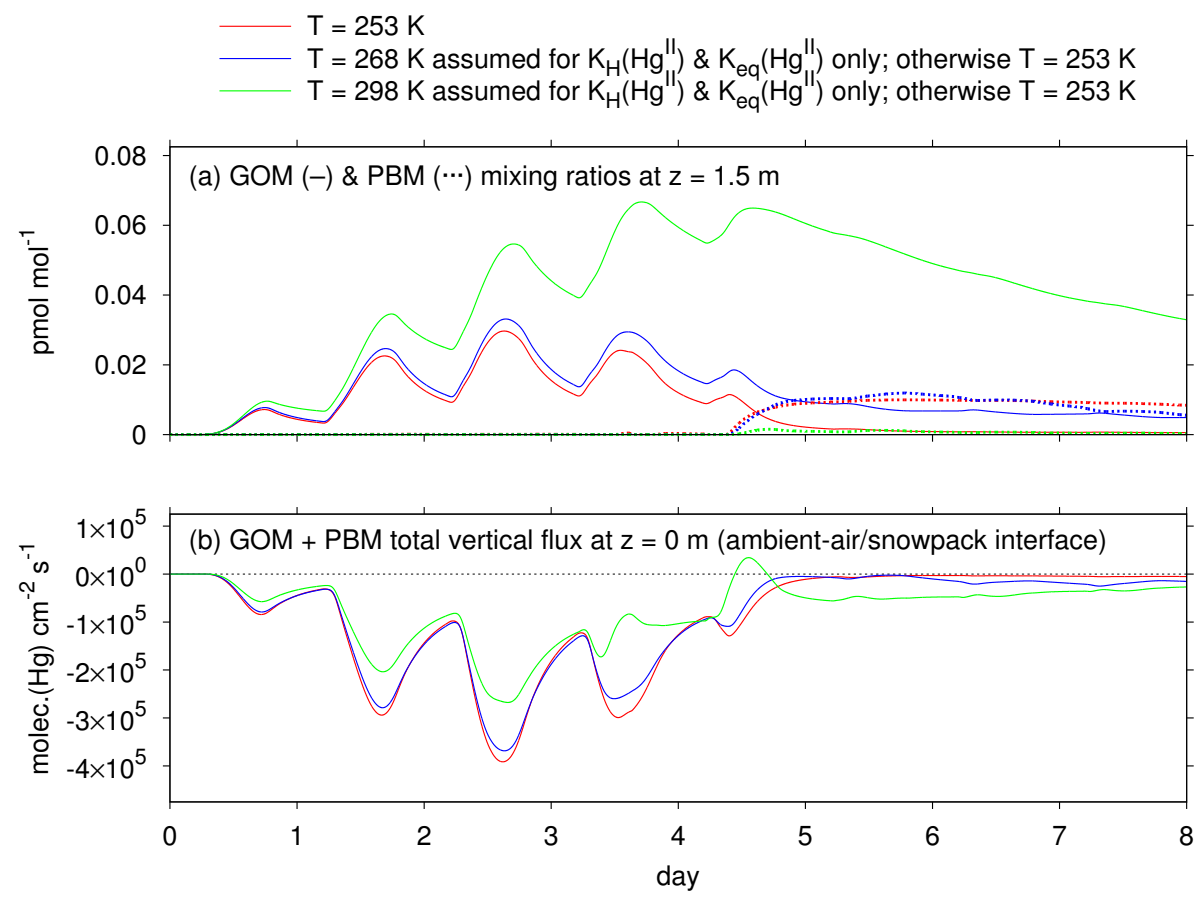

Fig. 6. Sensitivities of partitioning between GOM and PBM in the ambient air and their total air-snow fluxes on the choice of temperaturedependent thermodynamic parameters for $\mathrm{Hg}$ (II) species: (a) mixing ratios of GOM (solid lines) and PBM (dotted lines) simulated at $z=1.5 \mathrm{~m}$ in the ambient air above the snowpack and (b) total vertical fluxes of GOM and PBM at $z=0 \mathrm{~m}$. Red lines denote a base case from a model run at $U_{2}=4.5 \mathrm{~m} \mathrm{~s}^{-1}$ and $T=253 \mathrm{~K}$. Blue and green lines denote sensitivity runs performed with the same condition except that, for the calculations of Henry's law $\left(K_{\mathrm{H}}\right)$ and aqueous-phase stability constants for halide complexes $\left(K_{\text {eq }}\right)$ of $\mathrm{Hg}$ (II) $\mathrm{species,} T=268 \mathrm{~K}$ and $298 \mathrm{~K}$, respectively, were assumed. Scenario 1A was employed for mercury chemistry in all model runs. 

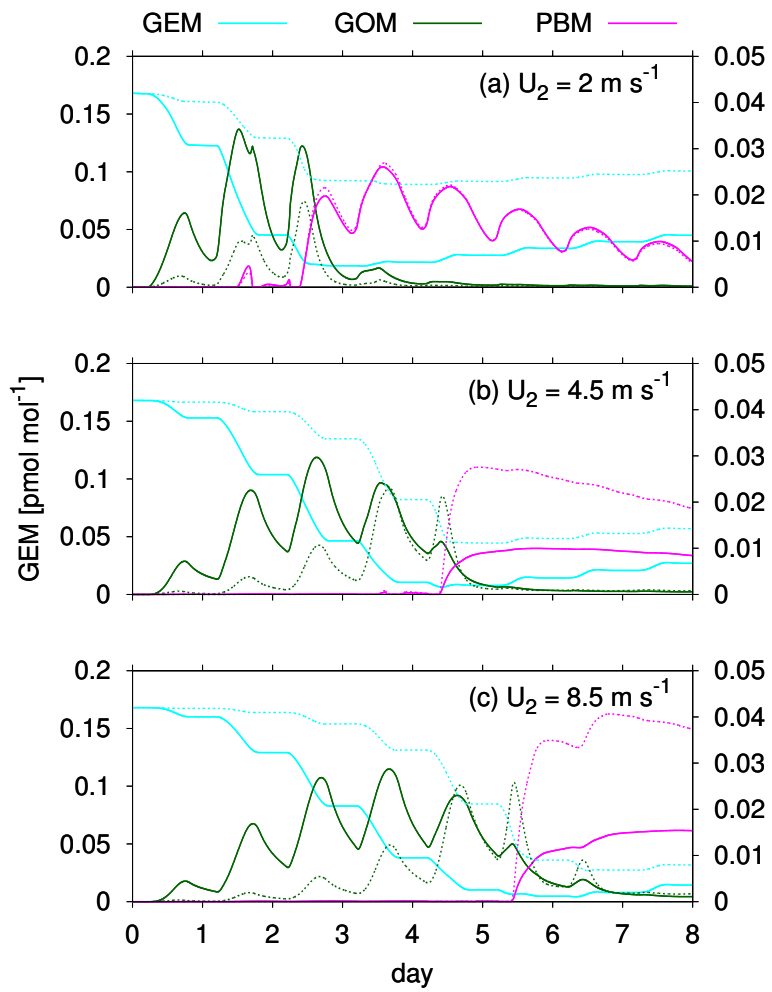

Fig. 7. Temporal evolution for the mixing ratios of GEM (light blue), GOM (dark green) and PBM (magenta) at the height of $1.5 \mathrm{~m}$ in the ambient air from model runs at $U_{2}=2.0 \mathrm{~m} \mathrm{~s}^{-1}$ (a), $4.5 \mathrm{~m} \mathrm{~s}^{-1}$ (b), and $8.5 \mathrm{~m} \mathrm{~s}^{-1}$ (c). Solid and dotted lines represent model runs with the gas-phase reaction $\mathrm{HgBr}+\mathrm{BrO}$ switched on (scenario 1A) and off (scenario 1C), respectively.

and by only raising (case 2) or lowering (case 3) the snowpack LLL volume by a factor of five while keeping the temperature at $253 \mathrm{~K}$ for calculating all other chemical and physical parameters. Again, these sensitivity runs resulted in the apparent dry deposition velocities of GOM species similar to those obtained in our base run where all the chemical and physical properties were calculated at $253 \mathrm{~K}$ (see Sect. S3 and Fig. S6 in the Supplement). We note, however, that there are other limitations in our model experiments. For example, in these model runs, we did not account for changes in the LLL thickness on the snow grains with impurity concentrations (Döppenschmidt and Butt, 2000; Cho et al., 2002). Also ignored was a pivotal role of snowmelt near the melting point of water in flushing the impurities out of the snowpack (e.g., Dommergue et al., 2003). Although it is beyond our present scope, our model could be further utilized to examine the role of these processes on the dry deposition of GOM species on snow surface.

\subsection{Uncertainties in the gas-phase mechanism of mercury oxidation}

Even with uncertainties in gas-phase kinetics, there is almost no doubt that bromine chemistry is critically involved in the oxidation of GEM during AMDEs (Calvert and Lindberg, 2004; Dastoor et al., 2008; Xie et al., 2008; Holmes et al., 2010; Subir et al., 2011; Stephens et al., 2012). But, if we are to advance our skills in predicting the location and magnitude of oxidized mercury depositing from the atmosphere during AMDEs, a better understanding of the mechanisms for reactive halogen release is required in the first place (Abbatt et al., 2012, and references therein). For example, one of our objectives to develop the PHANTAS model was to give new insights into what may be happening inside the polar snowpack when it releases reactive bromine to the atmosphere, as discussed in Part 1. We also need a full identification of reactants involved in the GEM oxidation and a better quantification of the rate coefficient for each step of the elementary reactions.

As mentioned earlier, gas-phase oxidation of GEM initiated via reaction with $\mathrm{Br}$-atoms involves a series of competing elementary reactions before ending up with thermally stable products such as $\mathrm{HgBr}_{2}$ (Calvert and Lindberg, 2004; Goodsite et al., 2004, 2012). As reviewed by Subir et al. (2011), the transition state theory (TST) and the RiceRamsberger-Kassel-Markus (RRKM) theory have been employed to approximate the dynamics of these reactions at the quantum level (e.g., Khalizov et al., 2003; Goodsite et al., 2004, 2012); however, the rate constants estimated by both methods are subject to some level of uncertainty. Balabanov et al. (2005) and Shepler et al. (2007) performed more rigorous calculations by employing a higher level of quantum mechanical theory, supposedly more accurate than the TST and the RRKM theory, to derive the global potential energy surfaces of the reaction dynamics for the same elementary reactions involved in the Br-initiated GEM oxidation (see Sect. S1 of the Supplement). A few laboratory studies measured the rate constants of net oxidation of GEM initiated via Br-attack (e.g., Ariya et al., 2002). Unfortunately, their applicability would be limited to the environment with reactant concentrations similar to those in the experimental system and at room temperature at which the experiments were conducted. The rate constant of Reaction (R1), adopted from a laboratory study by Donohoue et al. (2006) for our model runs, was exceptional in this sense, as the experiment was designed to measure the reaction rate of this elementary step itself. Of course, this rate constant is also subject to potential errors associated with methodological uncertainties (Subir et al., 2011). Hence, for the simulation of GEM oxidation via bromine radical chemistry in the gas phase, modelers must presently choose one of the following options: (1) lumping the whole reaction steps to a single net reaction while scaling down a laboratory-determined rate constant of the net reaction, or (2) resolving each of the elementary reaction steps 
but in most cases using theoretically estimated rate constants. Here we chose the latter. We then created four basic scenarios using combinations of the rate constants for Reactions (R1), (R2), (R3) and (R6) as listed in Table 2 and tentatively selected the scenario 1A as our baseline (see Sect. 2.2).

One of the major assumptions in our scheme of mercury chemistry is the feasibility of Reaction (R6). Our choice is based on a box model study by Calvert and Lindberg (2004) in which the rate constant of $\mathrm{HgBr}+\mathrm{BrO}$ (Reaction R6) was simply assumed to be the same as that of $\mathrm{HgBr}+\mathrm{Br}$ (Reaction R3). Although recent theoretical calculations of bond energies support the viability of Reaction (R6) (Dibble et al., 2012), its rate constant adopted in our model is still considered to be highly uncertain. As a lucid test of this problem, we examined a sensitivity of simulated concentrations of GEM, GOM and PBM on Reaction (R6) by switching this reaction off (scenario 1B, see Fig. 7a-c). In this case, a further oxidation of $\mathrm{HgBr}$ (i.e., an initial product of $\mathrm{Br}$ attack on GEM) is accomplished solely by the next attack from $\mathrm{Br}$-atoms, whose concentrations are generally lower by at least an order of magnitude than those of $\mathrm{BrO}$ radicals (Fig. 8a). Consequently, a larger fraction of $\mathrm{HgBr}$ dissociates back to $\mathrm{Hg}$ and $\mathrm{Br}$ via Reaction (R2), dropping the net rate of GEM oxidation (Fig. 8b-c). At the height of $1.5 \mathrm{~m}$ above the snow surface, the lowest mixing ratios of GEM simulated in 8 day model runs at $U_{2}=2.0-8.5 \mathrm{~m} \mathrm{~s}^{-1}$ are $0.018-0.036 \mathrm{pmol} \mathrm{mol}^{-1}$ without Reaction (R6), as compared to $0.004-0.018 \mathrm{pmol} \mathrm{mol}^{-1}$ in base runs with Reaction (R6). Maximum dips from the background (initial) level of GEM ( $0.168 \mathrm{pmol} \mathrm{mol}^{-1}$ assumed in this study) are therefore $0.150-0.164 \mathrm{pmol} \mathrm{mol}^{-1}$ and $0.132-0.150 \mathrm{pmol} \mathrm{mol}^{-1}$ with and without Reaction (R6), respectively. Although the total amounts of GEM oxidized and GOM produced become smaller by neglecting Reaction (R6), the buildup of PBM after the maturity of AMDEs occurs more substantially than in the base runs (Fig. 7a-c). As discussed later, in the model runs without Reaction (R6), a major acceleration occurs in the net GEM oxidation when the concentrations of $\mathrm{Br}$-atoms ramp up shortly before the GOM-PBM partitioning is shifted from GOM to PBM.

According to working definitions by Steffen et al. (2002) and Cole and Steffen (2010), GEM concentrations below $\sim 1 \mathrm{ng} \mathrm{m}^{-3}$ (or $\sim 0.12 \mathrm{pmol} \mathrm{mol}^{-1}$ ) are considered to be under the category of AMDEs. In our model runs, the lowest GEM levels simulated in the ABL always meet this criterion even without Reaction (R6) in the chemical scheme. Here we note that the temperature dependence of the gas-phase kinetics of Reaction (R2) is presumably one of the key factors for determining the net oxidation rate of GEM via reactions initiated by Br-attack (Goodsite et al., 2004). This is indicated from our estimated changes in the net oxidation rate of GEM by varying temperature between 238 and $268 \mathrm{~K}$ for the calculation of gas-phase mercury kinetics (Fig. 8b-c). Field observations suggest that, at the air temperature of $253 \mathrm{~K}$ assumed in our base model runs, AMDEs should occur nearly as often as ODEs (Tarasick and Bottenheim, 2002; Gauchard et al., 2005; Brooks et al., 2008; Cole and Steffen, 2010). All of our scenarios for mercury chemistry are successful in reproducing AMDEs concurrent with ODEs at air temperatures below $253 \mathrm{~K}$.

Goodsite et al. (2004) suggested that the reactions of $\mathrm{HgBr}$ with $\mathrm{OH}$-radical, I-atom and $\mathrm{Br}$-atom are all viable pathways for the formation of thermally stable GOM. In our model runs, however, the concentrations of $\mathrm{OH}$-radical are probably too low (Fig. 8a), as compared to those of Br-atom, to make a difference in the net oxidation rate of GEM. In the Antarctic $\mathrm{ABL}$ over the frozen ocean, inorganic iodine from unknown sources can lead to the concentrations of I-atom even higher than those of $\mathrm{Br}$-atoms, making the reaction $\mathrm{HgBr}+\mathrm{I}$ one of the major potential routes for the formation of stable GOM (Saiz-Lopez et al., 2008). Even in the Arctic ABL where evidence suggests relatively low concentrations of I-atom as compared to the Southern Ocean ABL, this reaction might be as important as Reaction (R3) under some circumstances (Calvert and Lindberg, 2004). We do not address this issue here, as our model scheme does not contain iodine chemistry.

The theoretical calculations of bond energies for the products of the $\mathrm{HgBr}+\mathrm{X}$ reactions indicate $\mathrm{NO}_{2}$ and $\mathrm{HO}_{2}$ perhaps as viable as $\mathrm{BrO}$ to form thermally stable GOM in the atmosphere (Dibble et al., 2012). In our model runs, the atmospheric concentrations of $\mathrm{HO}_{2}$-radical are on the same order as those of Br-atom (Fig. 8a). Hence, $\mathrm{HO}_{2}$ appears to be a fairly strong candidate that can enhance the net oxidation rate of GEM, but probably not as much as BrO (Fig. 8d). In the SIA, as a result of the release of $\mathrm{NO}_{\mathrm{x}}$ and HONO via $\mathrm{NO}_{3}^{-}$photolysis on the snow grains, chances are high that the mixing ratios of $\mathrm{NO}_{2}$ exceed those of $\mathrm{BrO}$ (e.g., Peterson and Honrath, 2001). This is the case in our model runs where the $\mathrm{NO}_{2}$ mixing ratios in the SIA are similar to and sometimes well in excess of $\mathrm{BrO}$ mixing ratios (Fig. 9a). If indeed $\mathrm{NO}_{2}$ is as reactive as $\mathrm{Br}$ and/or $\mathrm{BrO}$ towards $\mathrm{HgBr}, \mathrm{NO}_{2}$ is a strong candidate that can enhance the net oxidation rate of GEM in the SIA (Fig. 9b-d).

There are yet other possibilities of the net GEM oxidation rate in the model. For example, if the rate constant of Reaction (R1) is actually closer to a high-level theoretical estimate by Shepler et al. (2007) (viz., scenario 2, see Table 2) than that adopted from an experimental study by Donohoue et al. (2006) (scenario 1), the rates of net GEM oxidation can be doubled from those simulated with the scenario 1 of mercury chemistry (Figs. S7-8 in the Supplement). Scenarios 3 and 4 also simulate greater rates of net GEM oxidation than the scenario 1, by adopting higher rate constants for Reactions (R3) and (R6) and, additionally, a lower rate constant for Reaction (R2) in the scenario 4 (Figs. S7 and S9-10 in the Supplement).

It is actually puzzling that the rate constant of Reaction (R1) determined by Donohoue et al. (2006) was significantly lower than those of net GEM oxidation initiated via Reaction (R1) as reported from other laboratory studies 

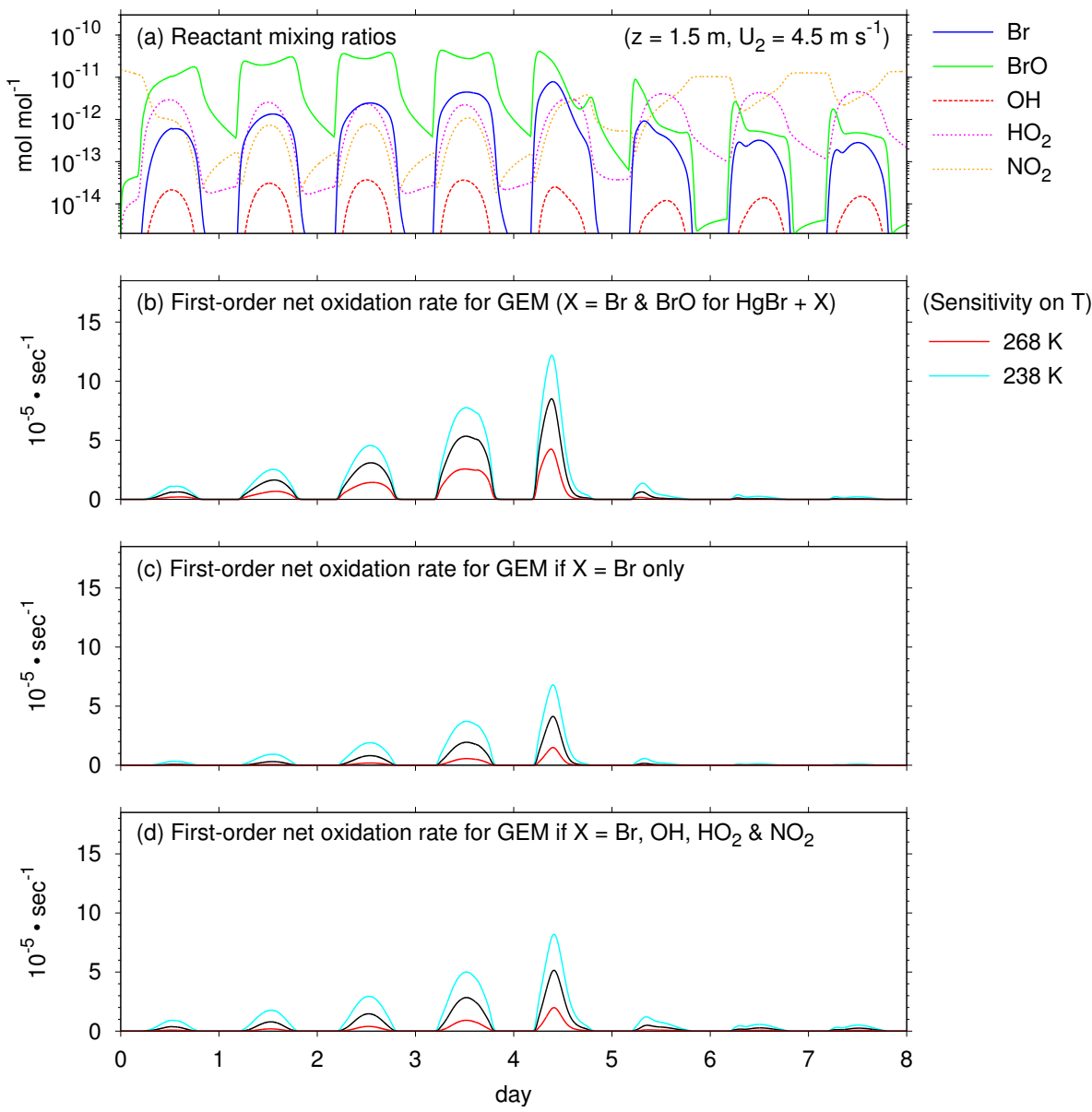

Fig. 8. (a) Temporal evolution for the mixing ratios of potential reactants $\left(\mathrm{Br}, \mathrm{BrO}, \mathrm{OH}, \mathrm{HO}_{2}\right.$ and $\left.\mathrm{NO}_{2}\right)$ for $\mathrm{Hg}$ and $\mathrm{HgBr}$ in the gas phase at the height of $1.5 \mathrm{~m}$ in the ambient air from a model run employing scenario $1 \mathrm{~A}$ at $U_{2}=4.5 \mathrm{~m} \mathrm{~s}^{-1}$; (b) First-order net oxidation rates of GEM calculated at $1.5 \mathrm{~m}$ height from this model run (black line). Potential changes in the net GEM oxidation rates arising from changes in temperature are also estimated by raising (red line) and dropping (light-blue line) temperature by $15 \mathrm{~K}$ from $253 \mathrm{~K}$ for the calculation of rate constants of gas-phase $\mathrm{Hg}$ oxidation kinetics while using the output of the model run at $253 \mathrm{~K}$; (c) the same as (b) but re-estimated by assuming only $\mathrm{Br}$-atoms can react with $\mathrm{HgBr}$ to form a stable $\mathrm{Hg}$ (II) product (i.e., the reaction $\mathrm{HgBr}+\mathrm{BrO}$ switched off); and (d) the same as (c) but re-estimated by assuming $\mathrm{OH}, \mathrm{HO}_{2}$ and $\mathrm{NO}_{2}$ can react, in addition to $\mathrm{Br}$, with $\mathrm{HgBr}$ to form stable $\mathrm{Hg}$ (II) products.

(Ariya et al., 2002; Subir et al., 2011). Products of GEM oxidation are often found to be adsorbed and/or aggregated as clusters on the surface of reaction vessels rather than identified in the gas phase, indicating that part or all of the reactions may have been mediated heterogeneously by "wall effects" (Subir et al., 2011, and references therein). The type of surfaces conducive to the "wall effects" and their reaction mechanism(s) have not been elucidated yet. However, it will not be very surprising if redox reactions of mercury turn out to be mediated heterogeneously on various environmental surfaces (aerosols, vegetation, etc.) to a degree that they can change the overall rates of the reactions in many parts of the atmosphere (Subir et al., 2012). Although it is beyond the scope of this study, the surface adsorption of mercury compounds and their potential reactions might indeed play a role especially in the SIA because of high surface-to-volume ratios.

Kinetics of gas-phase bromine chemistry leading to ozone loss is now well understood and constrained extensively by laboratory experiments (e.g., Atkinson et al., 2007). Hence, for given concentrations of bromine radicals, the net photochemical loss rates of ozone can be estimated with greater confidence than the net oxidation rates of GEM. Scatter plots of data between the concentrations of total gaseous mercury (TGM = GEM + GOM) and ozone can thus serve as an alternative means to test the realism of our reaction mechanism for mercury. In our base runs with the scenario $1 \mathrm{~A}$ of mercury chemistry, the concentrations of TGM and ozone (at the height of $1.5 \mathrm{~m}$ in the air) exhibit a compact linear relationship (Fig. 10a). This correlation becomes slightly disturbed if we assume the "fast" photo-reduction of $\mathrm{Hg}$ (II) in the 

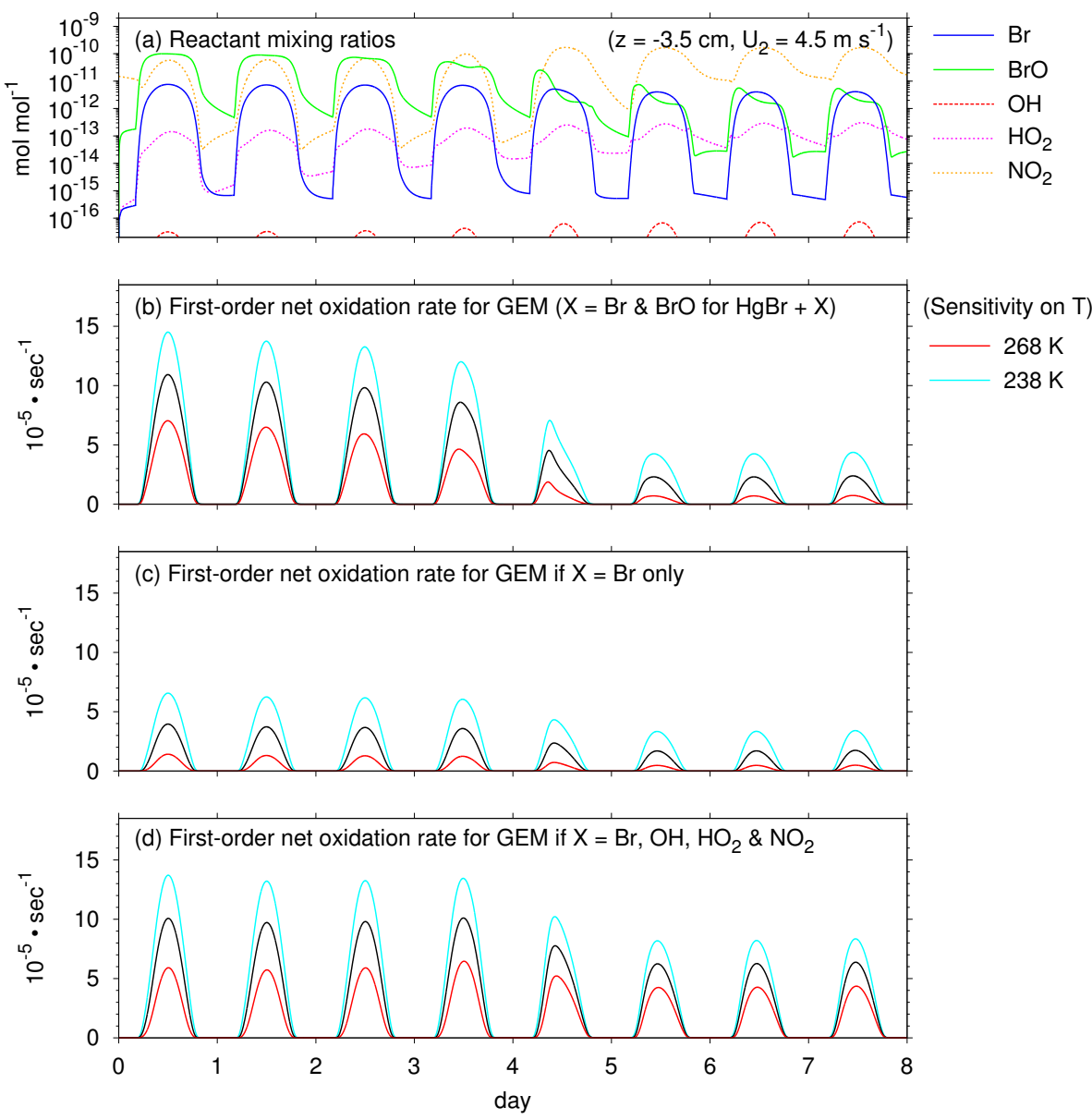

Fig. 9. The same as Fig. 8 but in the SIA at the depth of $3.5 \mathrm{~cm}$.

snowpack (scenario 1B) to accelerate the recovering of GEM after the maturity of AMDEs (Fig. 10b). If, by neglecting Reaction (R6), Br-atom is assumed to be a single reactant supporting the formation of GOM (scenario 1C), the relationship becomes non-linear in that the rate of net GEM oxidation is accelerated as ozone is depleted to sufficiently low levels (Fig. 10c). Here, we note that the simulated concentrations of Br-atom ramp up particularly when ozone levels drop below $10 \mathrm{nmol} \mathrm{mol}^{-1}$, in reasonable agreement with evidence from field studies (see Sect. 3.2 in Part 1). The scatter plots of the same kind have been created by using field data obtained in the polar regions from both hemispheres, showing roughly linear relationships between the TGM and ozone concentrations (Schroeder et al., 1998; Ebinghaus et al., 2002); although not conclusively, the field data appear to favor the scenario of Reaction (R6) operating effectively during the AMDEs if we adopt scenario 1 for the rate constants of Reactions (R1), (R2) and (R3). On the other hand, the viability of Reaction (R6) does not appear to be well supported if we adopt scenarios 2; in this case, TGM is depleted rather too rapidly as compared to ozone if we turn on Reaction (R6) and make it operate at the same rate constant as Reaction (R3)
(Fig. 10d and f). In scenario 3, model results on the correlations between TGM and ozone do not strongly negate the viability of Reaction (R6) (Fig. $10 \mathrm{~g}-\mathrm{i}$ ). In scenario 4, the thermal decomposition of $\mathrm{HgBr}$ (R2) is not fast enough at the temperature of $253 \mathrm{~K}$ assumed here to compete with reactions that stabilize $\mathrm{HgBr}$ to $\mathrm{Hg}$ (II) species. In scenario $4 \mathrm{C}$, as much as $87 \%$ of $\mathrm{HgBr}$ is stabilized to $\mathrm{HgBr}_{2}$ even by $1 \mathrm{pmol} \mathrm{mol}^{-1}$ of $\mathrm{Br}$-atoms. Therefore, switching on Reaction (R6) in scenario 4A does not significantly increase the net oxidation rate of GEM. Nonetheless, the curve of relationships between the concentrations of TGM and ozone becomes somewhat more linear by neglecting Reaction (R6) in scenario $4 \mathrm{C}$ than in scenario $4 \mathrm{~A}$ (Fig. $10 \mathrm{j}$ and $\mathrm{l}$ ). In scenarios $3 \mathrm{~B}$ and $4 \mathrm{~B}$, by employing the faster rates of insnow $\mathrm{Hg}$ (II) photo-reduction, the curves of relationships between the TGM and ozone concentrations can be made apparently more linear, albeit with lower correlations between the two variables, than in scenarios $3 \mathrm{~A}$ and $4 \mathrm{~A}$ (Fig. 10h and $\mathrm{k}$ ). Comparison between models and observations using such scatter plots will become more compelling by using a 3-D model simulating the transport of bromine, ozone and 

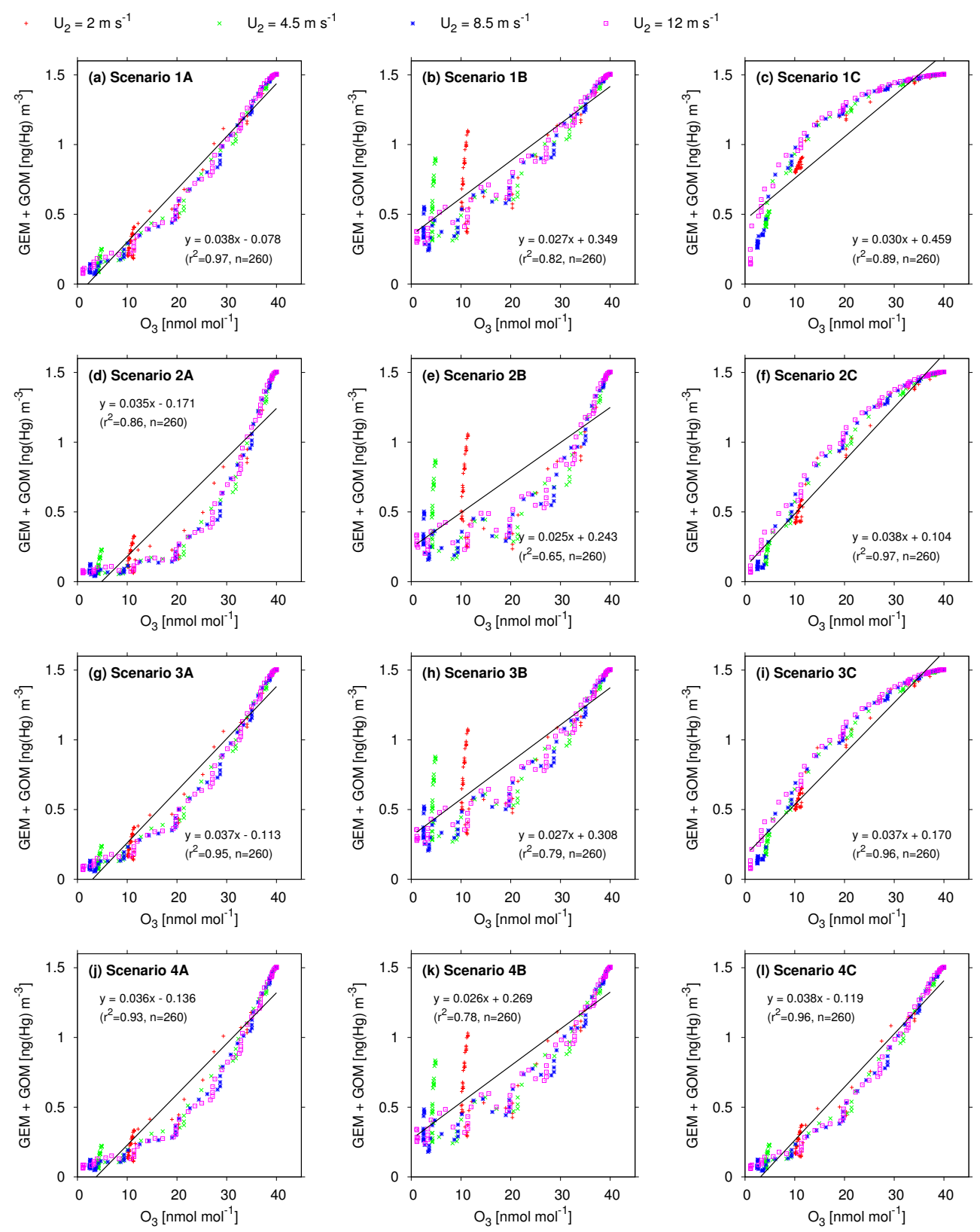

Fig. 10. Scatter plots of 3-hourly model output to show correlations between the concentrations of total gaseous mercury (GEM + GOM) and the mixing ratios of ozone at the height of $1.5 \mathrm{~m}$ in the ambient air, plotted collectively from model runs at $U_{2}=2.0 \mathrm{~m} \mathrm{~s}^{-1}, 4.5 \mathrm{~m} \mathrm{~s}^{-1}$, $8.5 \mathrm{~m} \mathrm{~s}^{-1}$, and $12.0 \mathrm{~m} \mathrm{~s}^{-1}$ for each scenario of mercury chemistry. Units for the concentrations of total gaseous mercury and the mixing ratios of ozone are $\mathrm{ng}(\mathrm{Hg})$ per standard cubic meter (at $0^{\circ} \mathrm{C}$ and $\left.1 \mathrm{~atm}\right)$ and nmol mol${ }^{-1}$, respectively; the same as used for scatter plots of the same kind by Schroeder et al. (1998) and Ebinghaus et al. (2002).

mercury and their chemical interactions over a wide range of temperatures (e.g., Holmes et al., 2010).

In our simulated conditions, scenarios $1 \mathrm{~A}$ and $4 \mathrm{C}$ obtain similar rates of net GEM oxidation and resultant TGM depletion in the ABL (Fig. S7 in the Supplement and Fig. 10a and 1), despite the fact that Reaction (R6) turned on in the former and off in the latter. Also, GOM builds up in the air at similar rates between these two scenarios. However, the speciation of GOM is quite different between the two scenarios. In scenario $4 \mathrm{C}, \mathrm{HgBr}_{2}$ is a single stable product from gas-phase reactions subsequent to $\mathrm{Br}$-attack on GEM. $\mathrm{HgBr}_{2}$ is then converted mainly to $\mathrm{HgBrCl}$ and $\mathrm{HgCl}_{2}$ via ion-exchange reactions in the aerosols (see discussion in Sect. 3.1), and thus these three species constitute a predominant component of GOM (Fig. 11). This is remarkably different from a situation in scenario $1 \mathrm{~A}$ where more than 


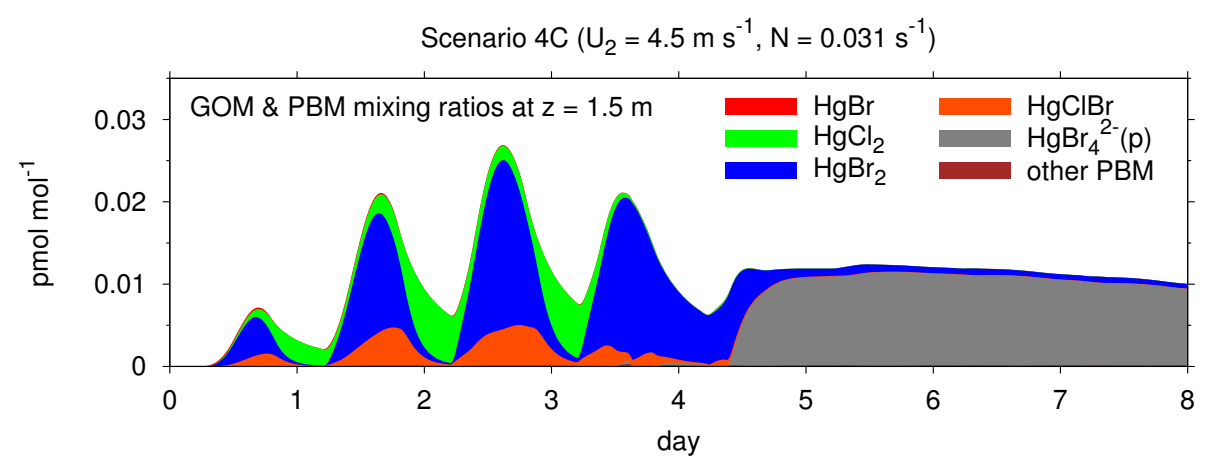

Fig. 11. Speciation of GOM and PBM at $z=1.5 \mathrm{~m}$ in ambient air above the snowpack as simulated with scenario $4 \mathrm{C}$ at $U_{2}=4.5 \mathrm{~ms}$. Because of very low mixing ratios simulated, GOM species other than $\mathrm{HgBr}_{2}, \mathrm{HgCl}_{2}, \mathrm{HgClBr}$ and $\mathrm{HgBr}$ are neglected in this plot.
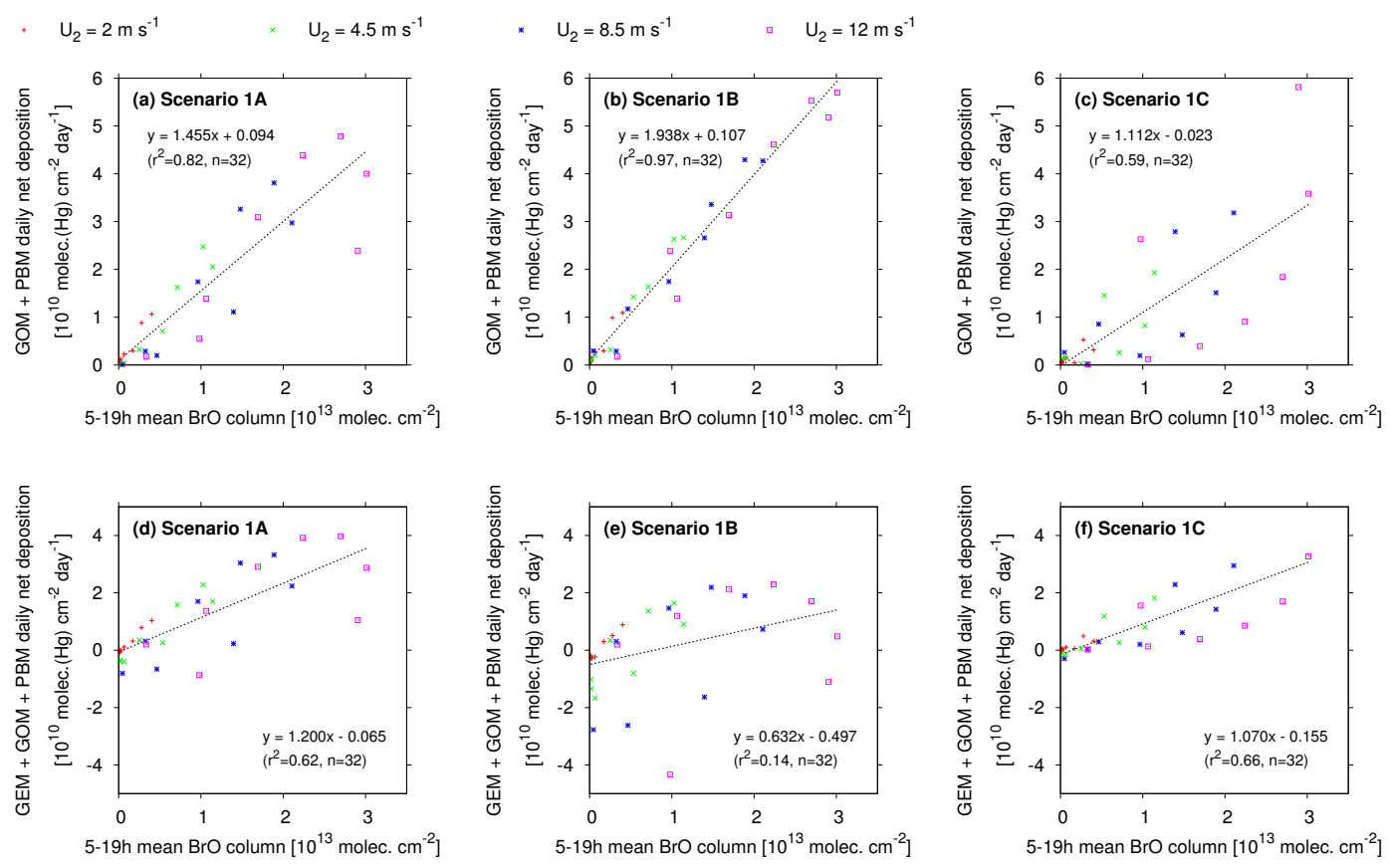

Fig. 12. Correlations between the daytime column amount of $\mathrm{BrO}$ in the atmosphere and the daily net deposition of mercury, either excluding GEM (a-c) or including GEM (d-f), from the atmosphere to the snowpack on each simulated day (day 1 to 8 ), plotted collectively from model runs at $U_{2}=2.0 \mathrm{~m} \mathrm{~s}^{-1}, 4.5 \mathrm{~m} \mathrm{~s}^{-1}, 8.5 \mathrm{~m} \mathrm{~s}^{-1}$, and $12.0 \mathrm{~m} \mathrm{~s}^{-1}$ for each of the scenarios 1A-C: (a) and (d) scenario $1 \mathrm{~A}$, (b) and (e) scenario $1 \mathrm{~B}$, and (c) and (f) scenario $1 \mathrm{C}$.

half of the GOM is made up of other species: $\mathrm{Hg}(\mathrm{OH}) \mathrm{Br}$, $\mathrm{Hg}(\mathrm{O}) \mathrm{Br}$ and $\mathrm{Hg}(\mathrm{OBr}) \mathrm{Br}$ formed via gas-phase reactions and $\mathrm{Hg}(\mathrm{OH}) \mathrm{Cl}$ formed via ion-exchange reactions subsequent to the aerosol uptake of $\mathrm{Hg}(\mathrm{OH}) \mathrm{Br}$ (Fig. 4a). Hence, if some of these oxygen-containing mercury species can be detected by instruments deployed in the field, it may provide a basis for better understanding of whether the GEM oxidation during AMDEs involves BrO-radical in addition to $\mathrm{Br}$-atom as assumed in the base case in this study.

\subsection{Relationship between BrO columns and the deposition of oxidized mercury in the ABL}

In our base runs with Reaction (R6) in the chemical scheme (scenario 1A), the model predicts a fairly compact linear relationship between the "daytime" (5:00-19:00 in local solar time) mean of atmospheric $\mathrm{BrO}$ column densities and the daily mean of total depositional fluxes of GOM and PBM (Fig. 12a). As discussed earlier, the net oxidation of GEM is facilitated strongly via Reaction (R6) if it is included in the model (except for scenario 4A, see Sect. 3.4). Also, while high levels of $\mathrm{BrO}$ are present in the $\mathrm{ABL}$, the accumulation of bromide in sub- $\mu \mathrm{m}$ aerosols remains minimal and thus the 
model predicts GOM dominating PBM in the partitioning of oxidized mercury as discussed in Sect. 3.3. Then, the dry deposition of GOM takes place rapidly enough to accomplish a near-complete loss of the oxidized mercury products from the atmosphere on the timescale of a day. The strong correlation $\left(r^{2}=0.82\right)$ between $\mathrm{BrO}$ columns and the depositional fluxes of GOM + PBM is also a consequence of increasing atmospheric $\mathrm{BrO}$ column values with increasing ABL thickness (see Sect. 3.5 in Part 1); the total amount of mercury oxidized and then deposited tends to be greater as the ABL gets deeper in response to increased surface wind speed assumed for diagnosing the profiles of turbulent diffusivity.

The correlation between BrO columns and the depositional fluxes of GOM + PBM increases even more $\left(r^{2}=\right.$ 0.97 ) in scenario $1 \mathrm{~B}$ where the faster photo-reduction of $\mathrm{Hg}(\mathrm{II})$ in the snowpack maintains the atmospheric concentrations of mercury higher than in the case of scenario $1 \mathrm{~A}$ (Fig. 12b). However, if we examine relationship between $\mathrm{BrO}$ columns and the net depositional fluxes of total mercury including GEM (Fig. 12d-e), the correlation is much weaker in the scenario $1 \mathrm{~B}\left(r^{2}=0.14\right)$ compared to scenario $1 \mathrm{~A}$ $\left(r^{2}=0.62\right)$. Thus, if the re-emissions of deposited mercury from the snowpack occur swiftly on the turnover timescale of $\sim 3$ days as assumed in the scenario $1 \mathrm{~B}$, the atmospheric concentration of reactive bromine is not a dominant predictor of the net loss of mercury from the atmosphere during the AMDEs; in this case, mechanisms and kinetics for the in-snow photo-reduction of $\mathrm{Hg}$ (II) are as important as the behavior of reactive bromine in the ABL.

The relationship between $\mathrm{BrO}$ columns and the deposition of GOM + PBM becomes somewhat scattered in scenario $1 \mathrm{C}$ where Reaction (R6) is switched off (Fig. 12b). In this scenario, the simulated rate of net GEM oxidation does not maximize when $\mathrm{BrO}$ reaches its highest levels, because temporal trends of the mixing ratios of $\mathrm{BrO}$ and $\mathrm{Br}$-atom are not nearly coherent (Fig. 8a). Nonetheless, there is still a sufficiently strong correlation $\left(r^{2}=0.59\right)$ between $\mathrm{BrO}$ columns and the deposition of GOM + PBM because, in the entire cycle of AMDEs/ODEs, the mixing ratios of $\mathrm{BrO}$ and $\mathrm{Br}$ atom are more or less correlated and because of the relationship between the ABL thickness and the total column amount of mercury being oxidized/deposited as noted above. In scenario $1 \mathrm{C}$, the correlation between $\mathrm{BrO}$ columns and the net depositional fluxes of total mercury is as strong as in the scenario 1A $\left(r^{2}=0.66\right.$, see Fig. 12f). Results from model runs with scenarios 2-4 of mercury chemistry exhibit the same general trends as those with the scenario 1 in the correlations between $\mathrm{BrO}$ columns and the depositional fluxes of $\mathrm{Hg}(\mathrm{II})$, except that the correlations become stronger with Reaction (R6) switched off (Figs. S11a-f, S12a-f and S13a-f in the Supplement).

Owing to inadequate understanding at the process level, it remains a challenge to assign the source strength of reactive bromine correctly across different domains of the troposphere, in particular for natural processes such as those in- volving saline ice surfaces and sea-salt aerosols, in 3-D models (e.g., Theys et al., 2011; Toyota et al., 2011; Parrella et al., 2012). Therefore, if one wishes to assess the deposition of mercury from the polar boundary layer by a 3-D model, it is useful to begin with $\mathrm{BrO}$ column data retrieved from satellite as external constraint for the simulation of AMDEs (e.g., Dastoor et al., 2008), as long as the satellite data are carefully processed to screen out $\mathrm{BrO}$ residing above the ABL (e.g., Theys et al., 2011; Sihler et al., 2012) and the concentrations of $\mathrm{Br}$-atom are estimated reasonably well from those of $\mathrm{BrO}$ by exploiting some ancillary data to calculate the $\mathrm{Br} / \mathrm{BrO}$ concentration ratios (e.g., Zeng et al., 2006).

\subsection{In-snow behavior of mercury after its deposition}

Figure 13a-e shows the temporal evolution of total dissolved mercury (THg) and its speciation in the LLL in each of the top six layers (0-3 cm depth) of snowpack as simulated with scenario $1 \mathrm{~A}$ of mercury chemistry at $U_{2}=4.5 \mathrm{~m} \mathrm{~s}^{-1}$. The model predicts that a major portion of GOM entering the snowpack from the atmosphere is taken up by snow grains within the top $1 \mathrm{~mm}$ layer. Until day 4, a rapid increase in the THg loading (up to $\sim 350 \mathrm{ng} \mathrm{L}^{-1}$ ) occurs in this top layer during the daytime, which parallels (with a short delay) changes in the dry depositional fluxes of GOM (Fig. 4b). The dry deposition of PBM has a minimal impact on the THg loading in the snowpack, as discussed in Sect. 3.3. The increase in the top-layer THg levels during the day is followed by plateaus at night as a result of vertical diffusion down through the LLL network with a smaller supply from the atmosphere. Underneath the top $1 \mathrm{~mm}$ layer, THg is sourced mostly via the vertical diffusion of oxidized mercury deposited from the atmosphere through the LLL network. However, this happens only within the top few centimeters of snowpack during the 8-day time span of our model run (Fig. 14a). THg builds up obviously at lower rates below the top $1 \mathrm{~mm}$ layer. But, within the top $1 \mathrm{~cm}$ layer, the delay in the THg buildup is on the order of a few days only. Thus, changes in the mean concentrations of THg in the top $3 \mathrm{~cm}$ layer of snowpack are represented well by the loading of mercury in the top $1 \mathrm{~cm}$ (Fig. 13f). Further below the depth of $3 \mathrm{~cm}$, the photo-oxidation of GEM in the SIA is a major source of THg (see Sect. 3.2), but it only results in a marginal loading of THg up to the order of $0.1 \mathrm{ng} \mathrm{L}^{-1}$ over 8 days (Fig. 14a).

If the vertical diffusion through the LLL network is switched off, the model predicts that up to around $1000 \mathrm{ng} \mathrm{L}^{-1}$ of $\mathrm{THg}$ can accumulate in the top $1 \mathrm{~mm}$ layer of snowpack (Fig. 14b). On the other hand, below the depth of $1 \mathrm{~mm}$, the THg levels never exceed $1 \mathrm{ng} \mathrm{L}^{-1}$ over 8 days. Douglas et al. (2005) measured dissolved mercury concentrations in frost flowers, hoar frost and "reference snow" along sea-ice leads sampled near Barrow in the spring of 2003 and 2004. In one sample of surface hoar with an estimated age of $\sim 11$ days, they measured $820 \mathrm{ng} \mathrm{L}^{-1}$ of mercury, as 

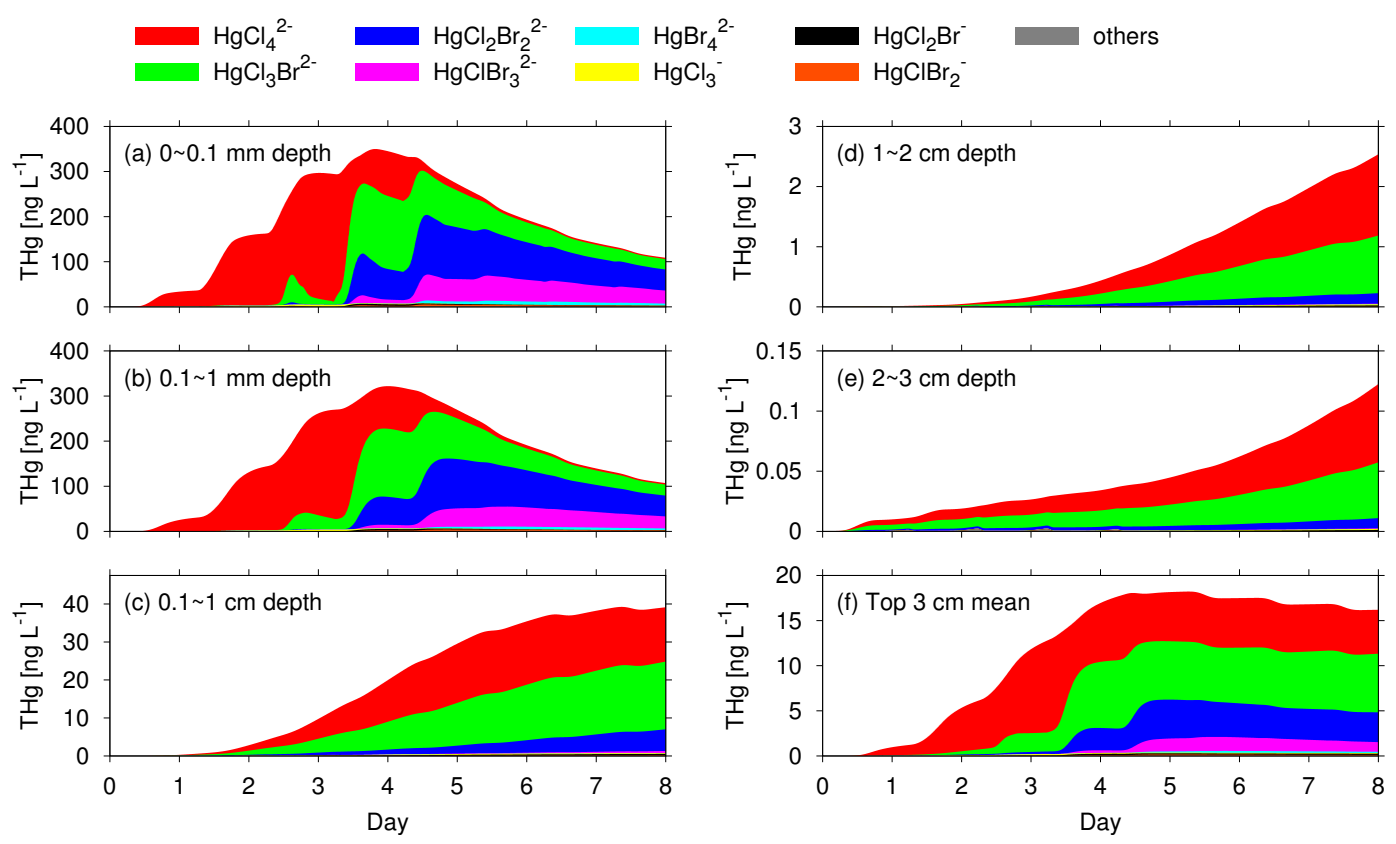

Fig. 13. Total concentrations and speciation of dissolved mercury in the top $3 \mathrm{~cm}$ of snowpack as simulated with scenario $1 \mathrm{~A}$ at $U_{2}=$ $4.5 \mathrm{~m} \mathrm{~s}^{-1}$ : (a) $0-0.1 \mathrm{~mm}$ depth (the topmost snowpack layer), (b) $0.1-1 \mathrm{~mm}$ depth, (c) $0.1-1 \mathrm{~cm} \mathrm{depth,} \mathrm{(d)} 1-2 \mathrm{~cm} \mathrm{depth,} \mathrm{(e)} 2-3 \mathrm{~cm} \mathrm{depth}$, and (f) average over the top $3 \mathrm{~cm}$.

compared to $91 \mathrm{ngL}^{-1}$ found in the reference snow sampled nearby. This observation might indicate that mercury deposited from the atmosphere can stay in a very thin layer at the top of the snowpack without migrating much into the bulk of underlying snowpack over 10 days or so. However, the hoar frost itself is formed and grows by the condensation of water vapor and thus deposited mercury might be occluded inside the ice structure via burial uptake (Douglas and Sturm, 2004). If this occurs, the deposited mercury would be indeed much less mobile than in the LLL network (Asaduzzaman et al., 2012).

Simulated speciation of $\mathrm{THg}$ is dominated by $\mathrm{HgCl}_{4}^{2-}$, $\mathrm{HgCl}_{3} \mathrm{Br}^{2-}, \mathrm{HgCl}_{2} \mathrm{Br}_{2}^{2-}$ and $\mathrm{HgClBr}_{3}^{2-}$ (Fig. 13a-f). Concentration ratios between these major species exhibit notable variations with time especially in the top $1 \mathrm{~mm}$ layer, in response to changes in bromide concentrations via multiphase photochemical processing (see Fig. 4, bottom row, in Part 1). The initial molar ratio between bromide and chloride in the LLL was assumed to be the same as that in seawater ( $=1 / 650$, Millero et al., 2008). Although our model ignored wind-blown snow (Jones et al., 2009) and its sublimated residues (or sea-salt aerosols) (Yang et al., 2008) over the frozen ocean, the speciation of $\mathrm{Hg}$ (II) in these atmospheric particles would be not very different from what is simulated in the LLL of our model snowpack. In the windblown snow particles sampled at Barrow, Brooks et al. (2008) measured as high as $\sim 500 \mathrm{ng} \mathrm{L}^{-1}$ of mercury. For the study of $\mathrm{Hg}$ (II) speciation in seawater, a few thermodynamic models have considered the formation of mixed-halide $\mathrm{Hg}(\mathrm{II})$ complexes. For example, Dyrssen and Wedborg (1980), as cited in Lindqvist and Rodhe (1985), estimated that ca. $18 \%$ of inorganic $\mathrm{Hg}$ (II) in seawater would exist as mixed $\mathrm{Hg}$ (II)chloride-bromide compounds $\left(\mathrm{HgCl}_{3} \mathrm{Br}^{2-}, \mathrm{HgCl}_{2} \mathrm{Br}^{-}\right.$and $\mathrm{HgClBr}$ ).

Here we note that the role of DOM is ignored in our chemical scheme. $\mathrm{Hg}$ (II)-(organo-)sulfur complexes formed via interactions with humic materials can dominate the $\mathrm{Hg}$ (II) speciation in terrestrial and estuarine waters, but this is rather unlikely to be the case in the ocean remote from the coast (e.g., Mantoura et al., 1978). Hence, even if the humic materials are rejected from freezing seawater into brine along with inorganic solutes (e.g., Giannelli et al., 2001), the fraction of organically bound $\mathrm{Hg}(\mathrm{II})$ in brine-laden sea ice and overlying snowpack is expected to be smaller than the fraction bound to chloride and bromide (Mantoura et al., 1978). Observational evidence, however, suggests that biological activities can create (and also consume) DOM in the sea ice (Thomas et al., 2001). This leaves some possibility that a notable fraction of $\mathrm{Hg}$ (II) is bound to organic matters not only in the terrestrial snow cover but also in the snowpack on land-fast ice and even on pelagic sea ice.

Figure 15 shows changes in the buildup rate of THg in the top $3 \mathrm{~cm}$ of snowpack from eight model runs (at four different wind speeds and with two different in-snow $\mathrm{Hg}(\mathrm{II})$ photo-reduction scenarios). As noted in Sect. 3.5, the deposition of oxidized mercury from the atmosphere is simulated to increase with the increase in diagnosed ABL thickness, as the surface wind speed is increased (see Sect. 2.7 in 

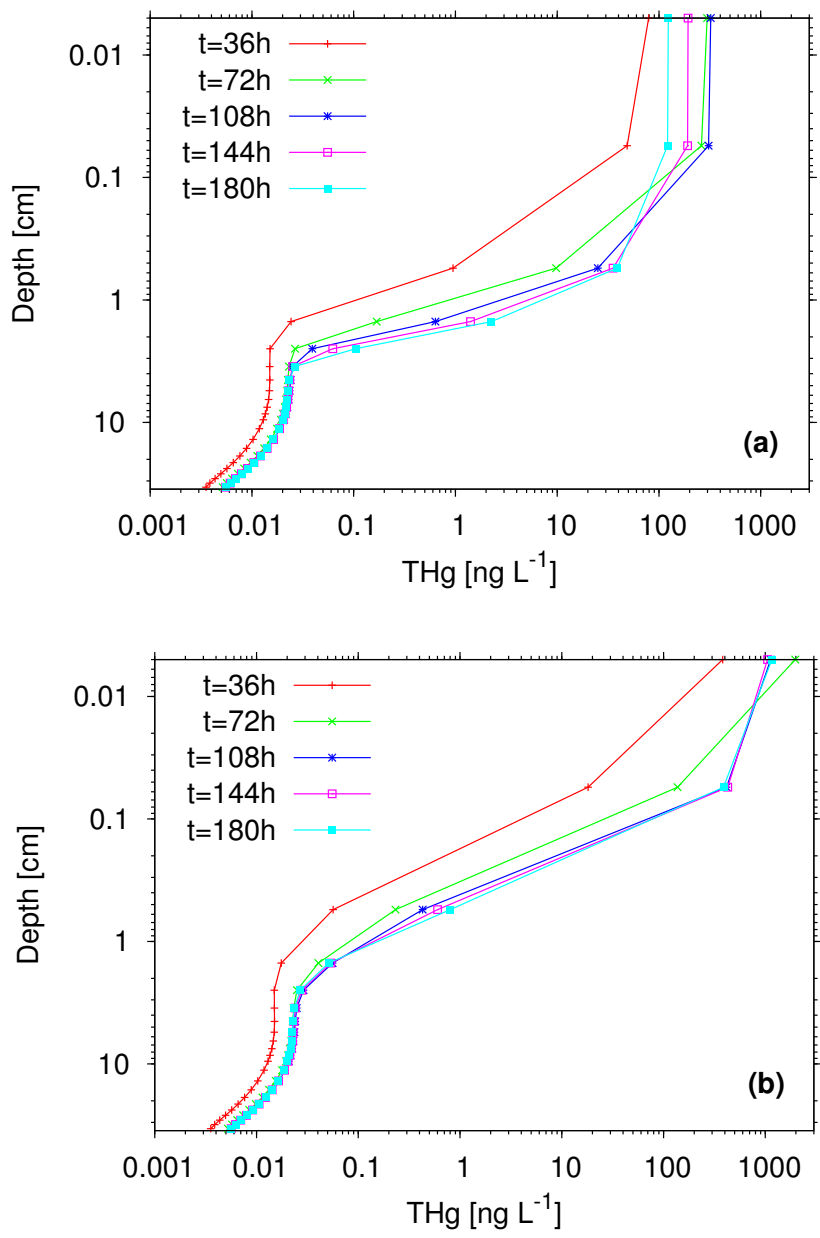

Fig. 14. Concentration profiles of total dissolved mercury as simulated in the model run employing scenario $1 \mathrm{~A}$ at $U_{2}=4.5 \mathrm{~m} \mathrm{~s}^{-1}$ : (a) the base case with vertical diffusion through the LLL network in the snowpack and (b) the case without vertical diffusion through the LLL network.

Part 1). At $U_{2}=2.0 \mathrm{~m} \mathrm{~s}^{-1}$ where the ABL thickness never exceeds $44 \mathrm{~m}$, THg accumulation in the top $3 \mathrm{~cm}$ of snowpack does not exceed $5 \mathrm{ng} \mathrm{L}^{-1}$ over the course of simulated AMDEs. At higher wind speeds $\left(U_{2}=4.5-12.0 \mathrm{~m} \mathrm{~s}^{-1}\right)$ and hence with greater ABL thickness (119-429 m), the top $3 \mathrm{~cm}$ snow accumulates up to $14-57 \mathrm{ng} \mathrm{L}^{-1}$ of $\mathrm{THg}$ at some point of each model run over 8 days. The increases in the snowpack THg levels either drop significantly or reverse to decreasing trends, once the partitioning of oxidized mercury in the ABL is shifted from GOM to PBM. This gives a possible explanation for sometimes a positive and other times a lack of connection between mercury levels in the surface snow and the depletion of mercury in the surface air (Durnford and Dastoor, 2011, and references therein).

\section{Conclusions}

To study the physical and chemical processes involved in reactive bromine release and its impacts on AMDEs and ODEs in the springtime Arctic, we have developed PHANTAS, a 1-D model that simulates multiphase chemistry and transport of trace constituents throughout porous snowpack and in the overlying ABL. A common set of reactions is employed to describe multiphase chemistry of a gas-aerosol system in the atmosphere and of a gas-liquid/brine system in the snowpack. Building on results reported in Part 1 of the study on in-snow bromine activation and its two-way interactions with ozone (Toyota et al., 2014), this paper is focused on processes related to AMDEs. For the chemical mechanism of mercury, we have incorporated an explicit description of each elementary step involved in the net oxidation of GEM to GOM with temperature-dependent rate coefficients adopted from the literature. We have tested several scenarios of the kinetic reaction rates and the chemical mechanisms based on the past theoretical and experimental studies. Also, for a description of the gas-aerosol and gas-LLL partitioning of $\mathrm{Hg}$ (II) species, we have used Henry's law for GOM and thermodynamic equilibrium constants for the coordination complexes of $\mathrm{Hg}(\mathrm{II})$ with chloride $\left(\mathrm{Cl}^{-}\right)$, bromide $\left(\mathrm{Br}^{-}\right)$and hydroxyl $\left(\mathrm{OH}^{-}\right)$in the aqueous phase (viz., sulfate aerosols in the air and the LLL in the snowpack) with temperature dependence adopted directly from the literature and/or estimated from reference thermodynamic data. Sensitivity studies have been performed to explore the effects of changes in temperature and the profiles of vertical diffusivity in the ABL on the behavior of mercury in the air-snowpack system.

According to our model runs, during AMDEs, there is a fair possibility for $\mathrm{BrO}$ radical to participate critically in the net oxidation of GEM via reaction with $\mathrm{HgBr}$, which is a thermally unstable initial product formed via the reaction $\mathrm{Hg}+\mathrm{Br}$. The timing of major GEM oxidation during the concurrent progress of AMDEs and ODEs is shown to depend strongly on whether or not the reaction $\mathrm{HgBr}+\mathrm{BrO}$ is viable under atmospheric conditions and proceeds at a sufficiently fast rate. In the SIA, $\mathrm{NO}_{2}$ might also play a key role in the formation of a thermally stable oxidized mercury via the reaction $\mathrm{HgBr}+\mathrm{NO}_{2}$. On the basis of theoretical calculations of bond energies, Dibble et al. (2012) indicated the viability of these reactions under atmospheric conditions. However, their rate constants have not been explored theoretically or experimentally and hence are recommended to be studied in the future. Also, the speciation of GOM can change significantly if species other than Br-atom are involved in the stabilization of $\mathrm{HgBr}$ after its formation via Br-attack on GEM. This may be verified if measurements of GOM speciation are accomplished in the field (e.g., Ariya et al., 2002; Raofie and Ariya, 2004). For example, the predominance of oxygenated mercury species such as $\mathrm{Hg}(\mathrm{OBr}) \mathrm{Br}$ and $\mathrm{Hg}(\mathrm{OH}) \mathrm{Br}$ over $\mathrm{HgBr}_{2}$ is a strong indication that $\mathrm{BrO}$ is involved critically in the stabilization of $\mathrm{HgBr}$ during the AMDEs. 
Total dissolved $\mathrm{Hg}$ in the top $3 \mathrm{~cm}$ of snowpack at the end of each day

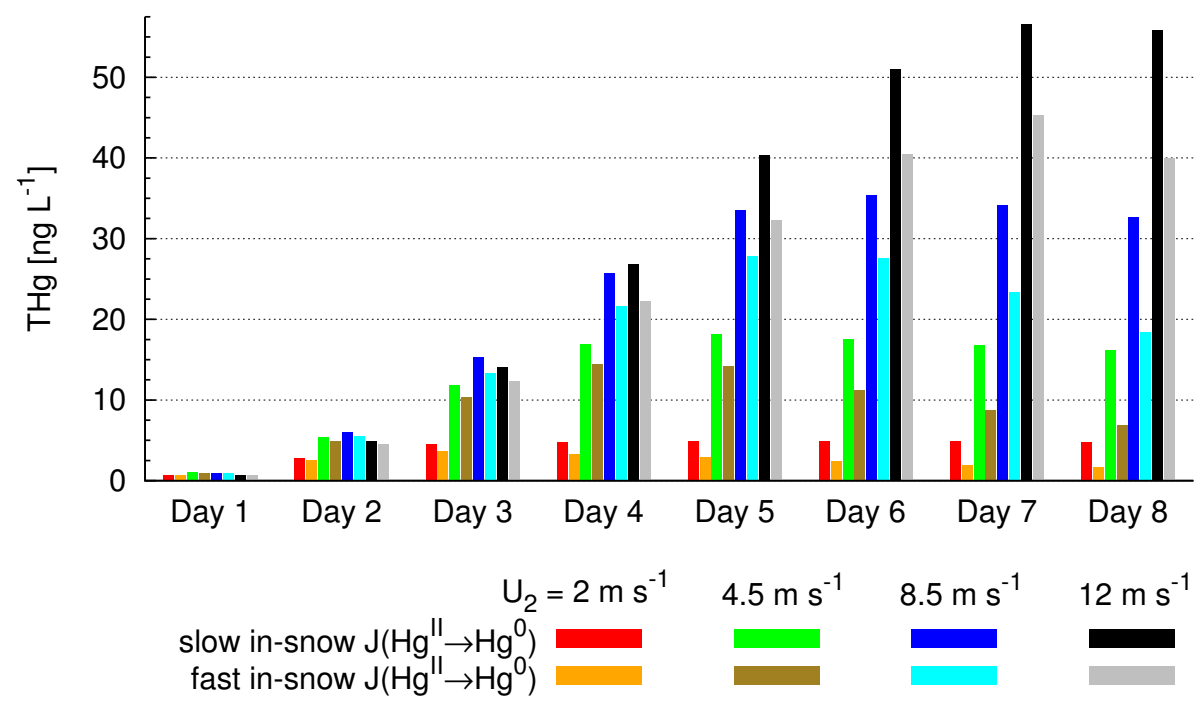

Fig. 15. Total concentrations of dissolved mercury averaged in the top $3 \mathrm{~cm}$ of snowpack at the end of each day (from day 1 to day 8 ) as simulated in model runs employing scenarios $1 \mathrm{~A}$ and $1 \mathrm{~B}$ ("slow" and "fast" in-snow $\mathrm{Hg}(\mathrm{II})$ photo-reduction scenarios, respectively) at $U_{2}=2.0 \mathrm{~m} \mathrm{~s}^{-1}, 4.5 \mathrm{~m} \mathrm{~s}^{-1}, 8.5 \mathrm{~m} \mathrm{~s}^{-1}$, and $12.0 \mathrm{~m} \mathrm{~s}^{-1}$.

The gas-aerosol partitioning of oxidized mercury was predicted to be sensitive to bromide content in the aerosols. According to model calculations (e.g., Sander et al., 1997; Toyota et al., 2014), in the springtime Arctic, high concentrations of particulate bromide are encountered especially in air masses where ozone is significantly depleted. While in the buildup stage of reactive bromine in the ABL with relatively high concentrations of ozone, multiphase recycling occurs very actively to maintain the concentrations of particulate bromide to minimal levels. At this point, a vast majority of oxidized mercury stays in the gas phase as GOM. Only when particulate bromide starts building up in the air, does GOM become susceptible to uptake to the aerosols to form PBM. Here, $\mathrm{HgBr}_{4}^{2-}$ constitutes a dominant fraction of PBM in our model runs. Owing to the temperature dependence of the estimated thermodynamic constants, the buildup of PBM is predicted to be suppressed significantly when temperature is raised from $253 \mathrm{~K}$ to $268 \mathrm{~K}$ due to changes in the Henry's law of $\mathrm{Hg}(\mathrm{II})$ species and the stability of their coordination complexes in the model. This appears to be consistent, at least qualitatively, with the temperature dependence of the observed GOM-PBM partitioning at Alert (Cobbett et al., 2007; Steffen et al., 2014). We have used reference thermochemical data from Wagman et al. (1982) and Hepler and Olofsson (1975) to derive thermodynamic constants and their temperature dependence for the simulation of GOMPBM partitioning. But these constants should be re-examined experimentally.

Sulfate aerosols prevailing in the Arctic haze are too acidic (Li, 1994; Staebler et al., 1999) to build up particulate chloride via uptake of gaseous $\mathrm{HCl}$. On the other hand, if PBM is formed in deliquesced sea-salt aerosols (currently ignored in our model), its speciation patterns would be similar to what is simulated in the LLL of our modeled snowpack, perhaps dominated by $\mathrm{HgCl}_{4}^{2-}, \mathrm{HgCl}_{3} \mathrm{Br}^{2-}, \mathrm{HgCl}_{2} \mathrm{Br}_{2}^{2-}$ and $\mathrm{HgClBr}_{3}{ }^{2-}$. The role of sea-salt aerosols as an efficient scavenger of GOM has been examined in a few box model studies based on aqueous-phase mechanisms including the formation of coordination complexes similar to ours but without the temperature dependence of the thermodynamic constants (Hedgecock et al., 2005; Xie et al., 2008; Holmes et al., 2009). We note, however, that, in a study of the GOM-PBM partitioning using observational data at Alert, Steffen et al. (2014) suggested sea-salt aerosols to be of secondary importance because they were not so abundant as sulfate aerosols.

During field measurements of speciated mercury, ozone and $\mathrm{BrO}$ in the surface air on sea ice near Barrow in March 2009 , temporal changes in the concentrations of GEM, PBM and ozone exhibited a linear relationship in that PBM built up when GEM and ozone were depleted, whereas the concentration of RGM was not correlated very well with any of them but with that of $\mathrm{BrO}$ (Steffen et al., 2013). This observation gives a strong support to our present model results in the following two aspects: (1) PBM builds up via the aerosol uptake of GOM when particulate bromide levels increase as a result of ozone depletion in the air and (2) $\mathrm{BrO}$ is involved in the net oxidation of GEM during AMDEs. A caveat is that one field study at Ny Ålesund, Svalbard, indicated a persistence of relatively high particulate bromide levels regardless of ozone concentration levels in the air (Staebler et al., 1999). If actual factors controlling the atmospheric concentrations of particulate bromide are largely misrepresented in 
our model calculations, the GOM-PBM partitioning during AMDEs may be not as sensitive to the progress of concurrent ODEs as simulated in our model. This will be the case especially when particulate bromide is sourced via sublimation of wind-blown snow (Yang et al., 2008).

GOM is predicted to be very susceptible to dry deposition to the snow surface, in agreement with a field study of RGM vertical fluxes (Skov et al., 2006). Since the dry deposition of PBM (in the sub- $\mu \mathrm{m}$ size range) occurs much more slowly than that of GOM, PBM is not expected to be deposited readily after its formation unless scavenged by episodic precipitation. Therefore, during the AMDEs, a major input of oxidized mercury from the atmosphere to the snowpack is simulated to take place by the deposition of GOM. This is consistent with some of the previous observational studies, which found a strong link between high levels of GOM in the surface air and the accumulation of deposited mercury in the surface snow in the springtime Arctic (Lindberg et al., 2002; Steffen et al., 2014).

As a final note, we have discussed the multiphase partitioning of mercury species from the viewpoint of Henry's law and ionic interactions in the aqueous phase. This approach makes much sense for simulating the partitioning of mercury into deliquesced aerosols. Sulfate is indeed a primary component of dry mass in Arctic "haze" aerosols (e.g., Staebler et al., 1999; Quinn et al., 2007) and, with incomplete neutralization by ammonium typical of the Arctic, the multi-component system of $\mathrm{NH}_{4} \mathrm{HSO}_{4}-\mathrm{H}_{2} \mathrm{SO}_{4}-\mathrm{H}_{2} \mathrm{O}$ is expected to remain as liquid (or deliquesced) particles rather than solids over the wide ranges of temperature and relative humidity (e.g., Cziczo and Abbatt, 2001). In snowpack, however, the interface between SIA and snow grains may not be always coated by liquid/brine-like layers as assumed in our model (e.g., Domine et al., 2013). While the so-called "quasi-liquid layer" is known to exist at temperatures down to $\sim 200 \mathrm{~K}$ even on the surface of ice virtually free from any contaminants, the uptake of gaseous species on such an ice surface is often represented better by adsorption on the solid surface (Abbatt, 2003). Thus, high concentrations of mercury observed during the Arctic springtime in diamond dust and surface hoar on the snowpack have been attributed to the efficient uptake of GOM via surface adsorption or via "burial" uptake through co-adsorption with water vapor (Douglas et al., 2005, 2008). At this point, however, the icesurface adsorption of GOM is a qualitative speculation based on the experimentally known picture of ice-surface adsorption for non-mercury species (e.g., Abbatt, 2003) and of the GOM adsorption on solid substrates other than ice at higher temperatures than those of our present interest (e.g., Rutter and Schauer, 2007; Subir et al., 2012). On the other hand, by measuring the adsorption isotherm of GEM on ice itself, Bartels-Rausch et al. (2008) indicated that the ice-surface adsorption of GEM should barely facilitate its mass transfer from the air to the snowpack. Although the GOM adsorption on "brine-less" ice needs to be studied experimentally in the future, we suggest that the aqueous-phase ligand chemistry of halides $\left(\mathrm{Cl}^{-}\right.$and $\left.\mathrm{Br}^{-}\right)$gives an alternative explanation for the efficient uptake of GOM in coastal and marine snowpack during the polar springtime.

In conclusion, our model simulations have the following implications: to predict the exact timing and magnitude of AMDEs and their impacts on the mercury loading in the polar snow cover, we would likely need also to predict correctly the concurrent progress of ODEs and its impacts on the partitioning of reactive bromine in the gas phase and on bromide content in the aerosols along with the vertical structure of the events.

\section{Supplementary material related to this article is available online at http://www.atmos-chem-phys.net/14/ 4135/2014/acp-14-4135-2014-supplement.pdf.}

Acknowledgements. This study was supported by funding from the Clean Air Regulatory Agenda (CARA) at Environment Canada. We wish to thank M. Subir, A. Steffen, G. Kos, P. A. Ariya and F. Wang for useful discussion on mercury chemistry and measurements. We are also grateful to comments from the referees and the editor.

Edited by: J. W. Bottenheim

\section{References}

Abbatt, J. P. D.: Interactions of atmospheric trace gases with ice surfaces: adsorption and reaction, Chem. Rev., 103, 4783-4800, 2003.

Abbatt, J. P. D., Thomas, J. L., Abrahamsson, K., Boxe, C., Granfors, A., Jones, A. E., King, M. D., Saiz-Lopez, A., Shepson, P. B., Sodeau, J., Toohey, D. W., Toubin, C., von Glasow, R., Wren, S. N., and Yang, X.: Halogen activation via interactions with environmental ice and snow in the polar lower troposphere and other regions, Atmos. Chem. Phys., 12, 6237-6271, doi:10.5194/acp-12-6237-2012, 2012.

Albert, M. R. and Shultz, E. F.: Snow and firn properties and airsnow transport processes at Summit, Greenland, Atmos. Environ., 36, 2789-2797, 2002.

Allard, B. and Arsenie, I.: Abiotic reduction of mercury by humic substances in aquatic system - an important process for the mercury cycle, Water Air Soil Poll., 56, 457-464, 1991.

AMAP: AMAP Assessment 2011: Mercury in the Arctic, Arctic Monitoring and Assessment Programme (AMAP), Oslo, Norway, 2011.

Amos, H. M., Jacob, D. J., Holmes, C. D., Fisher, J. A., Wang, Q., Yantosca, R. M., Corbitt, E. S., Galarneau, E., Rutter, A. P., Gustin, M. S., Steffen, A., Schauer, J. J., Graydon, J. A., St. Louis, V. L., Talbot, R. W., Edgerton, E. S., Zhang, Y., and Sunderland, E. M.: Gas-particle partitioning of atmospheric $\mathrm{Hg}(\mathrm{II})$ and its effect on global mercury deposition, Atmos. Chem. Phys., 12, 591-603, doi:10.5194/acp-12-591-2012, 2012. 
Andersson, M. E., Gårdfeldt, K., Wängberg, I., and Strömberg, D.: Determination of Henry's law constant for elemental mercury, Chemosphere, 73, 587-592, 2008.

Ariya, P. A., Khalizov, A., and Gidas, A.: Reactions of gaseous mercury with atomic and molecular halogens: kinetics, product studies, and atmospheric implications, J. Phys. Chem. A, 106, 73107320, 2002.

Ariya, P. A., Dastoor, A. P., Amyot, M., Schroeder, W. H., Barrie, L., Anlauf, K., Raofie, F., Ryzhkov, A., Davignon, D., Lalonde, J., and Steffen, A.: The Arctic: a sink for mercury, Tellus B, 56, 397-403, 2004.

Asaduzzaman, A., Wang, F., and Schreckenbach, G.: Quantumchemical Study of the diffusion of $\operatorname{Hg}(0$, I, II) into the Ice(Ih), J. Phys. Chem., 116, 5151-5154, 2012.

Aspmo, K., Temme, C., Berg, T., Ferrari, C., Gauchard, P.-A., Fain, X., and Wibetoe, G.: Mercury in the Atmosphere, Snow and Melt Water Ponds in the North Atlantic Ocean during Arctic Summer, Environ. Sci. Technol., 40, 4083-4089, 2006.

Atkinson, R., Baulch, D. L., Cox, R. A., Crowley, J. N., Hampson, R. F., Hynes, R. G., Jenkin, M. E., Rossi, M. J., and Troe, J.: Evaluated kinetic and photochemical data for atmospheric chemistry: Volume III - gas phase reactions of inorganic halogens, Atmos. Chem. Phys., 7, 981-1191, doi:10.5194/acp-7-981-2007, 2007.

Balabanov, N. B., Shepler, B. C., and Peterson, K. A.: Accurate global potential energy surface and reaction dynamics for the ground state of $\mathrm{HgBr}_{2}$, J. Phys. Chem. A, 109, 8765-8773, 2005.

Banic, C. M., Beauchamp, S. T., Tordon, R. J., Schroeder, W. H., Steffen, A., Anlauf, K. A., and Wong, H. K. T.: Vertical distribution of gaseous elemental mercury in Canada, J. Geophys. Res., 108, 4264, doi:10.1029/2002JD002116, 2003.

Barret, M., Domine, F., Houdier, S., Gallet, J.-C., Weibring, P., Walega, J., Fried, A., and Richter, D.: Formaldehyde in the Alaskan Arctic snowpack: Partitioning and physical processes involved in air-snow exchanges, J. Geophys. Res., 116, D00R03, doi:10.1029/2011JD016038, 2011.

Barrie, L. A. and Barrie, M. J.: Chemical components of lower tropospheric aerosols in the high Arctic: Six years of observations, J. Atmos. Chem., 11, 211-226, 1990.

Barrie, L. A., Bottenheim, J. W., Schnell, R. C., Crutzen, P. J., and Rasmussen, R. A.: Ozone destruction and photochemical reactions at polar sunrise in the lower Arctic troposphere, Nature, 334, 138-141, 1988.

Bartels-Rausch, T., Huthwelker, T., Jöri, M., Gäggeler, H. W., and Ammann, M.: Interaction of gaseous elemental mercury with snow surfaces: laboratory investigation, Environ. Res. Lett., 3, 045009, doi:10.1088/1748-9326/3/4/045009, 2008.

Bartels-Rausch, T., Krysztofiak, G., Bernhard, A., Schläppi, M., Schwikowski, M., and Ammann, M.: Photoinduced reduction of divalent mercury in ice by organic matter, Chemosphere, 82, 199-203, 2011.

Bottenheim, J. W. and Chan, E.: A trajectory study into the origin of spring time Arctic boundary layer ozone depletion, J. Geophys. Res., 111, D19301, doi:10.1029/2006JD007055, 2006.

Brooks, S., Lindberg, S., Southworth, G., and Arimoto, R.: Springtime atmospheric mercury speciation in the McMurdo, Antarctica coastal region, Atmos. Environ., 42, 2885-2893, 2008.

Brooks, S. B., Saiz-Lopez, A., Skov, H., Lindberg, S. E., Plane, J. M. C., and Goodsite, M. E.: The mass balance of mercury in the springtime arctic environment, Geophys. Res. Lett., 33, L13812, doi:10.1029/2005GL025525, 2006.

Calvert, J. G. and Lindberg, S. E.: The potential influence of iodinecontaining compounds on the chemistry of the troposphere in the polar spring. II. Mercury depletion, Atmos. Environ., 38, 51055116, 2004.

Calvert, J. G. and Lindberg, S. E.: Mechanisms of mercury removal by $\mathrm{O}_{3}$ and $\mathrm{OH}$ in the atmosphere, Atmos. Environ., 39, 33553367, 2005.

Carignano, M. A., Shepson, P. B., and Szleifer, I.: Ions at the ice/vapor interface, Chem. Phys. Lett., 436, 99-103, 2007.

Cho, H., Shepson, P. B., Barrie, L. A., Cowin, J. P., and Zaveri, R.: NMR investigation of the quasi-brine layer in ice/brine mixtures, J. Phys. Chem. B, 106, 11226-11232, 2002.

Cobbett, F. D., Steffen, A., Lawson, G., and Heyst, B. J. V.: GEM fluxes and atmospheric mercury concentrations (GEM, RGM and $\mathrm{Hg}^{\mathrm{p}}$ ) in the Canadian Arctic at Alert, Nunavut, Canada (February-June 2005), Atmos. Environ., 41, 6527-6543, 2007.

Cole, A. S. and Steffen, A.: Trends in long-term gaseous mercury observations in the Arctic and effects of temperature and other atmospheric conditions, Atmos. Chem. Phys., 10, 4661-4672, doi:10.5194/acp-10-4661-2010, 2010.

Cunningham, J. and Waddington, E. D.: Air flow and dry deposition of non-sea salt sulfate in polar firn: Paleoclimatic implications, Atmos. Environ., 27A, 2943-2956, 1993.

Cziczo, D. J. and Abbatt, J. P. D.: Ice nucleation in $\mathrm{NH}_{4} \mathrm{HSO}_{4}$, $\mathrm{NH}_{4} \mathrm{NO}_{3}$, and $\mathrm{H}_{2} \mathrm{SO}_{4}$ aqueous particles: Implications for cirrus cloud formation, Geophys. Res. Lett., 28, 963-966, 2001.

Dash, J. G., Fu, H., and Wettlaufer, J. S.: The premelting of ice and its environmental consequences, Rep. Prog. Phys., 58, 115-167, 1995.

Dastoor, A. P. and Durnford, D. A.: Arctic Ocean: Is it a sink or a source of atmospheric mercury?, Environ. Sci. Technol., 48, 1707-1717, 2014.

Dastoor, A. P. and Larocque, Y.: Global circulation of atmospheric mercury: a modeling study, Atmos. Environ., 38, 147-161, 2004.

Dastoor, A. P., Davingnon, D., Theys, N., Roozendael, M. V., Steffen, A., and Ariya, P. A.: Modeling dynamic exchange of gaseous elemental mercury at polar sunrise, Environ. Sci. Technol., 42, 5183-5188, 2008.

Dibble, T. S., Zelie, M. J., and Mao, H.: Thermodynamics of reactions of $\mathrm{ClHg}$ and $\mathrm{BrHg}$ radicals with atmospherically abundant free radicals, Atmos. Chem. Phys., 12, 10271-10279, doi:10.5194/acp-12-10271-2012, 2012.

Domine, F., Cabanes, A., and Legagneux, L.: Structure, microphysics, and surface area of the Arctic snowpack near Alert during the ALERT2000 campaign, Atmos. Environ., 36, 2753-2765, 2002.

Domine, F., Sparapani, R., Ianniello, A., and Beine, H. J.: The origin of sea salt in snow on Arctic sea ice and in coastal regions, Atmos. Chem. Phys., 4, 2259-2271, doi:10.5194/acp-4-2259-2004, 2004.

Domine, F., Albert, M., Huthwelker, T., Jacobi, H.-W., Kokhanovsky, A. A., Lehning, M., Picard, G., and Simpson, W. R.: Snow physics as relevant to snow photochemistry, Atmos. Chem. Phys., 8, 171-208, doi:10.5194/acp-8-171-2008, 2008. 
Domine, F., Bock, J., Voisin, D., and Donaldson, D. J.: Can we model snow photochemistry? Problems with the current approaches, J. Phys. Chem. A, 117, 4733-4749, 2013.

Dommergue, A., Ferrari, C. P., Gauchard, P.-A., Boutron, C. F., Poissant, L., Pilote, M., Jitaru, P., and Adams, F.: The fate of mercury species in a sub-arctic snowpack during snowmelt, Geophys. Res. Lett., 30, 1621, doi:10.1029/2003GL017308, 2003.

Dommergue, A., Bahlmann, E., Ebinghaus, R., Ferrari, C., and Boutron, C.: Laboratory simulation of $\mathrm{Hg}^{0}$ emissions from a snowpack, Anal. Bioanal. Chem., 388, 319-327, 2007.

Donohoue, D. L., Bauer, D., Cossairt, B., and Hynes, A. J.: Temperature and pressure dependent rate coefficients for the reaction of $\mathrm{Hg}$ with $\mathrm{Br}$ and the reaction of $\mathrm{Br}$ with $\mathrm{Br}$ : a pulsed laser photolysis-pulsed laser induced fluorescence study, J. Phys. Chem. A, 110, 6623-6632, 2006.

Döppenschmidt, A. and Butt, H.-J.: Measuring Thickness of the Liquid-like Layer on Ice Surfaces with Atomic Force Microscopy, Langmuir, 16, 6709-6714, 2000.

Douglas, T. A., Sturm, M., Simpson, W., Brooks, S., Lindberg, S., and Perovich, D.: Elevated mercury measured in snow and frost flowers near Arctic sea ice leads, Geophys. Res. Lett., 32, L04502, doi:10.1029/2004GL022132, 2005.

Douglas, T. A. and Sturm, M.: Arctic haze, mercury and the chemical composition of snow across northwestern Alaska, Atmos. Environ., 38, 805-820, 2004.

Douglas, T. A., Sturm, M., Simpson, W. R., Blum, J. D., AlvarezAviles, L., Keeler, G., Perovich, D., Biswas, A., and Johnson, K.: Influence of Snow and Ice Crystal Formation and Accumulation on Mercury Deposition to the Arctic, Environ. Sci. Technol., 42, 1542-1551, 2008.

Durnford, D. and Dastoor, A.: The behavior of mercury in the cryosphere: A review of what we know from observations, J. Geophys. Res., 116, D06305, doi:10.1029/2010JD014809, 2011.

Durnford, D., Dastoor, A., Ryzhkov, A., Poissant, L., Pilote, M., and Figueras-Nieto, D.: How relevant is the deposition of mercury onto snowpacks? - Part 2: A modeling study, Atmos. Chem. Phys., 12, 9251-9274, doi:10.5194/acp-12-9251-2012, 2012.

Dyrssen, D. and Wedborg, M.: Major and minor elements, chemical speciation in estuarine waters, in: Chemistry and biochemistry of estuaries, edited by: Olausson, E. and Cato, I., John Wiley, Chichester, 1980.

Ebinghaus, R., Kock, H. H., Temme, C., Einax, J. W., Lowe, A. G., Richter, A., Burrows, J. P., and Schroeder, W. H.: Antarctic springtime depletion of atmospheric mercury, Environ. Sci. Technol., 36, 1238-1244, 2002.

Evans, M. J., Jacob, D. J., Atlas, E., Cantrell, C. A., Eisele, F., Flocke, F., Fried, A., Mauldin, R. L., Ridley, B. A., Wert, B., Talbot, R., Blake, D., Heikes, B., Snow, J., Walega, J., Weinheimer, A. J., and Dibb, J.: Coupled evolution of $\mathrm{BrO}_{\mathrm{x}}-\mathrm{ClO}_{\mathrm{x}}-$ $\mathrm{HO}_{\mathrm{x}}-\mathrm{NO}_{\mathrm{x}}$ chemistry during bromine-catalyzed ozone depletion events in the arctic boundary layer, J. Geophys. Res., 108, 8368, doi:10.1029/2002JD002732, 2003.

Fain, X., Ferrari, C. P., Gauchard, P.-A., Magand, O., and Boutron, C.: Fast depletion of gaseous elemental mercury in the Kongsvegen Glacier snowpack in Svalbard, Geophys. Res. Lett., 33, L06826, doi:10.1029/2005GL025223, 2006.

Faïn, X., Grangeon, S., Balhmann, E., Fritsche, J., Obrist, D., Dommergue, A., Ferrari, C., Cairns, W., Ebinghaus, R., Barbante, C., Cescon, P., and Boutron, C.: Diurnal production of gaseous mer- cury in the alpine snowpack before snowmelt, J. Geophys. Res., 112, D21311, doi:10.1029/2007JD008520, 2007.

Ferrari, C. P., Dommergue, A., Boutron, C. F., Jitaru, P., and Adams, F. C.: Profiles of Mercury in the snow pack at Station Nord, Greenland shortly after polar sunrise, Geophys. Res. Lett., 31, L03401, doi:10.1029/2003GL018961, 2004.

Ferrari, C. P., Gauchard, P.-A., Aspmo, K., Dommergue, A., Magand, O., Bahlmann, E., Nagorski, S., Temme, C., Ebinghaus, R., Steffen, A., Banic, C., Berg, T., Planchon, F., Barbant, C., Cescon, P., and Boutron, C. F.: Snow-to-air exchanges of mercury in an Arctic seasonal snow pack in Ny-Ålesund, Svalbard, Atmos. Environ., 39, 7633-7645, 2005.

Fisher, J. A., Jacob, D. J., Soerensen, A. L., Amos, H. M., Steffen, A., and Sunderland, E. M.: Riverine source of Arctic Ocean mercury inferred from atmospheric observations, Nat. Geosci., 5, 499-504, doi:10.1038/NGEO1478, 2012.

Fitzenberger, R., Bosch, H., Camy-Peyret, C., Chipperfield, M. P., Harder, H., Platt, U., Sinnhuber, B.-M., Wagner, T., and Pfeilsticker, K.: First profile measurements of tropospheric BrO, Geophys. Res. Lett., 27, 2921-2924, 2000.

Fuller, E. N., Schettle, P. D., and Giddings, J. C.: A new method for prediction of binary gas-phase diffusion coefficients, Ind. Eng. Chem., 58, 19-27, 1966.

Fuller, E. N., Ensley, K., and Giddings, J. C.: Diffusion of halogenated hydrocarbons in helium. Effect of structure on collision cross sections, J. Phys. Chem., 73, 3679-3685, 1969.

Gårdfeldt, K. and Jonsson, M.: Is bimolecular reduction of $\mathrm{Hg}(\mathrm{II})$ complexes possible in aqueous systems of environmental importance, J. Phys. Chem. A, 107, 4478-4482, 2003.

Gårdfeldt, K., Sommar, J., Strömberg, D., and Feng, X.: Oxidation of atomic mercury by hydroxyl radicals and photoinduced decomposition of methylmercury in the aqueous phase, Atmos. Environ., 35, 3039-3047, 2001.

Gauchard, P.-A., Aspmo, K., Temme, C., Steffen, A., Ferrari, C., Berg, T., Ström, J., Kaleschke, L., Dommergue, A., Bahlmann, E., Magand, O., Planchon, F., Ebinghaus, R., Banic, C., Nagorski, S., Baussand, P., and Boutron, C.: Study of the origin of atmospheric mercury depletion events recorded in $\mathrm{Ny}$ Ålesund, Svalbard, spring 2003, Atmos. Environ., 39, 7620 7632, 2005.

Giannelli, V., Thomas, D. N., Haas, C., Kattner, G., Kennedy, H., and Dieckmann, G. S.: Behaviour of dissolved organic matter and inorganic nutrients during experimental sea-ice formation, Ann. Glaciol., 33, 317-321, 2001.

Gladich, I., Pfalzgraff, W., Maršálek, O., Jungwirth, P., Roselová, M., and Neshyba, S.: Arrhenius analysis of anisotropic surface self-diffusion on the prismatic facet of ice, Phys. Chem. Chem. Phys., 13, 19960-19969, 2011.

Goodsite, M. E., Plane, J. M. C., and Skov, H.: A theoretical study of the oxidation of $\mathrm{Hg}^{0}$ to $\mathrm{HgBr}_{2}$ in the troposphere, Environ. Sci. Technol., 38, 1772-1776, 2004.

Goodsite, M. E., Plane, J. M. C., and Skov, H.: Correction to A Theoretical Study of the Oxidation of $\mathrm{Hg} 0$ to $\mathrm{HgBr} 2$ in the Troposphere, Environ. Sci. Tech., 46, 5262-5262, doi:10.1021/es301201c, 2012.

Harder, S. L., Warren, S. G., Charlson, R. J., and Covert, D. S.: Filtering of air through snow as a mechanism for aerosol deposition to the Antarctic ice sheet, J. Geophys. Res., 101, 18729-18743, doi:10.1029/96JD01174, 1996. 
Hedgecock, I. M., Trunfio, G. A., Pirrone, N., and Sprovieri, F.: Mercury chemistry in the MBL: Mediterranean case and sensitivity studies using the AMCOTS (Atmospheric Mercury Chemistry over the Sea) model, Atmos. Environ., 39, 7217-7230, 2005.

Hepler, L. G. and Olofsson, G.: Mercury: Thermodynamic properties, chemical equilibria, and standard potentials, Chem. Rev., 75, 585-602, 1975.

Hirdman, D., Aspmo, K., Burkhart, J. F., Eckhardt, S., Sodemann, H., and Stohl, A.: Transport of mercury in the Arctic atmosphere: Evidence for a spring-time net sink and summer-time source, Geophys. Res. Lett., 36, L12814, doi:10.1029/2009GL038345, 2009.

Hirdman, D., Burkhart, J. F., Sodemann, H., Eckhardt, S., Jefferson, A., Quinn, P. K., Sharma, S., Ström, J., and Stohl, A.: Longterm trends of black carbon and sulphate aerosol in the Arctic: changes in atmospheric transport and source region emissions, Atmos. Chem. Phys., 10, 9351-9368, doi:10.5194/acp-10-93512010, 2010.

Holmes, C. D., Jacob, D. J., Mason, R. P., and Jaffe, D. A.: Sources and deposition of reactive gaseous mercury in the marine atmosphere, Atmos. Environ., 43, 2278-2285, 2009.

Holmes, C. D., Jacob, D. J., Corbitt, E. S., Mao, J., Yang, X., Talbot, R., and Slemr, F.: Global atmospheric model for mercury including oxidation by bromine atoms, Atmos. Chem. Phys., 10, 12037-12057, doi:10.5194/acp-10-12037-2010, 2010.

Huthwelker, T., Ammann, M., and Peter, T.: The Uptake of Acidic Gases on Ice, Chem. Rev., 106, 1375-1444, 2006.

Inoue, J., Liu, J., Pinto, J. O., and Curry, J. A.: Intercomparison of Arctic regional climate models: Modeling clouds and radiation for SHEBA in May 1998, J. Climate, 19, 4167-4178, 2006.

Iverfeldt, $\AA$. and Lindqvist, O.: Determination of distribution equilibria between water and air (in Swedish with English summary), Report no. 415, Project Coal, Health and Environment, The Swedish State Power Board, S-16287, Vällingby, Sweden, 1980.

Johnson, K. P., Blum, J. D., Keeler, G. J., and Douglas, T. A.: Investigation of the deposition and emission of mercury in arctic snow during an atmospheric mercury depletion event, J. Geophys. Res., 113, D17304, doi:10.1029/2008JD009893, 2008.

Jones, A. E., Anderson, P. S., Begoin, M., Brough, N., Hutterli, M. A., Marshall, G. J., Richter, A., Roscoe, H. K., and Wolff, E. W.: $\mathrm{BrO}$, blizzards, and drivers of polar tropospheric ozone depletion events, Atmos. Chem. Phys., 9, 4639-4652, doi:10.5194/acp-94639-2009, 2009.

Khalizov, A. F., Viswanathan, B., Larregaray, P., and Ariya, P. A.: A theoretical study on the reactions of $\mathrm{Hg}$ with halogens: atmospheric implications, J. Phys. Chem. A, 107, 6360-6365, 2003.

King, M. D. and Simpson, W. R.: Extinction of UV radiation in Arctic snow at Alert, Canada $\left(82^{\circ} \mathrm{N}\right)$, J. Geophys. Res., 106, 1249912507, 2001.

Kirk, J. L., St. Louis, V. L., and Sharp, M. J.: Rapid reduction and reemission of mercury deposited into snowpacks during atmospheric mercury depletion events at Churchill, Manitoba, Canada, Environ. Sci. Technol., 40, 7590-7596, 2006.

Koop, T., Kapilashrami, A., Molina, L. T., and Molina, M. J.: Phase transitions of sea-salt/water mixtures at low temperatures: Implications for ozone chemistry in the polar marine boundary layer, J. Geophys. Res., 105, 26393-26402, 2000.
Korhonen, H., Carslaw, K. S., Spracklen, D. V., Ridley, D. A., and Ström, J.: A global model study of processes controlling aerosol size distributions in the Arctic spring and summer, J. Geophys. Res., 113, D08211, doi:10.1029/2007JD009114, 2008.

Kylling, A., Stamnes, K., and Tsay, S.-C.: A reliable and efficient two-stream algorithm for spherical radiative transfer: Documentation of accuracy in realistic layered media, J. Atmos. Chem., 21, 115-150, 1995.

Lalonde, J. D., Amyot, M., and Poulain, A. J.: The Role of Mercury Redox Reactions in Snow on Snow-to-Air Mercury Transfer, Environ. Sci. Technol., 36, 174-178, 2002.

Lalonde, J. D., Amyot, M., Doyon, M.-R., and Auclair, J.-C.: Photoinduced $\mathrm{Hg}(\mathrm{II})$ reduction in snow from the remote and temperate Experimental Lakes Area (Ontario, Canada), J. Geophys. Res., 108, 4200, doi:10.1029/2001JD001534, 2003.

Li, S.-M.: Equilibrium of particle nitrite with gas-phase HONO: tropospheric measurements in the high arctic during polar sunrise, J. Geophys. Res., 99, 25469-25478, 1994.

Liao, J., Sihler, H., Huey, L. G., Neuman, J. A., Tanner, D. J., Friess, U., Platt, U., Flocke, F. M., Orlando, J. J., Shepson, P. B., Beine, H. J., Weinheimer, A. J., Sjostedt, S. J., Nowak, J. B., Knapp, D. J., Staebler, R. M., Zheng, W., Sander, R., Hall, S. R., and Ullmann, K.: A comparison of Arctic BrO measurements by chemical ionization mass spectrometry and long path differential optical absorption spectroscopy, J. Geophys. Res., 116, D00R02, doi:10.1029/2010JD014788, 2011.

Lin, C.-J. and Pehkonen, S. O.: Oxidation of elemental mercury by aqueous chlorine $\left(\mathrm{HOCI} / \mathrm{OCI}^{-}\right)$: Implications for tropospheric mercury chemistry, J. Geophys. Res., 103D, 28093-28102, 1998.

Lindberg, S. E., Brooks, S., abd Karen J. Scott, C.-J. L., Landis, M. S., Stevens, R. K., Goodsite, M., and Richter, A.: Dynamic oxidation of gaseous mercury in the Arctic troposphere at polar sunrise, Environ. Sci. Technol., 36, 1245-1256, 2002.

Lindqvist, O. and Rodhe, H.: Atmospheric mercury - a review, Tellus, 37B, 136-159, 1985.

Lu, J. Y., Schroeder, W. H., Barrie, L. A., Steffen, A., Welch, H. E., Martin, K., Lockhart, L., Hunt, R. V., Boila, G., and Richter, A.: Magnification of atmospheric mercury deposition to polar regions in springtime: the link to tropospheric ozone depletion chemistry, Geophys. Res. Lett., 28, 3219-3222, 2001.

Lyman, S. N., Jaffe, D. A., and Gustin, M. S.: Release of mercury halides from $\mathrm{KCl}$ denuders in the presence of ozone, Atmos. Chem. Phys., 10, 8197-8204, doi:10.5194/acp-10-81972010, 2010.

Mantoura, R. F. C., Dickson, A., and Riley, J. P.: The complexation of metals with humic materials in natural waters, Estuar. Coast. Mar. Sci., 6, 387-408, 1978.

Mao, H., Talbot, R. W., Sive, B. C., Kim, S. Y., Blake, D. R., and Weinheimer, A. J.: Arctic mercury depletion and its quantitative link with halogens, J. Atmos. Chem., 65, 145-170, 2010.

Marcus, Y. and Eliezer, I.: Mercury(II) halide mixed complexes in solution. V. Comparison of calculated and experimental stability constants, J. Phys. Chem., 66, 1661-1663, 1962.

Massman, W.: Molecular diffusivities of $\mathrm{Hg}$ vapor in air, $\mathrm{O}_{2}$ and $\mathrm{N}_{2}$ near STP and the kinematic viscosity and thermal diffusivity of air near STP, Atmos. Environ., 33, 453-457, 1999.

Millero, F. J., Feistel, R., Wright, D. G., and McDougall, T. J.: The composition of Standard Seawater and the definition of the 
Reference-Composition Salinity Scale, Deep-Sea Res. Pt. I, 55, 50-72, 2008.

Morin, S., Marion, G. M., von Glasow, R., Voisin, D., Bouchez, J., and Savarino, J.: Precipitation of salts in freezing seawater and ozone depletion events: a status report, Atmos. Chem. Phys., 8, 7317-7324, doi:10.5194/acp-8-7317-2008, 2008.

Mulvaney, R., Wolff, E. W., and Oates, K.: Sulphuric acid at grain boundaries in Antarctic ice, Natrue, 331, 247-249, 1988.

Munthe, J. and McElroy, W. J.: Some aqueous reactions of potential importance in the atmospheric chemistry of mercury, Atmos. Environ., 26A, 553-557, 1992.

Nazhat, N. B. and Asmus, K.-D.: Reduction of mercuric chloride by hydrated electrons and reducing radicals in aqueous solutions. Formation and reactions of $\mathrm{HgCl}$, J. Phys. Chem., 77, 614-620, 1973.

Oltmans, S. J., Schnell, R. C., Sheridan, P. J., Peterson, R. E., Li, S.-M., Winchester, J. W., Tans, P. P., Sturges, W. T., Kahl, J. D., and Barrie, L. A.: Seasonal surface ozone and filterable bromine relationship in the high Arctic, Atmos. Environ., 23, 2431-2441, 1989.

Outridge, P. M., Macdonald, R. W., Wang, F., Stern, G. A., and Dastoor, A. P.: A mass balance inventory of mercury in the Arctic Ocean, Environ. Chem., 5, 89-111, doi:10.1071/EN08002, 2008.

Pal, B. and Ariya, P. A.: Studies of ozone initiated reactions of gaseous mercury: kinetics, product studies, and atmospheric implications, Phys. Chem. Chem. Phys., 6, 572-579, 2004.

Parrella, J. P., Jacob, D. J., Liang, Q., Zhang, Y., Mickley, L. J., Miller, B., Evans, M. J., Yang, X., Pyle, J. A., Theys, N., and Roozendael, M. V.: Tropospheric bromine chemistry: implications for present and pre-industrial ozone and mercury, Atmos. Chem. Phys., 12, 6723-6740, doi:10.5194/acp-12-6723-2012, 2012

Pehkonen, S. O. and Lin, C. J.: Aqueous photochemistry of divalent mercury with organic acids, J. Air Waste Manage., 48, 144-150, 1998.

Persson, P. O. G., Fairall, C. W., Andreas, E. L., Guest, P. S., and Perovich, D. K.: Measurements near the Atmospheric Surface Flux Group tower at SHEBA: Near-surface conditions and surface energy budget, J. Geophys. Res., 107, 8045, doi:10.1029/2000JC000705, 2002.

Peterson, M. and Honrath, R.: Observations of rapid photochemical destruction of ozone in snowpack interstitial air, Geophys. Res. Lett., 28, 511-514, 2001.

Peterson, M., Barber, D., and Green, S.: Monte Carlo modeling and measurements of actinic flux levels in Summit, Greenland snowpack, Atmos. Environ., 36, 2545-2551, 2002.

Petroff, A. and Zhang, L.: Development and validation of a size-resolved particle dry deposition scheme for application in aerosol transport models, Geosci. Model Dev., 3, 753-769, doi:10.5194/gmd-3-753-2010, 2010.

Platt, U. and Lehrer, E.: Arctic Tropospheric Ozone Chemistry, ARCTOC, Final Report of the EU-Project No. EV5V-CT930318, Heidelberg, 1996.

Pleijel, K. and Munthe, J.: Modelling the atmospheric mercury cycle-chemistry in fog droplets, Atmos. Environ., 29, 14411457, 1995.

Pöhler, D., Vogel, L., Frieß, U., and Platt, U.: Observation of halogen species in the Amundsen Gulf, Arctic, by active long-path differential optical absorption spectroscopy, P. Natl. Acad. Sci. USA, 107, 6582-6587, doi:10.1073/pnas.0912231107, 2010.

Qiu, R., Green, S. A., Honrath, R. E., Peterson, M. C., Lu, Y., and Dziobak, M.: Measurements of $J_{\mathrm{NO}_{3}^{-}}$in snow by nitrate-based actinometry, Atmos. Environ., 36, 2563-2571, 2002.

Quinn, P. K., Shaw, G., Andrews, E., Dutton, E. G., Ruoho-Airola, T., and Gong, S. L.: Arctic haze: current trends and knowledge gaps, Tellus B, 59, 99-114, 2007.

Raofie, F. and Ariya, P. A.: Kinetics and products study of the reaction of BrO radicals with gaseous mercury, J. Phys. IV, 107, 1119-1121, 2003.

Raofie, F. and Ariya, P. A.: Product study of the gas-phase BrOinitiated oxidation of $\mathrm{Hg}$ : evidence for stable $\mathrm{Hg}^{1+}$ compounds, Environ. Sci. Technol., 38, 4319-4326, 2004.

Rosenthal, W., Saleta, J., and Dozier, J.: Scanning electron microscopy of impurity structures in snow, Cold Reg. Sci. Technol., 47, 80-89, 2007.

Rutter, A. P. and Schauer, J. J.: The effect of temperature on the gas-particle partitioning of reactive mercury in atmospheric aerosols, Atmos. Environ., 41, 8647-8657, 2007.

Saiz-Lopez, A., Plane, J. M. C., Mahajan, A. S., Anderson, P. S., Bauguitte, S. J.-B., Jones, A. E., Roscoe, H. K., Salmon, R. A., Bloss, W. J., Lee, J. D., and Heard, D. E.: On the vertical distribution of boundary layer halogens over coastal Antarctica: implications for $\mathrm{O}_{3}, \mathrm{HO}_{\mathrm{x}}, \mathrm{NO}_{\mathrm{x}}$ and the $\mathrm{Hg}$ lifetime, Atmos. Chem. Phys., 8, 887-900, doi:10.5194/acp-8-887-2008, 2008.

Sander, R., Vogt, R., Harris, G. W., and Crutzen, P. J.: Modeling the chemistry of ozone, halogen compounds, and hydrocarbons in the arctic troposphere during spring, Tellus B, 49, 522-532, 1997.

Sander, R., Burrows, J., and Kaleschke, L.: Carbonate precipitation in brine - a potential trigger for tropospheric ozone depletion events, Atmos. Chem. Phys., 6, 4653-4658, doi:10.5194/acp-64653-2006, 2006.

Sanemasa, I.: The solubility of elemental mercury vapor in water, B. Chem. Soc. Jpn., 48, 1795-1798, 1975.

Schroeder, W. H., Anlauf, K. G., Barrie, L. A., Lu, J. Y., Steffen, A., Schneeberger, D. R., and Berg, T.: Arctic springtime depletion of mercury, Nature, 394, 331-332, 1998.

Seigneur, C. and Lohman, K.: Effect of bromine chemistry on the atmospheric mercury cycle, J. Geophys. Res., 113, D23309, doi:10.1029/2008JD010262, 2008.

Selin, N. E., Jacob, D. J., Park, R. J., Yantosca, R. M., Strode, S., Jaeglé, L., and Jaffe, D.: Chemical cycling and deposition of atmospheric mercury: Global constraints from observations, J. Geophys. Res., 112, D02308, doi:10.1029/2006JD007450, 2007.

Shepler, B. C., Balabanov, N. B., and Peterson, K. A.: $\mathrm{Hg}+\mathrm{Br} \rightarrow$ $\mathrm{HgBr}$ recombination and collision-induced dissociation dynamics, J. Chem. Phys., 127, 164304, doi:10.1063/1.2777142, 2007.

Shindell, D. T., Chin, M., Dentener, F., Doherty, R. M., Faluvegi, G., Fiore, A. M., Hess, P., Koch, D. M., MacKenzie, I. A., Sanderson, M. G., Schultz, M. G., Schulz, M., Stevenson, D. S., Teich, H., Textor, C., Wild, O., Bergmann, D. J., Bey, I., Bian, H., Cuvelier, C., Duncan, B. N., Folberth, G., Horowitz, L. W., Jonson, J., Kaminski, J. W., Marmer, E., Park, R., Pringle, K. J., Schroeder, S., Szopa, S., Takemura, T., Zeng, G., Keating, T. J., and Zuber, A.: A multi-model assessment of pollution transport to the Arctic, Atmos. Chem. Phys., 8, 5353-5372, doi:10.5194/acp-8 5353-2008, 2008. 
Si, L. and Ariya, P. A.: Reduction of oxidized mercury species by dicarboxylic acids (C2-C4): kinetic and product studies, Environ. Sci. Technol., 42, 5150-5155, 2008.

Si, L. and Ariya, P. A.: Aqueous photoreduction of oxidized mercury species in presence of selected alkanethiols, Chemosphere, 84, 1079-1084, 2011.

Sihler, H., Platt, U., Beirle, S., Marbach, T., Kühl, S., Dörner, S., Verschaeve, J., Frieß, U., Pöhler, D., Vogel, L., Sander, R., and Wagner, T.: Tropospheric BrO column densities in the Arctic derived from satellite: retrieval and comparison to ground-based measurements, Atmos. Meas. Tech., 5, 27792807, doi:10.5194/amt-5-2779-2012, 2012.

Simpson, W. R., King, M. D., Beine, H. J., Honrath, R. E., and Zhou, X.: Radiation-transfer modeling of snow-pack photochemical processes during ALERT 2000, Atmos. Environ., 36, 26632670, 2002.

Simpson, W. R., von Glasow, R., Riedel, K., Anderson, P., Ariya, P., Bottenheim, J., Burrows, J., Carpenter, L. J., Frieß, U., Goodsite, M. E., Heard, D., Hutterli, M., Jacobi, H.-W., Kaleschke, L., Neff, B., Plane, J., Platt, U., Richter, A., Roscoe, H., Sander, R., Shepson, P., Sodeau, J., Steffen, A., Wagner, T., and Wolff, E.: Halogens and their role in polar boundary-layer ozone depletion, Atmos. Chem. Phys., 7, 4375-4418, doi:10.5194/acp-74375-2007, 2007.

Skov, H., Brooks, S. B., Goodsite, M. E., Lindberg, S. E., Meyers, T. P., Landis, M. S., Larsen, M. R., Jensen, B., McConville, G., and Christensen, J.: Fluxes of reactive gaseous mercury measured with a newly developed method using relaxed eddy accumulation, Atmos. Environ., 40, 5542-5463, 2006.

Smith, R. S. and Kay, B. D.: The existence of supercooled liquid water at $150 \mathrm{~K}$, Nature, 398, 788-791, 1999.

Snider, G., Raofie, F., and Ariya, P. A.: Effects of relative humidity and $\mathrm{CO}(\mathrm{g})$ on the $\mathrm{O}_{3}$-initiated oxidation reaction of $\mathrm{Hg}^{0}(\mathrm{~g})$ : kinetic and product studies, Phys. Chem. Chem. Phys., 10, 56165623, 2008.

Sommar, J., Lindqvist, O., and Strömberg, D.: Distriution equilibrium of mercury (II) chloride between water and air applied to flue gas scrubbing, J. Air Waste Manage., 50, 1663-1666, 2000.

Sommar, J., Andersson, M. E., and Jacobi, H.-W.: Circumpolar measurements of speciated mercury, ozone and carbon monoxide in the boundary layer of the Arctic Ocean, Atmos. Chem. Phys., 10, 5031-5045, doi:10.5194/acp-10-5031-2010, 2010.

Spiro, T. G. and Hume, D. N.: A spectrophotometric study of the saturated mixed complexes of mercury(II)-bromide-iodide, Inorg. Chem., 2, 340-345, 1963.

Staebler, R., Toom-Sauntry, D., Barrie, L., Langendörfer, U., Lehrer, E., Li, S.-M., and Dryfhout-Clark, H.: Physical and chemical characteristics of aerosols at Spitsbergen in the spring of 1996, J. Geophys. Res., 104D, 5515-5529, 1999.

Steen, A. O., Berg, T., Dastoor, A. P., Durnford, D. A., Engelsen, O., Hole, L. R., and Pfaffhuber, K. A.: Natural and anthropogenic atmospheric mercury in the European Arctic: a fractionation study, Atmos. Chem. Phys., 11, 6273-6284, doi:10.5194/acp-11-62732011, 2011.

Steeneveld, G. J., van de Wiel, B. J. H., and Holtslag, A. A. M.: Diagnostic equations for the stable boundary layer heights: Evaluation and dimensional analysis, J. Appl. Meteorol. Clim., 46, 212-225, 2007.
Steffen, A., Schroeder, W., Bottenheim, J., Narayan, J., and Fuentes, J. D.: Atmospheric mercury concentrations: measurements and profiles near snow and ice surfaces in the Canadian Arctic during Alert 2000, Atmos. Environ., 36, 2653-2661, 2002.

Steffen, A., Douglas, T., Amyot, M., Ariya, P., Aspmo, K., Berg, T., Bottenheim, J., Brooks, S., Cobbett, F., Dastoor, A., Dommergue, A., Ebinghaus, R., Ferrari, C., Gardfeldt, K., Goodsite, M. E., Lean, D., Poulain, A. J., Scherz, C., Skov, H., Sommar, J., and Temme, C.: A synthesis of atmospheric mercury depletion event chemistry in the atmosphere and snow, Atmos. Chem. Phys., 8 , 1445-1482, doi:10.5194/acp-8-1445-2008, 2008.

Steffen, A., Bottenheim, J., Cole, A., Douglas, T. A., Ebinghaus, R., Friess, U., Netcheva, S., Nghiem, S., Sihler, H., and Staebler, R.: Atmospheric mercury over sea ice during the OASIS-2009 campaign, Atmos. Chem. Phys., 13, 7007-7021, doi:10.5194/acp-137007-2013, 2013.

Steffen, A., Bottenheim, J., Cole, A., Ebinghaus, R., Lawson, G., and Leaitch, W. R.: Atmospheric mercury speciation and mercury in snow over time at Alert, Canada, Atmos. Chem. Phys., 14, 2219-2231, doi:10.5194/acp-14-2219-2014, 2014.

Stephens, C. R., Shepson, P. B., Steffen, A., Bottenheim, J. W., Liao, J., Huey, L. G., Apel, E., Weinheimer, A., Hall, S. R., Cantrell, C., Sive, B. C., Knapp, D. J., Montzka, D. D., and Hornbrook, R. S.: The relative importance of chlorine and bromine radicals in the oxidation of atmospheric mercury at Barrow, Alaska, J. Geophys. Res., 117, D00R11, doi:10.1029/2011JD016649, 2012.

Subir, M., Ariya, P. A., and Dastoor, A. P.: A review of uncertainties in atmospheric modeling of mercury chemistry I. Uncertainties in existing kinetic parameters Fundamental limitations and the importance of heterogeneous chemistry, Atmos. Environ., 45, 5664-5676, 2011.

Subir, M., Ariya, P. A., and Dastoor, A. P.: A review of the sources of uncertainties in atmospheric mercury modeling II. Mercury surface and heterogeneous chemistry A missing link, Atmos. Environ., 46, 1-10, 2012.

Tarasick, D. W. and Bottenheim, J. W.: Surface ozone depletion episodes in the Arctic and Antarctic from historical ozonesonde records, Atmos. Chem. Phys., 2, 197-205, doi:10.5194/acp-2197-2002, 2002.

Theys, N., Van Roozendael, M., Hendrick, F., Yang, X., De Smedt, I., Richter, A., Begoin, M., Errera, Q., Johnston, P. V., Kreher, K., and De Mazière, M.: Global observations of tropospheric BrO columns using GOME-2 satellite data, Atmos. Chem. Phys., 11, 1791-1811, doi:10.5194/acp-11-1791-2011, 2011.

Thomas, D. N., Kattner, G., Engbrodt, R., Giannelli, V., Kennedy, H., Haas, C., and Dieckmann, G. S.: Dissolved organic matter in Antarctic sea ice, Ann. Glaciol., 33, 297-303, 2001.

Thomas, J. L., Stutz, J., Lefer, B., Huey, L. G., Toyota, K., Dibb, J. E., and von Glasow, R.: Modeling chemistry in and above snow at Summit, Greenland - Part 1: Model description and results, Atmos. Chem. Phys., 11, 4899-4914, doi:10.5194/acp-11-48992011, 2011.

Toyota, K., Takahashi, M., and Akimoto, H.: Modeling multiphase halogen chemistry in the marine boundary layer with size-segregated aerosol module: Implications for quasi-sizedependent approach, Geophys. Res. Lett., 28, 2899-2902, 2001.

Toyota, K., Kanaya, Y., Takahashi, M., and Akimoto, H.: A box model study on photochemical interactions between VOCs and reactive halogen species in the marine boundary layer, 
Atmos. Chem. Phys., 4, 1961-1987, doi:10.5194/acp-4-19612004, 2004.

Toyota, K., McConnell, J. C., Lupu, A., Neary, L., McLinden, C. A., Richter, A., Kwok, R., Semeniuk, K., Kaminski, J. W., Gong, S.-L., Jarosz, J., Chipperfield, M. P., and Sioris, C. E.: Analysis of reactive bromine production and ozone depletion in the Arctic boundary layer using 3-D simulations with GEM-AQ: inference from synoptic-scale patterns, Atmos. Chem. Phys., 11, 3949-3979, doi:10.5194/acp-11-3949-2011, 2011.

Toyota, K., McConnell, J. C., Staebler, R. M., and Dastoor, A. P.: Air-snowpack exchange of bromine, ozone and mercury in the springtime Arctic simulated by the 1-D model PHANTAS - Part 1: In-snow bromine activation and its impact on ozone, Atmos. Chem. Phys., 14, 4101-4133, doi:10.5194/acp-14-41012014, 2014.

Tuckermann, M., Ackermann, R., Göltz, C., Lorenzen-schmidt, H., Senne, T., Stutz, J., Trost, B., Unold, W., and Platt, U.: DOASobservation of halogen radical-catalysed arctic boundary layer ozone destruction during the ARCTOC-campaigns 1995 and 1996 in Ny-Ålesund, Spitsbergen, Tellus B, 49, 533-555, 1997.

Van Loon, L., Mader, E., and Scott, S. L.: Reduction of the Aqueous Mercuric Ion by Sulfite: UV Spectrum of $\mathrm{HgSO}_{3}$ and Its Intramolecular Redox Reaction, J. Phys. Chem. A, 104, 16211626, 2000.

Van Loon, L., Mader, E., and Scott, S. L.: Sulfite Stabilization and Reduction of the Aqueous Mercuric Ion: Kinetic Determination of Sequential Formation Constants, J. Phys. Chem. A, 105, 3190-3195, 2001.
Wagman, D., Evans, W., Parker, V., Schumm, R., Halow, I., Bailey, S., Churney, K., and Nuttall, R.: The NBS Tables of Chemical of Chemical Thermodynamic Properties, J. Phys. Chem. Ref. Data, 11 (Suppl. 2), 1982.

Wang, Z. and Pehkonen, S. O.: Oxidation of elemental mercury by aqueous bromine: atmospheric implications, Atmos. Environ., 38, 3675-3688, 2004.

Warren, S. G. and Wiscombe, W. J.: A model for the spectral albedo of snow. II: Snow containing atmospheric aerosols, J. Atmos. Sci., 37, 2734-2745, 1980.

Warren, S. G., Rigor, I. G., Untersteiner, N., Radionov, V. F., Bryazgin, N. N., Aleksandrov, Y. I., and Colony, R.: Snow depth on Arctic sea ice, J. Climate, 12, 1814-1829, 1999.

Wennberg, P.: Bromine explosion, Nature, 397, 299-301, 1999.

Xiao, Z. F., Strömberg, D., and Lindqvist, O.: Influence of humic substances on photolysis of divalent mercury in aqueous solution, Water Air Soil Poll., 80, 789-798, 1995.

Xie, Z.-Q., Sander, R., Pöschl, U., and Slemr, F.: Simulation of atmospheric mercury depletion events (AMDEs) during polar springtime using the MECCA box model, Atmos. Chem. Phys., 8, 7165-7180, doi:10.5194/acp-8-7165-2008, 2008.

Yang, X., Pyle, J. A., and Cox, R. A.: Sea salt aerosol production and bromine release: Role of snow on sea ice, Geophys. Res. Lett., 35, L16815, doi:10.1029/2008GL034536, 2008.

Zeng, T., Wang, Y., Chance, K., Blake, N., Blake, D., and Ridley, B.: Halogen-driven low-altitude $\mathrm{O}_{3}$ and hydrocarbon losses in spring at northern high latitudes, J. Geophys. Res., 111, D17313, doi:10.1029/2005JD006706, 2006. 


\section{Appendix A}

\section{Thermodynamic equilibria for $\mathrm{Hg}(\mathrm{II})$-halide complexes in the aqueous phase}

The aqueous-phase equilibrium constant $K^{\ominus}$ at standard ambient temperature $\left(T^{\ominus}=298.15 \mathrm{~K}\right)$ for a reversible reaction $\mathrm{A}_{1}+\mathrm{A}_{2}+\cdots \rightleftarrows \mathrm{B}_{1}+\mathrm{B}_{2}+\cdots$ is obtained by

$$
K^{\ominus}=\frac{\prod\left[\mathrm{B}_{i}\right]}{\prod\left[\mathrm{A}_{i}\right]}=\exp \left(-\frac{\Delta G^{\ominus}}{R T^{\ominus}}\right),
$$

where $\Delta G^{\ominus}$ is a net change in the Gibbs free energy (i.e., $\left.\sum \Delta G_{\mathrm{f}}^{\ominus}\left(\mathrm{B}_{i}\right)-\sum \Delta G_{\mathrm{f}}^{\ominus}\left(\mathrm{A}_{i}\right)\right)$, and $R$ is the gas constant. According to the van't Hoff equation, temperature dependence of the equilibrium constant can be expressed by using a net change in the standard enthalpy, $\Delta H^{\ominus}=\sum \Delta H_{\mathrm{f}}^{\ominus}\left(\mathrm{B}_{i}\right)-$ $\sum \Delta H_{\mathrm{f}}^{\ominus}\left(\mathrm{A}_{i}\right)$ :

$$
K(T)=K^{\ominus} \times \exp \left[\frac{-\Delta H^{\ominus}}{R}\left(\frac{1}{T}-\frac{1}{T^{\ominus}}\right)\right] .
$$

In this study, we simulate the formation of coordination complexes of $\mathrm{Hg}(\mathrm{II})$ with chloride, bromide and hydroxyl anions in aerosols and in the LLL of snowpack. In the case of coordination complexes formed with a single type of anions (e.g., $\left.\mathrm{HgCl}_{4}^{2-}, \mathrm{HgCl}_{3}^{-}\right), K(T)$ can be calculated simply by using the values of $\Delta G_{\mathrm{f}}^{\ominus}$ and $\Delta H_{\mathrm{f}}^{\ominus}$ available from a critical review on the thermochemical constants of mercury compounds by Hepler and Olofsson (1975) and a comprehensive thermochemical table compiled by Wagman et al. (1982).

For mixed-ligand formation such as in the $\mathrm{Hg}$ (II)-chloridebromide system, we employ an empirical approach proposed by Marcus and Eliezer (1962) and Spiro and Hume (1963). For example, exchange between $\mathrm{Cl}^{-}$and $\mathrm{Br}^{-}$in a saturated, tetrahedral coordination, consisting of four halide anions around $\mathrm{Hg}^{2+}$, will proceed in the following stoichiometry:

$$
\mathrm{HgCl}_{4}^{2-}+n \mathrm{Br}^{-} \rightleftarrows \mathrm{HgCl}_{4-n} \mathrm{Br}_{n}^{2-}+n \mathrm{Cl}^{-} \quad(n=1-4) .
$$

The calculation of the equilibrium constant for each step of this halide exchange begins with looking at changes in free energy by total replacement:

$$
\mathrm{HgCl}_{4}^{2-}+4 \mathrm{Br}^{-} \rightleftarrows \mathrm{HgBr}_{4}^{2-}+4 \mathrm{Cl}^{-},
$$

where the $\Delta G_{\mathrm{f}}^{\ominus}$ and $\Delta H_{\mathrm{f}}^{\ominus}$ values for each species in this reaction are taken from from Hepler and Olofsson (1975) and/or Wagman et al. (1982). This free energy change is divided equally between the successive replacement steps and then a contribution from an entropy change arising from the mixing of the ligands ("statistical effect") is added. These procedures end up in the following formulation:

$$
\log \gamma_{n}=\frac{n}{4} \log \gamma_{4}+\log \frac{4 !}{(4-n) ! n !},
$$

where

$$
\gamma_{n}=\frac{\left[\mathrm{HgCl}_{4-n} \mathrm{Br}_{n}^{2-}\right]\left[\mathrm{Cl}^{-}\right]^{n}}{\left[\mathrm{HgCl}_{4}^{2-}\right]\left[\mathrm{Br}^{-}\right]^{n}} .
$$

Note that the second term in the right-hand side of Eq. (A3) represents the "statistical effect" and is independent of temperature. But $\gamma_{4}$ calculated by Eq. (A2) is dependent on temperature as well as $\gamma_{n}$. Dyrssen and Wedborg (1980) estimated the speciation of inorganic $\mathrm{Hg}$ (II) in seawater, based on Eq. (A3) for the stability constants of mixed-chloridebromide $\mathrm{Hg}$ (II) complexes at $25^{\circ} \mathrm{C}$.

According to Marcus and Eliezer (1962) and Spiro and Hume (1963), the $\gamma_{n}$ values thus calculated should be adjusted further by an "electrostatic effect" arising from coulombic repulsion and polarization between different ligands:

$\log \gamma_{n}=\frac{n}{4} \log \gamma_{4}+\log \frac{4 !}{(4-n) ! n !}+\log \frac{\Delta E_{\mathrm{el}}}{k_{\mathrm{b}} T}$,

where $\Delta E_{\mathrm{el}}$ is a difference between $\mathrm{HgCl}_{4-n} \mathrm{Br}_{n}^{2-}$ and $\mathrm{HgCl}_{4}^{2-}$ in the electrostatic energy of coulombic interactions inside the molecules and $k_{\mathrm{b}}$ is the Boltzmann constant. Details on the calculation of $\Delta E_{\mathrm{el}}$ can be found in Marcus and Eliezer (1962). The example above describes the case with saturated (tetrahedral) coordination, but unsaturated complexes such as $\mathrm{HgCl}_{2} \mathrm{Br}^{-}$and $\mathrm{HgClBr}$ can be dealt with by the same approach (Marcus and Eliezer, 1962). In this study, we use Eq. (A4) (or its variant forms for the unsaturated complexes) to calculate the equilibrium constants associated with the mixed-ligand $\mathrm{Hg}$ (II) complex formation. 